\title{
Determination and analysis of natural gas vehicle tailpipe emissions based on continuous CVS measurement
}

Jingang Fu

West Virginia University

Follow this and additional works at: https://researchrepository.wvu.edu/etd

\section{Recommended Citation}

Fu, Jingang, "Determination and analysis of natural gas vehicle tailpipe emissions based on continuous CVS measurement" (1998). Graduate Theses, Dissertations, and Problem Reports. 914.

https://researchrepository.wvu.edu/etd/914

This Thesis is protected by copyright and/or related rights. It has been brought to you by the The Research Repository @ WVU with permission from the rights-holder(s). You are free to use this Thesis in any way that is permitted by the copyright and related rights legislation that applies to your use. For other uses you must obtain permission from the rights-holder(s) directly, unless additional rights are indicated by a Creative Commons license in the record and/ or on the work itself. This Thesis has been accepted for inclusion in WVU Graduate Theses, Dissertations, and Problem Reports collection by an authorized administrator of The Research Repository @ WVU. For more information, please contact researchrepository@mail.wvu.edu. 


\title{
Determination and Analysis of Natural Gas Vehicle Tailpipe Emissions Based on Continuous CVS Measurement
}

\author{
Jingang Fu
}

Thesis Submitted to the faculty of College of Engineering and Mineral

Resources at West Virginia University in partial fulfillment of the requirements for the degree of

\author{
Master of Science \\ in \\ Mechanical Engineering
Wen G. Wang, Ph.D., Chair
Nigel N. Clark, Ph.D.
Mridul Gautam, Ph.D.

November 13, 1998

Morgantown, West Virginia

Keywords: Engine Emissions, Dilution Factor, CVS Measurement 


\title{
Determination and Analysis of Natural Gas Vehicle Tailpipe Emissions Based on Continuous CVS Measurement
}

\author{
Jingang $\mathrm{Fu}$
}

\begin{abstract}
(Abstract)
In an effort to collect emissions data and research emission profiles from heavyduty vehicles, WVU is now operating two Transportable Heavy-duty Vehicle Emissions Testing Laboratories and have conducted over 1,000 emission tests on diesel and alternative fueled heavy-duty vehicles. The laboratories emission measurement system employs Constant Volume Sampler (CVS) system to continuously measure the pollutant concentrations in the dilution tunnel. Subsequent mass emissions calculations were based on CFR-40, which uses average dilution factor to account for background pollutants.

However, it is recognized that due to the mechanism of the CVS system, the dilution factor varies from constant during the whole test cycle and there exists difference between vehicle tailpipe emission concentrations and dilution tunnel emission concentrations. Based on the continuous measurement data obtained from natural gas vehicle emission tests, a new approach used in this study can be used to calculate instantaneous dilution factor of the CVS system during the test cycle. Vehicle tailpipe or engine exhaust emission concentrations and emission rates can be derived from the instantaneous dilution factor. Mass emissions of gaseous pollutant species, such as $\mathrm{CO}_{2}$, $\mathrm{CO}, \mathrm{NO}_{\mathrm{x}}$, and $\mathrm{HC}$, can be obtained by integration of tailpipe emission rate over the test cycle. Comparing with the current calculations, this method improves the accuracy of mass emission measurements, especially when the pollutant concentrations in the engine exhaust were approaching that in the ambient background air. The instantaneous dilution factor is also used to obtain the emissions concentrations in the raw engine exhaust prior to being diluted. In this study, emission modal analysis was made based on the emissions concentrations in the engine exhaust instead of those measured in the diluted mixture. Emission characteristics at different engine operation modes were analyzed for different natural gas engines and measures for reducing emissions were also discussed.
\end{abstract}




\section{ACKNOWLEDGEMENTS}

I wish to extend my most sincere gratitude to my research advisor: Dr. Wen G. Wang. This thesis is being able to be finished under his guidance, support, and encouragement. In fact, the work would be impossible without Dr. Wang's help.

Thanks are also due to my committee members, Dr. Clark and Dr. Gautam. Their insightful suggestions and discreet proofread to the draft are highly appreciated. I also want to thank them for joining the committee.

Special thanks are given to Mr. Wenwei Xie, the computer engineer in the transportable emission testing laboratories. All the emissions data used in the thesis were obtained from the laboratory database he designed and developed. Without his excellent work in the database management, this work would be extremely difficult.

I also want to thank my family members. My wife, lin, and her parents have helped me a lot during my study. My mother has encouraged my further education greatly with moral support.

The greatest thanks are given to God! 


\section{TABLE OF CONTENTS}

ACKNOWLEDGEMENTS $\ldots \ldots \ldots \ldots \ldots$

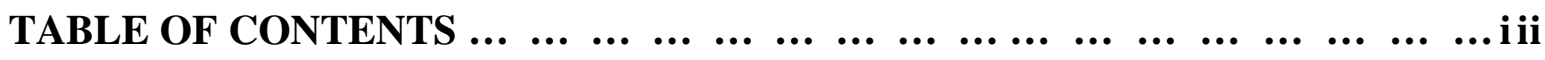

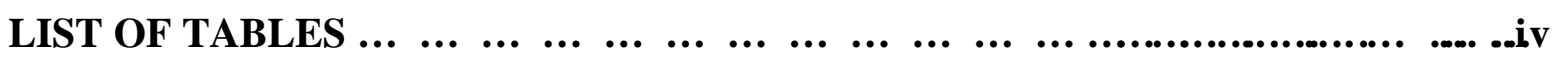

LIST OF FIGURES $\ldots \ldots \ldots \ldots$

ACRONYMS AND SYMBOLS $\ldots \ldots \ldots \ldots$

$\operatorname{ABSTRACT} \ldots \ldots \ldots \ldots$

Chapter 1: Introduction. $\ldots \ldots \ldots \ldots \ldots$

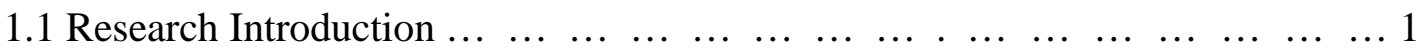

Chapter 2 WVU Heavy-duty Vehicle Emissions Testing ... . . . . . . . ..........4

2.1 Transportable Emission Testing Laboratory Overview $\ldots \ldots \ldots \ldots$

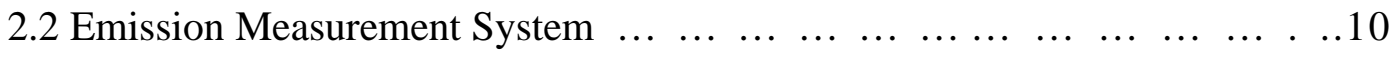

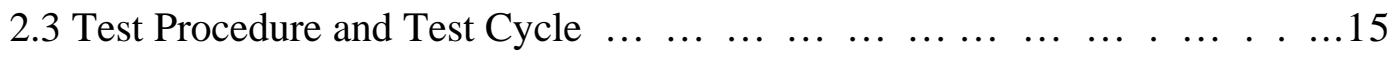

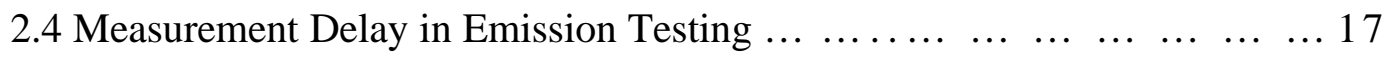

Chapter 3: Natural Gas Vehicle Review ... ....... . . . . . . . . . . . 22

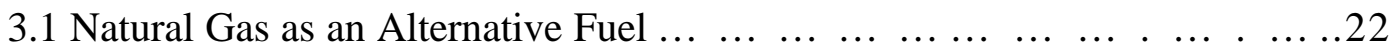

3.2 Natural Gas Engine and Vehicle Technology.... $\ldots \ldots \ldots \ldots \ldots$

$\begin{array}{llllllllllll}3.3 & \text { Emissions from Natural Gas Vehicles } & \ldots & \ldots & \ldots & \ldots & \ldots & \ldots & \ldots & \ldots & \ldots & \ldots\end{array}$

Chapter 4: Determination Of Instantaneous Dilution Factor... ... ... . .....31

4.1 Current Dilution Factor Calculation in WVU lab.. . $\ldots \ldots \ldots \ldots$

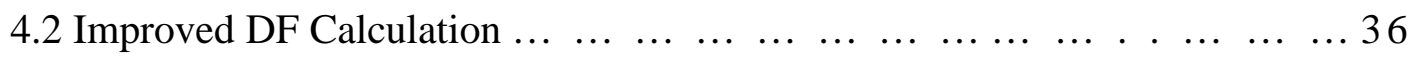

4.3 Calculating Instantaneous Dilution Factor $\ldots \ldots \ldots \ldots \ldots$

Chapter 5: Mass Emission Calculations ... $\ldots \ldots \ldots \ldots$

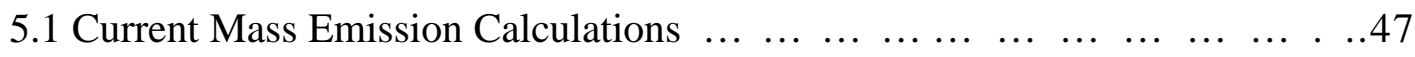

5.2 Mass Emission Calculations Based on Tailpipe Emission Concentrations ..53

$\begin{array}{lllllllllllllll}5.3 & \text { Modal Mass Emissions Analysis } \ldots & \ldots & \ldots & \ldots & \ldots & \ldots & \ldots & \ldots & \ldots & \ldots & \ldots & \ldots & .59\end{array}$ 
Chapter 6: Engine Exhaust Emission Analysis... $\ldots \ldots \ldots \ldots 2$

6.1 Emission Concentrations in Vehicle Tailpipe and Dilution Tunnel... ... .. 62

6.2 Determination of Vehicle Tailpipe Emission Concentrations... .. . . . . . . . .64

6.3 Modal Emission Analysis Based on Tailpipe Emission Concentrations... ... .67

Chapter 7: Summary And Conclusions ... $\ldots \ldots \ldots \ldots$... $\ldots \ldots \ldots$

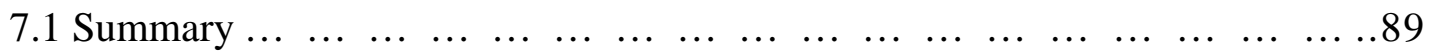

$\begin{array}{lllllllllllll}7.2 & \text { Conclusions and Future } \text { Work } \\ \ldots & \ldots & \ldots & \ldots & \ldots & \ldots & \ldots & \ldots & \ldots & \ldots & \ldots & \ldots & 90\end{array}$

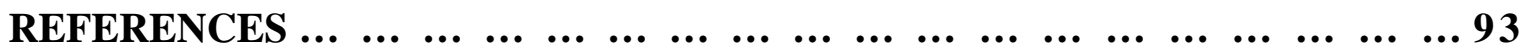




\section{LIST OF TABLES}

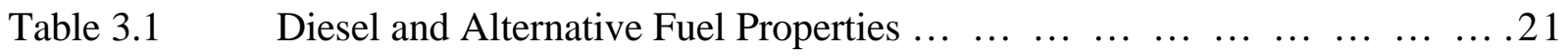

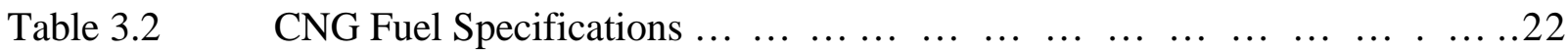

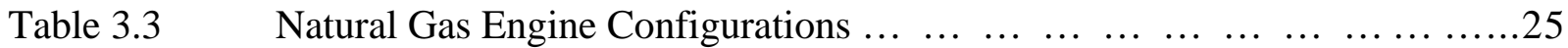

Table $5.1 \quad$ Mass Emissions Calculations with Two Methods.... . . $\ldots \quad \ldots \quad \ldots . .57$

Table 5.2 Modal Mass Emission Analysis for a DDC S50 Engine $\ldots \ldots \ldots$. . . . . . 60

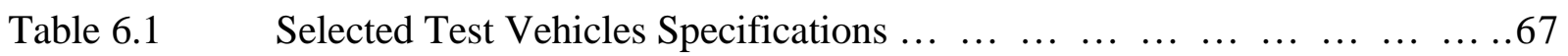




\section{LIST OF FIGURES}

Figure 2.1 WVU Transportable Heavy-duty Vehicle Emission Testing Laboratory in

$\begin{array}{llllllllllllllllllll}\text { Testing Site } & \ldots & \ldots & \ldots & \ldots & \ldots & \ldots & \ldots & \ldots & \ldots & \ldots & \ldots & \ldots & \ldots & \ldots & \ldots & \ldots & \ldots & \ldots & \ldots\end{array}$

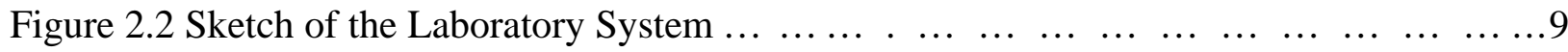

Figure 2.3 Major Components of the Chassis Dynamometer... $\ldots \begin{array}{llllllllllll} & \ldots & \ldots & \ldots & \ldots & \ldots & \ldots & \ldots & \ldots\end{array}$

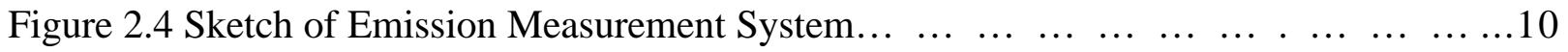

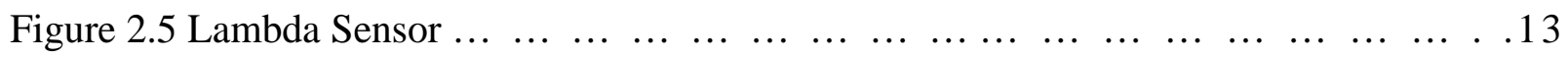

Figure 2.6 Sketch of $\mathrm{CBD}$ Cycle $\begin{array}{llllllllllllllllllllll}\ldots & \ldots & \ldots & \ldots & \ldots & \ldots & \ldots & \ldots & \ldots & \ldots & \ldots & \ldots & \ldots & \ldots & \ldots & \ldots & \ldots\end{array}$

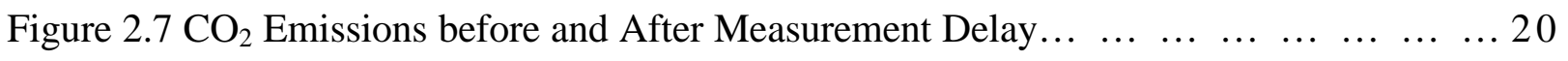

Figure $2.8 \mathrm{CO}$ Emissions before and After Measurement Delay... $\ldots \ldots \ldots \ldots$

Figure 4.1 Lambda Value for Natural Gas Vehicles... $\ldots \begin{array}{lllllllllllll} & \ldots & \ldots & \ldots & \ldots & \ldots & \ldots & \ldots & \ldots & \ldots & & \ldots\end{array}$

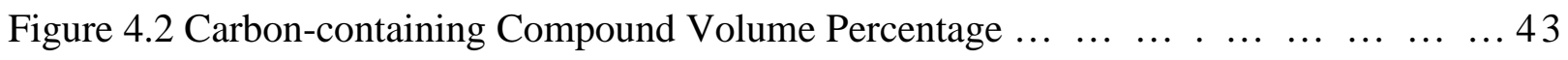

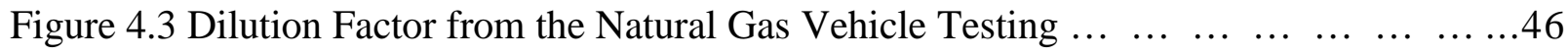

Figure 5.1 Mass Flow Rate in Dilution Tunnel and in Vehicle Tailpipe... . . . . . . . ...55

Figure $6.1 \mathrm{CO}_{2}$ Emissions from the Natural Gas Vehicle Testing $\ldots \ldots \ldots \ldots \ldots 3$

Figure 6.2 CO Emission Concentrations in Dilution Tunnel and Vehicle

$\begin{array}{lllllllllllllllllllllll}\text { Tailpipe } & \ldots & \ldots & \ldots & \ldots & \ldots & \ldots & \ldots & \ldots & \ldots & \ldots & \ldots & \ldots & \ldots & \ldots & \ldots & \ldots & \ldots & \ldots & \ldots & & . .66\end{array}$

Figure 6.3 Measured Lambda Value along with Vehicle Horsepower over the CBD Cycle

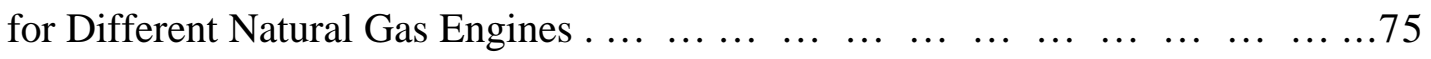

Figure 6.4 Dilution Factor and Flow Rate of Vehicle with DDC S50G Engine.... . . . . . .76

Figure $6.5 \mathrm{CO}_{2}$ Emissions from DDC S50 G Engine $\ldots \begin{array}{llllllllllllll} & \ldots & \ldots & \ldots & \ldots & \ldots & \ldots & \ldots & \ldots & \ldots & \ldots\end{array}$

Figure $6.6 \mathrm{NO}_{\mathrm{x}}$ Emissions from DDC S50 G Engine.. $\ldots \begin{array}{lllllllllllll} & \ldots & \ldots & \ldots & \ldots & \ldots & \ldots & \ldots & \ldots & \ldots & \ldots\end{array}$ 
Figure $6.7 \mathrm{CO}$ Emissions from DDC S50 G Engine...

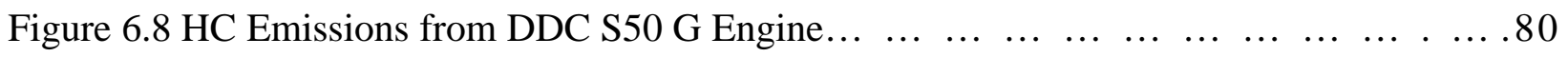

Figure $6.9 \mathrm{CO}_{2}$ Emissions from Cummins L10 Engine $\ldots \ldots \ldots \ldots$

Figure $6.10 \mathrm{NO}_{\mathrm{x}}$ Emissions from Cummins L10 Engine... $\ldots \ldots \ldots \ldots 2$

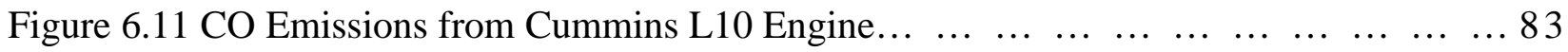

Figure $6.12 \mathrm{HC}$ Emissions from Cummins L10 Engine... $\ldots \begin{array}{llllllllllll} & \ldots & \ldots & \ldots & \ldots & \ldots & \ldots & \ldots & \ldots & \ldots & 84\end{array}$

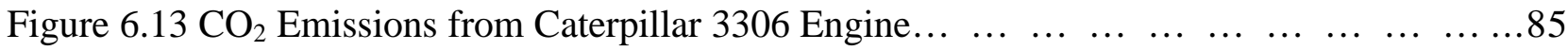

Figure $6.14 \mathrm{NO}_{\mathrm{x}}$ Emissions from Caterpillar 3306 Engine... $\ldots \begin{array}{lllllllllll} & \ldots & \ldots & \ldots & \ldots & \ldots & \ldots & \ldots & \ldots & \ldots & \ldots\end{array}$

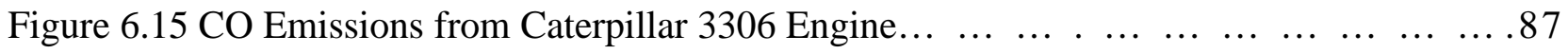

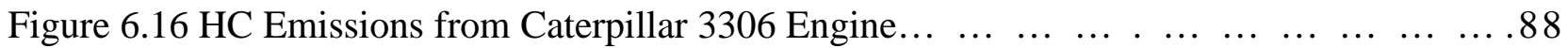




\section{ACRONYMS AND SYMBOLS}

\begin{tabular}{ll} 
Ci & Emission Concentration \\
CC & Central Business District \\
CFR & Carbon-containing Compound \\
CFV & Code of Federal Regulations \\
CVS & Critical Flow Venturi \\
DF & Constant Volume Sampler \\
ER & Dilution Factor \\
PPM & Emission Rate \\
$\rho$ & Parts Per Million in Volume \\
$\lambda$ & Density \\
\hline
\end{tabular}




\section{CHAPTER 1}

\section{INTRODUCTION}

\subsection{Research Introduction}

In today's world, reducing emissions from transportation sector is an urgent problem challenging engine researchers, manufacturers, and governmental policy makers. This is the motivation to advance engine combustion technology and adopt alternative fuels. To measure gaseous and particulate emissions from heavy-duty vehicles conveniently and accurately, WVU has designed and is now operating two Transportable Heavy-duty Vehicle Emissions Testing Laboratories. The two testing facilities have conducted more than 1,000 heavy-duty trucks and buses through 1992 to present. The laboratories have provided valuable data to both NREL (National Renewable Energy Laboratory) and fleet owners. The database created and maintained by laboratories staff is now an important source for researchers worldwide to study emissions from diesel and alternative fueled heavy-duty vehicles.

The transportable laboratory consists of chassis dynamometer unit and emission measurement and analysis unit. During the testing, heavy-duty vehicles fueled with diesel or alternative fuels were running on dynamometer on a specific cycle to simulate real driving conditions. Vehicle tailpipe exhaust was diluted by background air to a generally constant volume flow rate as entering the dilution

tunnel of the CVS system. Gaseous emission species such as $\mathrm{CO}_{2}, \mathrm{CO}, \mathrm{NO}_{\mathrm{x}}$, and 
$\mathrm{HC}$ were measured continuously with the frequency of $10 \mathrm{~Hz}$ by gas analyzers to determine their concentrations in the diluted mixture. The subsequent calculations of mass emissions used in the laboratories were mostly based on Code of Federal Regulations (CFR) Title 40, which considers the dilution factor during the exhaust dilution process as a constant.

Review of the calculation techniques indicates that it not only introduces errors in the mass emission calculations, but also confuses the vehicle tailpipe emissions with dilution tunnel measurement. Due to the mechanism of CVS system, the dilution factor during the exhaust dilution process in WVU heavy-duty vehicle emission testing is far from a constant and thus, there exist variances between vehicle tailpipe emission concentrations and measured dilution tunnel concentrations. In this study, a new approach is used to distinguish natural gas vehicle tailpipe emissions from dilution tunnel measurements. The critical parameter employed was the continuous air/fuel ratio measured by a Lambda sensor, which is currently available only in the natural gas vehicles. The instantaneous dilution factor in exhaust dilution process of natural gas vehicles is derived from air/fuel ratio. The emission concentrations in the undiluted exhaust were determined considering the instantaneous dilution factor and background pollutant. Based on the determined tailpipe emission concentrations, mass emissions of gaseous pollutant species can be computed by integrating the instantaneous tailpipe emission rates over the test phase. Comparing this method 
with current calculating method used in the laboratory, the former is closer to real conditions and thus improves the mass emissions calculation accuracy. This is noticeable when background emissions are relatively high or pollutant concentrations in the exhaust were at the same level as that in the ambient background air. As current vehicle emission standards are developing towards near-zero emissions, the improvement of accuracy is more desirable.

The restored engine exhaust emission concentrations also provide a valuable look into the engine combustion process, which is not possible from only the dilution tunnel measurement. By correlating the instantaneous engine exhaust emissions concentrations with vehicle horsepower and speed curves, modal analysis was made to study the emission characters at different engine operation modes for different natural gas engines and measures to reduce emission formation were discussed.

In the future work, empirical model or experimental method is needed to determine the air/fuel ratios for diesel compression ignition engines at different operating modes. More thorough and theoretical work is also needed for the emission modal analysis. 


\section{CHAPTER 2}

\section{WVU HEAVY-DUTY VEHICLE EMISSIONS TESTING}

\subsection{Description of WVU Transportable Heavy-duty Vehicle Emissions Testing Laboratories (THDVETL)}

In recent years, the increasingly stringent emission regulations on heavyduty vehicles pose a substantial challenge not only to heavy-duty engine manufacturers and the fuel industry, but also to the research and development efforts in the areas of heavy-duty vehicle emission measurement technology. Since 1989, WVU has designed, constructed, and is now operating two Transportable Heavy-duty Vehicle Emission Testing Laboratories (THDVETL). These unique transportable testing facilities are designed to measure specific constituents of exhaust gas emissions from heavy-duty vehicles powered by diesel or alternative fuel engines. The laboratories can be moved from one site to another, and the vehicles can be tested where they are housed, thus minimizing their time out of service. Figure 2.1 shows one of the transportable emission testing laboratories conducting a test in the test site.

The two laboratories each consists of three major systems: a chassis dynamometer system, an emission testing measurement system, and a data acquisition and control system. A sketch of the systems is shown in Figure 2.2.

The chassis dynamometer is built on a flat-bed trailer, which will be described later in this section. Equipment that measures emissions is located in a 
separate, enclosed instrument trailer parked near power absorber test bed. Detail of the measurement system is discussed in the next section. The data acquisition system monitors the measured species concentration, condition of analyzer and dilution tunnel with a frequency of $10 \mathrm{~Hz}$ and records them for later calculation. The components of the system are scattered in the vehicle drive train, power absorber, and flywheel system.

The chassis dynamometer system allows the heavy-duty vehicle to simulate real road driving condition through test cycles while it is running on a stationary test bed. The components which are identical on both sides are two eddy current power absorbers, two sets of flywheels, two drive trains, two torque transducers, and two sets of free rotating rollers, as shown in Figure 2.3. The power absorbers provide the road load simulation of the tested vehicle and the flywheel sets are capable of simulating vehicle inertia. Major components of the chassis dynamometer are as following:

\section{Power Absorbers}

Two Mustang eddy current absorbers (CC300) are used to simulate road load of the tested vehicle. The power is controlled by adjusting the amount of DC current supplied to field. The DC current energizes the stationary field coins of the absorber. Rotation of the iron rotors in the magnetic field generates eddy currents in the rotor which produce a force counter to the direction of the rotary 
motion. The absorbed energy is converted into heat in the rotors, then is dissipated into the atmosphere using curvilinear cooling fins. Flywheel Sets

The flywheel system is used to simulate the inertia of the tested vehicle. It consists of a series of selectable discs to allow simulation of inertia loads. Inertia generated by the flywheels varies according to the tested vehicle tire size. The inertia of the system has been calculated based on the inertia of the drive shafts, differentials, and power absorber. The final assembly of the flywheel sets consists of four driving rotors, eight flywheels of different sizes resting on bearings, and a drive shaft. The inertia of the vehicle is simulated by a combination of rotors and wheels.

\section{Drive-train}

The function of drive-train is to transfer power. Since power will be taken from both sides of the tested vehicle driving axle, components of the drive-train at both sides are identical. Hub adapters, with different standard sizes to match bolts of different wheel rims, replace the outer wheels of the driving axle. The transducer provides torque and speed data to the computer on a time basis. The end of the transducer drives a second shaft that has a variety of diameters. The shaft runs through a modified Mack rear end differential which drives a perpendicular shaft that runs at a higher speed ratio of 1:3.56 to drive the flywheel set. The other end of the second driving shaft is coupled to a third shaft with the 
same specifications. This shaft runs through a second Mack rear end differential which drives a perpendicular shaft to drive the power absorber.

During testing, the tested vehicle is backed onto the trailer and the rear wheels of the vehicle are positioned on small diameter free running rollers. The power is extracted from the drive wheels, on both sides of the vehicle, by torque shafts, equipped with torque transducers, coupled to the wheel lugs through hub adapters. The dynamometer system made the vehicle possible to simulate real driving situation while staying on the test bed. 


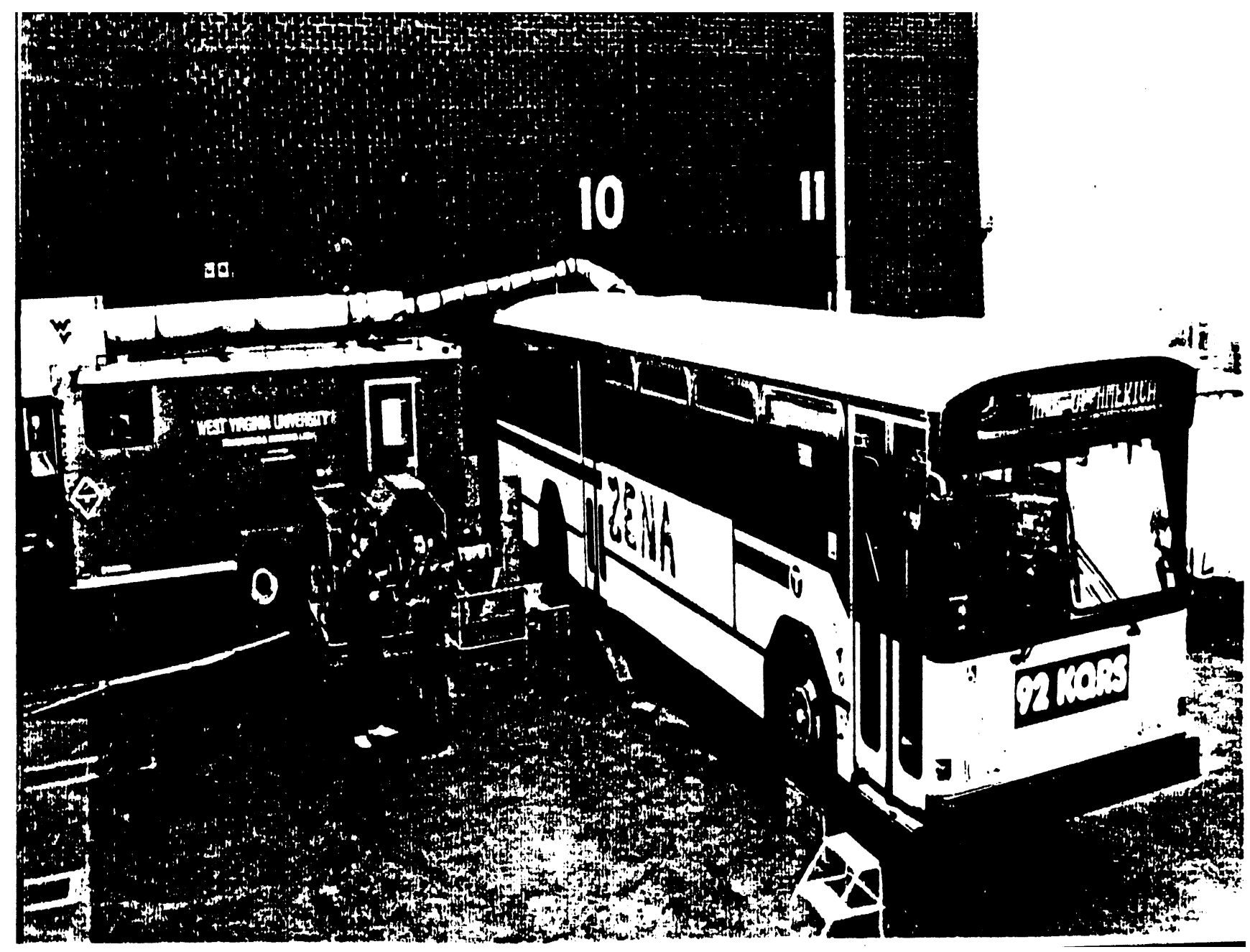

Figure 2.1 WVU Transportable Heavy-duty Vehicle Emissions Testing Laboratory at a Test Site 


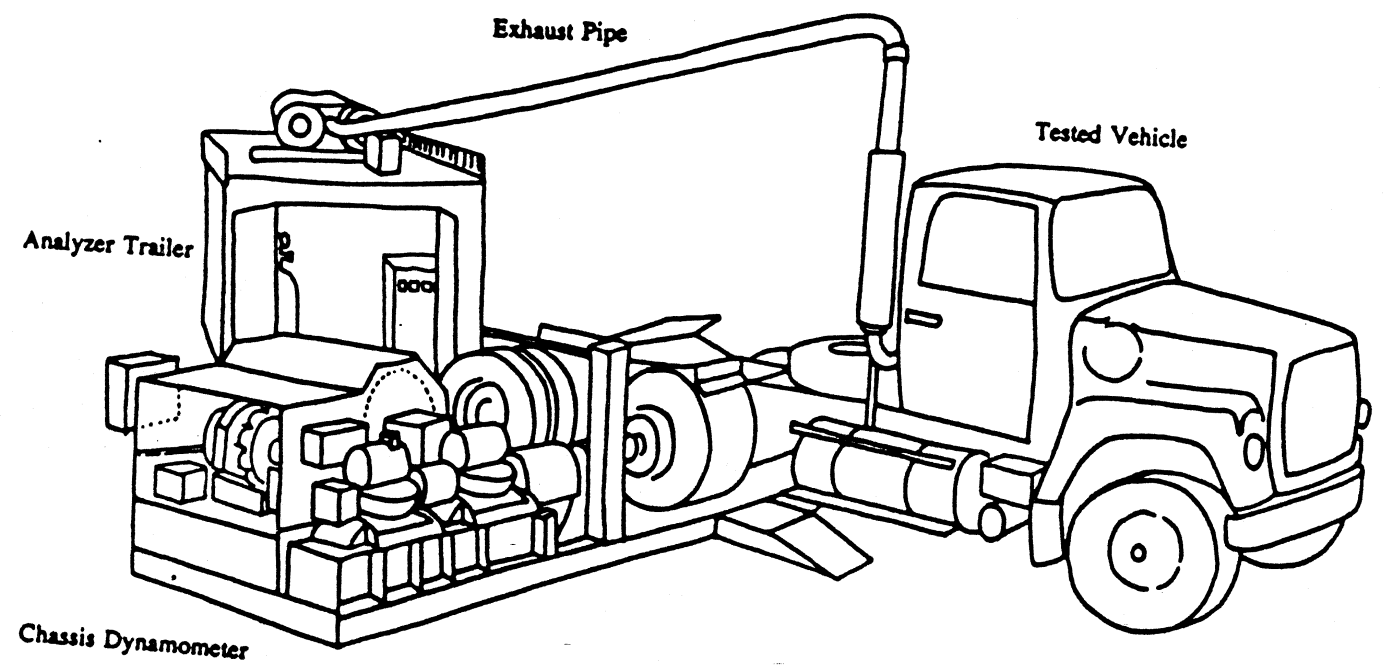

Figure 2.2 Sketch of the Laboratory System ${ }^{[14]}$

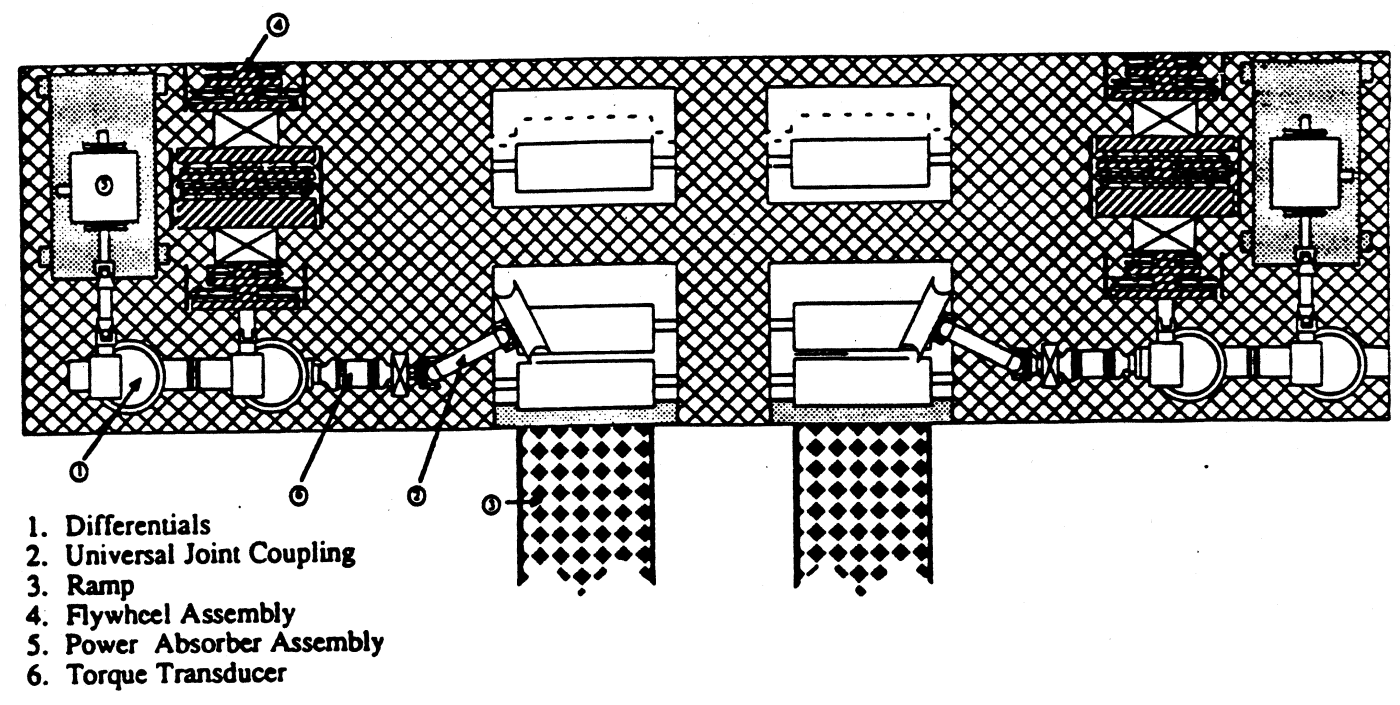

Figure 2.3 Major Components of the Chassis Dynamometer ${ }^{[14]}$ 


\subsection{Emission Measurement System}

During the WVU THDVETL emission testing, the tested vehicle is "driving" on the chassis dynamometer and the exhaust from the vehicle is ducted to the emission measurement system. A separate, enclosed trailer hosts all the exhaust gas analyzer, the necessary standard gases, and other accessories in analyzing exhaust emissions. The concentrations of hydrocarbon (HC), carbon dioxide $\left(\mathrm{CO}_{2}\right)$, carbon monoxide $(\mathrm{CO})$, and oxides of nitrogen $\left(\mathrm{NO}_{\mathrm{x}}\right)$ in the diluted mixture were measured continuously in the dilution tunnel. Particulate Matter (PM) emissions were determined gravimetrically. The whole measurement system included mainly the CFV-CVS system, gas analyzers, and particulate sampling system, as shown in fig. 2.4.

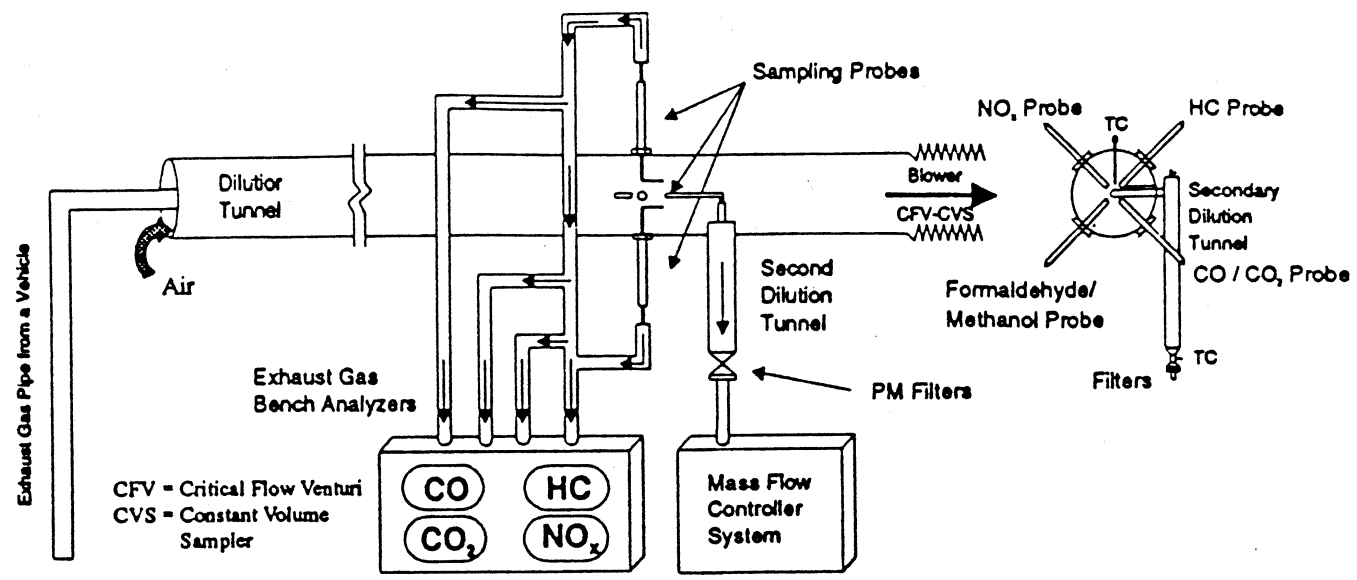

Figure 2.4 Sketch of Emission Measurement System ${ }^{[15]}$

\section{Dilution Tunnel and Critical Flow Venturies}

A full size stainless steel primary dilution tunnel, $21 \mathrm{ft}$. in length and $1.5 \mathrm{ft}$. in diameter, is used in the laboratory. One end of the tunnel is connected to a 
blower. The blower, driven by a 75hp electric motor, is used to draw exhaust and air mixture into the tunnel. The other end has three inlets: one for exhaust gas from vehicle tailpipe, the other two for background dilution air. The dilution air and exhaust are mixed together at the inlet of the tunnel and the flow through the smooth walled tunnel is highly turbulent.

The volume flow rate of the diluted mixture in the main tunnel, which is comprised of engine exhaust from vehicle tailpipe and background dilution air, is controlled by the Critical Flow Venturi (CFV). The flow in the main tunnel is determined by the following: ${ }^{[13]}$

$$
Q=K \frac{P}{\sqrt{T}}
$$

Where, $\mathrm{P}$ and $\mathrm{T}$ are the absolute pressure and temperature, respectively, at the inlet of the venturi. $\mathrm{K}$ is a coefficient that is determined by calibration. The pressure and temperature data, acquired at a rate of $10 \mathrm{~Hz}$, are used to calculate mass flow rate in the dilution tunnel. In a given inlet temperature and pressure, venturi flow rate can be altered by calibration coefficient $\mathrm{K}$. The flow rate used in a test is determined by the displacement of the engine being tested and on the detectable concentrations of the measured species in the sampling zone of the primary tunnel.

There is an auxiliary dilution tunnel that was used for particulate measurement. The other end of the auxiliary dilution tunnel is connected to the 70-mm filter holder. 


\section{Gas Analyzers}

In WVU laboratory, dilute continuous measurement of the regulated species is made using on-line instrument which are piped and wired in a panel inside the instrumentation trailer of the laboratory. The heated lines carry the sample from the tunnel to the analyzer where the $0-5 \mathrm{~V}$ output signals are sent to computer and concentrations are achieved.

$\mathrm{CO}$ and $\mathrm{CO}_{2}$ concentrations were measured using Non-dispersive Infra-red gas analyzers. $\mathrm{NO}_{\mathrm{x}}$ concentrations were measured using Chemiluminescent analyzer. A stand-alone heated flame ionization detector (HFID) was used to measure total hydrocarbon (THC).

\section{Particulate Sampling System}

In WVU Constant Volume Sampling (CVS) system, engine exhaust from vehicle tailpipe is drawn with dilution air into the primary dilution tunnel. A small part is drawn from the main tunnel and subjected to further dilution in a secondary tunnel to cool the exhaust to below $125^{\circ} \mathrm{F}$. A sample of gas from this tunnel is then drawn through two filters of Teflon-coated glass fiber in series. A microbalance with a sensitivity of $.001 \mathrm{mg}$ is used to weigh the filters. The mass of particulate emissions is determined from the proportional mass sample collected on the filter, the sample flow and the total flow over the test period. It is reported in gram per unit driving distance. 


\section{Lambda Sensor}

For natural gas vehicles tested in the transportable laboratories, lambda sensors were adopted as a measure to monitor the combustion in the natural gas engines. A lambda sensor is shown in figure 2.5. One electrode is exposed to air and the other electrode is exposed to the vehicle tailpipe exhaust gas. A flow of electrons between the two electrodes is directly related with the difference of the partial pressure of oxygen in the air and exhaust. The voltage output is then the function of oxygen level in the exhaust and the corresponding lambda value can be deduced. This type of sensor is used primarily for lean-burn control in lean-burn natural gas vehicles.

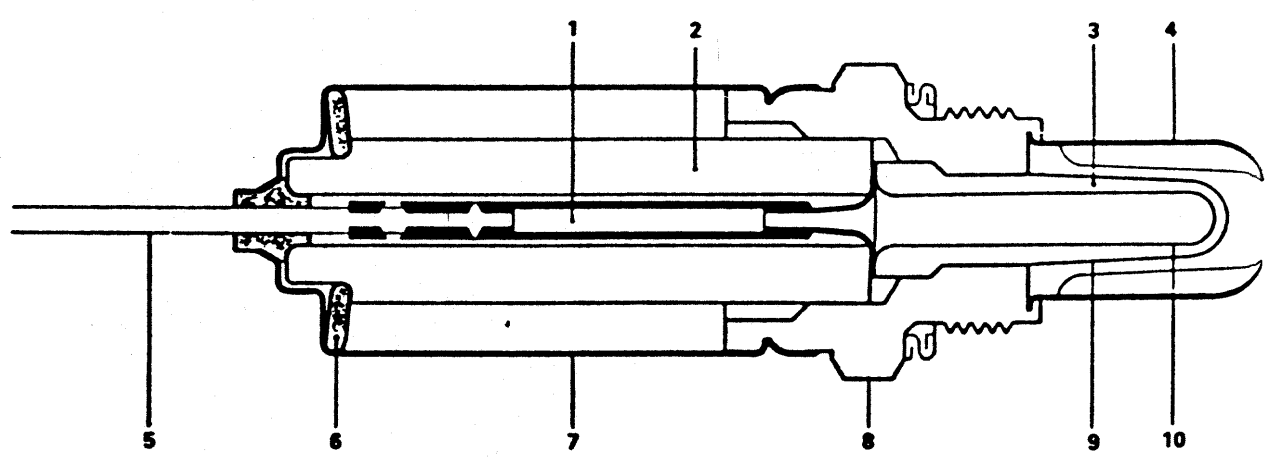

1 Contact element. 2 Protective ceramic element. 3 Sensor ceramic 4 Protective tube (exhaust end). 5 Electrical connection. 6 Disc spring 7. Protective sleeve (atmosphere end). 8 Housing (-) 9 Electrode (-). 10 Electrode(+).

Figure 2.5 Sketch of an Lambda Sensor ${ }^{[19]}$ 


\section{Bag Sampling}

During a test, dilution air and dilute exhaust samples are collected in two separate 5 cubic foot tedlar bags. The volume of bags, comparing to the total dilution tunnel mixture flow volume of about 10,000 cubic foot, is negligible and thus will not effect the mass emission calculation accuracy. The samples pulled into the bags are filtered to remove the particulate matter but the lines are neither heated nor passed through a refrigerator/dryer. Once the test is completed, the samples, from the filled bags, are introduced into the gas analyzers and their respective concentrations are measured. The concentrations measured in the background bag are used as background dilution air concentrations to correct for mass emission calculations. The dilute mixture bag sample is collected and analyzed only as a quality control/quality assurance check that provides a way to compare the results with the continuous sample. The concentrations measured in the sample bag also represent the average concentrations that occurred during the test. 


\subsection{Emission Testing Procedures and Test Cycles}

\section{Testing Procedures}

The emissions test procedures in the transportable laboratories include calibration of equipment, actual vehicle testing, data reduction and analysis. Prior to emission testing, calibrations are carried out on both the dynamometer and the instrumentation system to assure accurate simulation and measurement. The following steps are generally adopted for the actual vehicle testing:

1. Position and mount the vehicle onto the test bed.

2. Warm-up until the differentials of the dynamometer reached $100^{\circ} \mathrm{F}$.

3. Stop engine and allow a 20 minute cool down (soak) period.

4. Start the engine and begin the test.

5. At the end of the test, cool down for 20 minutes and prepare for the next test.

Tests for each vehicle were repeated until repeatable results were obtained. Usually four to five tests were needed to achieve repeatability. $\mathrm{CO}_{2}, \mathrm{CO}, \mathrm{NO}_{\mathrm{x}}$, and $\mathrm{HC}$ emissions data were generated by continuous readings and the results were integrated over the complete test cycle. PM emissions were obtained by passing through a secondary tunnel using the double-dilution method.

Test Cycles

Since transient operation of a vehicle is known to cause a significant proportion of the emissions, recognized vehicle test cycles prescribe a speedversus-time trace through which the vehicle must be operated were needed to 
perform the vehicle emission testing. The most commonly used cycle in WVU THDVETLs is the CBD cycle.

For urban buses, a Society of Automotive Engineers (SAE) Recommended Practice (J1376) provides a speed versus time schedule which consists of Central Business District (CBD) section. The CBD is composed of fourteen identical ramps. Each ramp takes 40 seconds, which include 10 seconds of acceleration from idle to $20 \mathrm{mph}(8.94 \mathrm{~m} / \mathrm{s}), 18.5$ seconds of steady state operation at $20 \mathrm{mph}$, 4.5 seconds for deceleration, and 7 seconds of idle periods, as shown in figure 2.6. This cycle is ideally suited for automatic transmission and calls for accelerations that demand a little less than full power for a typical transit bus.

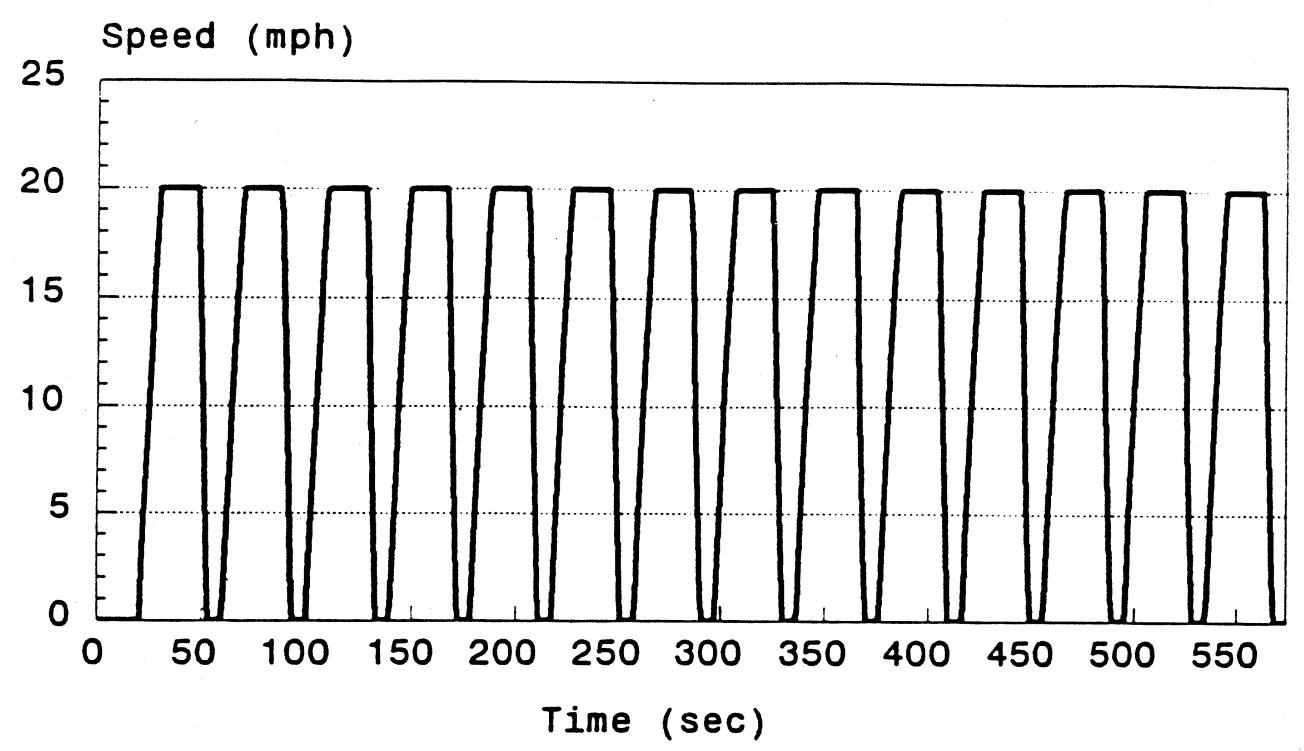

Figure 2.6 Sketch of CBD Cycle 


\subsection{Measurement Delay in the Emissions Testing}

Currently, emission rates are reported as mass of emissions per unit driving distance, which disregards the instantaneous emission profiles. Interests have been growing regarding the instantaneous emissions to the immediate vehicle operation conditions. Emission analyses are also conducted in connecting the emission concentration with instantaneous engine modes. But the fact is that, in WVU THDVETLs, and all other emission testing facilities, there exists the problem of time differences between the time at which a transient driving maneuver takes place in the engine and the time at which measurement are recorded at the instruments. That is to say, measured instantaneous emission concentrations were thought to reflect the emissions concentration from the engine a certain period of time ago. This measurement delay results from a combination of the time due to the transport of exhaust from the engine exhaust valve to gas analyzer and the analyzer response time.

J. Messer and N. Clark conducted research on measurement delay in WVU Transportable Heavy-duty Vehicle Emissions Testing Laboratories in $1995^{[7]}$. In the research, a mathematical model was developed using analyzer response time and appropriate fluid flow and heat transfer equations to predict the time delay between an engine transient and the resulting emission response. Typical emission delays for a transient bus test for $\mathrm{HC}, \mathrm{CO}, \mathrm{CO}_{2}$, and $\mathrm{NO}_{\mathrm{x}}$ were reported to be: 6.2 , 12.4, 11.4, and 18.7 seconds respectively. To validate the model, actual time 
delays were determined by cross correlating engine power with each measured emission concentration. Cross correlating is a process of comparing two tests of data against a common variable, time in our case, to find the relative time shift which causes the best match between the two sets of data. The coefficient can be calculated using the equation:

$$
\Pi_{\Delta t}=\frac{\sum_{\Delta t=-t_{\max }}^{t_{\max }-\Delta t}[P(t) \bullet R(t+\Delta t)]}{\sum_{\Delta t=-t_{\max }}^{t_{\max }-\Delta t}[P(t) \bullet R(t)]}
$$

Where $\Pi_{\Delta t}$ is the correlation coefficient, $P$ is the power, $R$ is the pollutant emission rate in gram per second, and $\Delta \mathrm{t}$ is the delay time. Correlation coefficient was calculated for each incremental shift in time and the time shift which yields the highest coefficient was defined as the delay time between the two signal.

Certainly, the underlying assumption of applying this method is that the emission rate increase with vehicle horsepower. Experiments had been done by this research to prove that for compression ignition engine, increase in power is proportional to the increase in $\mathrm{CO}_{2}, \mathrm{CO}$, and $\mathrm{NO}_{\mathrm{x}}$. For lean burn engine, this method could not be applied on some emission species. Experimental results were found to agree with the theoretical prediction.

Based on this research conclusion, measurement delay time in this study was determined using cross correlating when appropriate and convenient, especially for $\mathrm{CO}_{2}$ and $\mathrm{NO}_{\mathrm{x}}$. Otherwise, theoretical models were employed to find the delay time between the power and the measured emission concentration, 
especially for $\mathrm{CO}$ and $\mathrm{HC}$ in the natural gas engines. Fig 2.8 shows the $\mathrm{CO}_{2}$ emission rate from a natural gas vehicle powered by Cummins L10 CNG engine along with vehicle horsepower before and after the delay time adjustment. The delay time, 11 seconds, is determined using cross correlation. Fig 2.9 shows CO emissions from the same test, while the delay time, 12 seconds, is determined using the theoretical value. One can see that $\mathrm{CO}$ emissions do not correlate with vehicle horsepower for this engine.

It is understood that the delay is rather complex and emission species each has different delay time. It is also impossible to get an absolute delay time for one emission measurement since the engine exhaust flow is varying with the load thus altering the exhaust transportation time. More importantly, the heavily damped characteristics of the gas analyzers also introduce distortion of the output measurement. One may need to use signal reconstruction technique to restore the continuos emission concentration curve. 


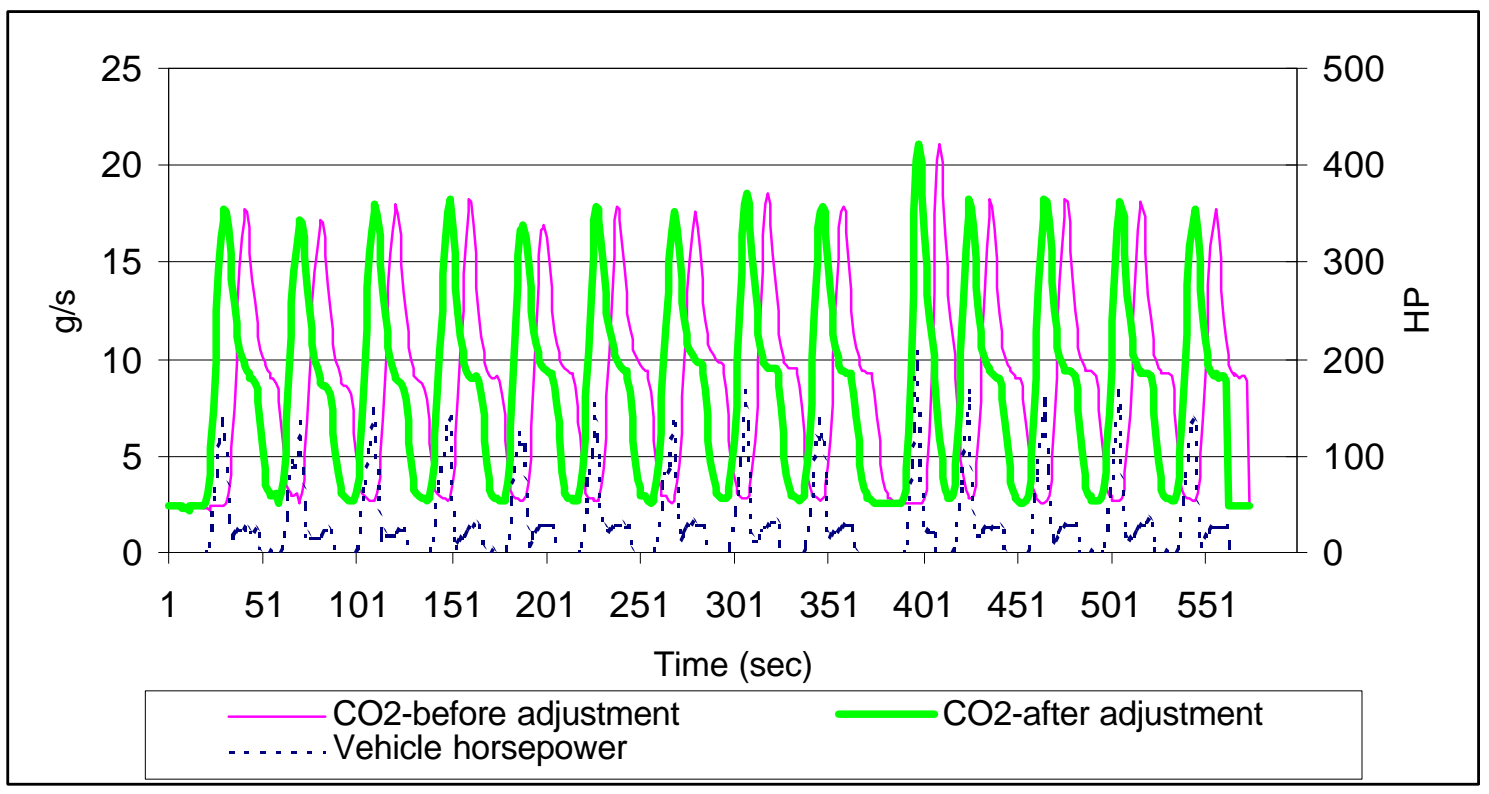

Figure 2.7 $\mathrm{CO}_{2}$ Emissions from a Natural Gas Vehicle Before and After Measurement Delay Time Adjustment

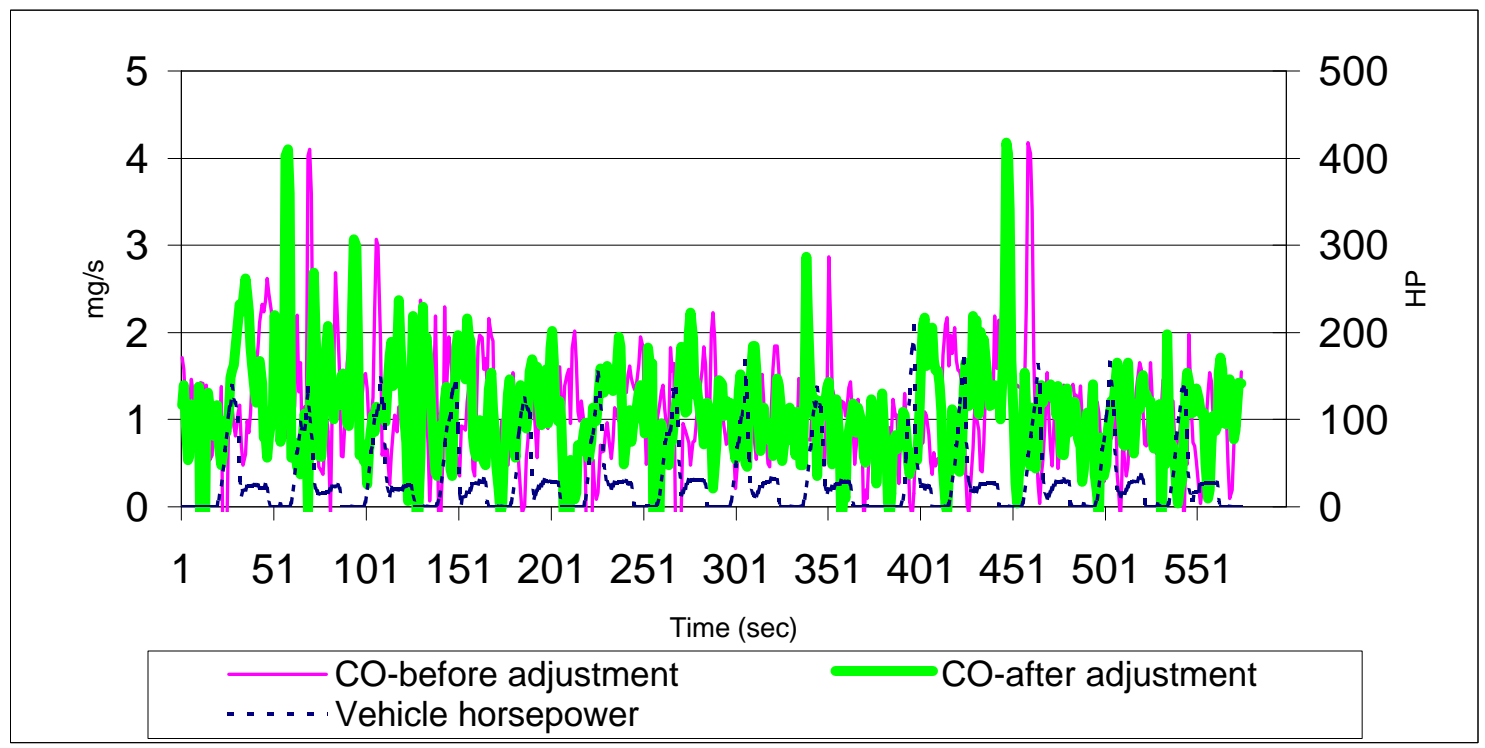

Figure 2.8 CO Emissions from a Natural Gas Vehicle Before and After Measurement Delay Time Adjustment 


\section{CHAPTER 3}

\section{NATURAL GAS VEHICLE REVIEW}

\subsection{Natural Gas as an Alternative Fuel}

Automotive fuels are the most important products manufactured and marketed by oil companies. With the ever-increasing governmental and public demand for cleaner combustion, the demand for alternative fuels also increases. The attractive alternative fuels in these years include natural gas (CNG, LNG), alcohol fuel (Methanol, Ethanol), and vegetable oil (Biodiesel). Table 3.1 lists the properties of conventional and alternative fuels in heavy-duty vehicle uses.

Table 3.1 Diesel and Alternative Fuel Properties ${ }^{[11]}$

\begin{tabular}{|c|c|c|c|c|c|}
\hline & $\begin{array}{c}\text { Diesel } \\
\text { Fuel }\end{array}$ & Biodiesel & $\begin{array}{c}\text { Natural } \\
\text { Gas }\end{array}$ & Methanol & Ethanol \\
\hline Appearance & $\begin{array}{c}\text { Amber } \\
\text { Liquid }\end{array}$ & $\begin{array}{c}\text { Amber } \\
\text { Liquid }\end{array}$ & $\begin{array}{c}\text { Colorless } \\
\text { Gas }\end{array}$ & Clear Liquid & Clear Liquid \\
\hline Boiling Pt., C & $188-340$ & $\begin{array}{c}\text { approx. } \\
280\end{array}$ & -162 & 65 & 78.5 \\
\hline Pour Pt., C & -29 & -4 & N/A & N/A & N/A \\
\hline Fuel Density & 0.85 & 0.889 & & 0.791 & 0.789 \\
\hline $\begin{array}{c}\text { Heat of Vapor., } \\
\text { KJ/Kg }\end{array}$ & $225-280$ & 440 & 509 & 1167 & 902 \\
\hline Water Soluble & NO & NO & NO & YES & YES \\
\hline $\begin{array}{c}\text { Viscosity, } \\
\text { @ 15 C }\end{array}$ & 2.6 & 3.6 & 0.011 & 0.65 & 1.3 \\
\hline $\begin{array}{c}\text { Stoichiometric } \\
\text { Air/Fuel Ratio }\end{array}$ & 15 & 12.6 & 17.2 & 6.45 & 8.95 \\
\hline $\begin{array}{c}\text { Octane } \\
\text { Number }\end{array}$ & 30 & 73 & 117 & 99 & 98 \\
\hline $\begin{array}{c}\text { Cetane } \\
\text { Number }\end{array}$ & $40-47$ & $47-52$ & -10 & $0-4$ & $5-15$ \\
\hline $\begin{array}{c}\text { Fuel Energy } \\
\text { Value, LHV, } \\
\text { MJ/Kg }\end{array}$ & 42.8 & 37.3 & 47 & 20.1 & 27.0 \\
\hline
\end{tabular}




\begin{tabular}{|c|c|c|c|c|c|}
\hline $\begin{array}{c}\text { Mass fuel with } \\
\text { same energy } \\
\text { (LHV) as one } \\
\text { volume of } \\
\text { diesel }\end{array}$ & 1 & 1.15 & 0.91 & 2.13 & 1.59 \\
\hline $\begin{array}{c}\text { Chemical } \\
\text { Formula }\end{array}$ & $\mathrm{CH}_{1.85}$ & $\mathrm{CH}_{1.8} \mathrm{O}_{0.1}$ & $\begin{array}{c}85 \%-95 \% \\
\mathrm{CH}_{4}\end{array}$ & $\mathrm{CH}_{3} \mathrm{OH}$ & $\mathrm{C}_{2} \mathrm{H}_{5} \mathrm{OH}$ \\
\hline Carbon, wt \% & 87.3 & 78.0 & 75.44 & 37.49 & 52.14 \\
\hline $\begin{array}{c}\text { Hydrogen, wt } \\
\%\end{array}$ & 12.5 & 11.7 & 24.56 & 12.58 & 13.13 \\
\hline Oxygen,wt \% & 0 & 10.3 & 0 & 49.94 & 34.73 \\
\hline
\end{tabular}

Among the alternative fuels, Natural gas, in the form of compressed natural gas, $\mathrm{CNG}$, and liquefied natural gas, $\mathrm{LNG}$, is the most promising alternative fuel. The principal constituent of natural gas is methane, which normally makes up $85 \%$ to $95 \%$ in total, with the remainder being made up of the heavier hydrocarbon, nitrogen, and water. The composition of natural gas varies throughout the country. It mainly depends on original gas composition and processing. The chemical composition for natural gas can be written as $\mathrm{CH}_{4}$ for various sources of natural gas in vehicular fuel applications. Table 3.2 gives the compositions of CNG used in some of the WVU emission testing.

Until recently, the major motivation of using the fuel was economic and energy security, as the natural gas costs lower and is more abundant than petroleum fuels. In recent years, focus has been on the environmental as well as the economic benefits. Recent advances in the technology of natural gas vehicles and engines, and more refilling facilities boost the visibility and market potential of the fuel. The stage may now be set for a major expansion in their use. 
Table 3.2 CNG Specifications ${ }^{[14]}$

\begin{tabular}{cccc} 
Component & \multicolumn{3}{c}{ Mole \% } \\
\hline Methane & New York City, & Parkersburg, WV & Pittsburgh, PA \\
Ethane & 2.0350 & 94.884 & 95.573 \\
Propane & 0.3703 & 2.591 & 2.489 \\
Iso-Butane & 0.0757 & 0.430 & 0.345 \\
N-Butane & 0.0806 & 0.044 & 0.066 \\
Iso-Pentane & 0.0306 & 0.069 & 0.068 \\
Nitrogen & 0.3364 & 0.021 & 0.030 \\
CO $_{2}$ & 0.7423 & 1.046 & 0.583 \\
Specific Gravity & 0.5800 & 0.836 & 0.650
\end{tabular}




\subsection{Natural Gas Engine and Vehicle Technology Review}

In conventional heavy-duty vehicle uses, most engines available are diesel compression ignition engines due to their higher thermal efficiency than that of spark ignition engines. As the advent and popularization of alternative fuels, engines were modified for alternative fuel or designed dedicatedly for alternative fuel uses. For natural gas, several engine technologies are available in market at current stage.

From fuel properties Table 3.1 we can see that natural gas has high octane number and low cetane number which makes it difficult to be used in compression ignition engines. One solution is to convert diesel engines to burn natural gas in the so-called dual fuel engine. This engine operates on a mixture of diesel and natural gas. The dual-fuel approach fumigates, or injects at low pressure, a natural gas and air mixture into the inlet stream, but leave the diesel injection pump in place. The natural gas is introduced to air stream to displace a portion of diesel fuel. Both fuels are used to power the engine. "Pilot-injection" and "fumigation" are also used to describe this combustion system. Emissions from this engine are generally lower than that of diesel engine. However, since the engine uses both natural gas and diesel, the benefit of using alternative fuel is not so distinct.

The best solution for the use of natural gas in heavy-duty vehicles is to use engines that have been dedicatedly designed for burning natural gas. Almost all diesel engine manufacturers have developed natural gas versions of previously 
sold engines. These engines use spark plug to initiate combustion and typically use a lean burn concept. The excess air does three things: first, more than adequate oxygen is available to complete the combustion to reduce some of emissions. Second, the extra air lowers the overall combustion temperature, thus reducing the formation of $\mathrm{NO}_{\mathrm{x}}$. Third: lean air-fuel combustion increases fuel economy and engine thermal efficiency. Lean-burn combustion is currently being pursued by all major diesel engine manufacturers as the preferred technology for heavy-duty natural gas engines.

Most natural gas engines tested in WVU heavy-duty vehicle emission testing were DDC Series 50G, Cummins L 10, and Caterpillar 3306 natural gas engines. Table 3.3 lists the configurations of the three most popular natural gas engines.

Table 3.3 Natural Gas Engine Specifications

\begin{tabular}{|l|l|l|l|}
\hline & DDC Series 50 G & Cummins L10 & Caterpillar 3306 \\
\hline Bore & N/A & 4.921 in. & $4.75 \mathrm{in}$. \\
\hline Stroke & N/A & $5.35 \mathrm{in}$. & $6.0 \mathrm{in}$. \\
\hline Rated Engine Power & $250 \mathrm{HP}$ & $240 \mathrm{HP}$ & $250 \mathrm{HP}$ \\
\hline Rated Engine Speed & $2100 \mathrm{RPM}$ & $2100 \mathrm{RPM}$ & $2100 \mathrm{RPM}$ \\
\hline Torque Peak & $780 \mathrm{lb} . \mathrm{ft}$. & $750 \mathrm{lb} . \mathrm{ft}$. & $820 \mathrm{lb} . \mathrm{ft}$. \\
\hline Displacement & $8.5 \mathrm{Liters}$ & $10 \mathrm{Liters}$ & $10.5 \mathrm{Liters}$ \\
\hline Compression Ratio & $10: 1$ & $10.5: 1$ & $10.5: 1$ \\
\hline
\end{tabular}




\begin{tabular}{|l|l|l|l|}
\hline Number of Cylinders & 4 & 6 & 6 \\
\hline Combustion Type & Spark ignited & Spark ignited & Spark ignited \\
Lean burn & Lean burn & Stoichiometric \\
\hline Operating Cycles & 4 & 4 & 4 \\
\hline Air/fuel Ratio & Electronically & Closed-loop & N/A \\
Control & Controlled (DDEC & Electronically & \\
& III) & Controlled (CM-420) & \\
\hline
\end{tabular}




\subsection{Emissions from Natural Gas Vehicles}

Natural gas fueled engines generally have very low emissions of reactive hydrocarbons, carbon monoxide, and particulate matter. The principal constituent of natural gas is methane, which normally makes up of $85 \%$ to $95 \%$ of the total. Since the methane $\left(\mathrm{CH}_{4}\right)$ molecule oxidizes with essentially no intermediate hydrocarbon constituents, efficient combustion and low emissions result as long as sufficient oxygen is present. ${ }^{[12]}$ When natural gas is burned under ideal conditions the exhaust will contain only water vapor, carbon dioxide and nitrogen. In an actual process, the exhaust also contains non-reacted and partially reacted fuel, carbon monoxide $(\mathrm{CO})$, oxides of nitrogen $\left(\mathrm{NO}_{\mathrm{x}}\right)$, and particulate matter $(\mathrm{PM})$.

\section{Carbon dioxide $\left(\mathrm{CO}_{2}\right)$}

Carbon dioxide, along with water vapor, is the major product of carbon-fuel combustion. It plays no significant role in ozone formation and is not toxic, thus generally not considered as pollutant. However, it is greenhouse gas since it absorbs heat energy radiation from the earth's surface. It's agreed that of the various greenhouse gases, $\mathrm{CO}_{2}$ contributes to around 50 percent of the warming effects. As global warming effects are receiving more and more attention, $\mathrm{CO}_{2}$ emission control is also in consideration. Methane, the predominant component of natural gas, has a lower carbon to hydrogen ratio than that of petroleum fuels, and therefore produce less carbon dioxide when burnt. On an equivalent energy basis, 
methane produces $73 \%$ of the $\mathrm{CO}_{2}$ emitted from the combustion of petroleum fuels.

\section{Oxides of Nitrogen $\left(\mathrm{NO}_{\mathbf{x}}\right)$}

$\mathrm{NO}_{\mathrm{x}}$ is a significant contributor to smog formation and is getting more and more strictly controlled. The mechanism that produces nitric oxides is generally understood. The following chemical reactions are of greatest importance.

$$
\begin{gathered}
\mathrm{N}+\mathrm{NO} \leftrightarrow \mathrm{N}_{2}+\mathrm{O} \\
\mathrm{N}+\mathrm{O}_{2} \leftrightarrow \mathrm{NO}+\mathrm{O} \\
\mathrm{N}+\mathrm{OH} \leftrightarrow \mathrm{NO}+\mathrm{H}
\end{gathered}
$$

The forward rate constants for these reactions are as follow:

$\mathrm{k}_{1}=2.7 * 10^{-11}$

$\mathrm{k}_{2}=1.1 * 10^{-14} \mathrm{~T} \exp (-3150 / \mathrm{T})$

$\mathrm{k}_{3}=7 * 10^{-11}$

Where the units of the constants are $\mathrm{cm}^{3}$ molecule $\mathrm{s}^{-1}$.

The chemical reaction rates increase strongly with temperature. As increased temperatures favor nitric oxide formation and the burned gas temperature are maximum at slightly rich combustion, the maximum nitric oxide occurs at slightly lean mixture. ${ }^{[2]}$

As is the case of diesel engines, $\mathrm{NO}_{\mathrm{x}}$ emissions are also a problem with natural gas fueled vehicles. For natural gas engines operating with stoichiometric combustion, a typical three-way catalyst in combination with closed-loop exhaust 
oxygen level feedback and exhaust gas recirculation can be used to control $\mathrm{NO}_{\mathrm{x}}$ emissions. As most natural gas engines employ lean-burn technology, the operation lowers the ability of catalysts to further reduce $\mathrm{NO}_{\mathrm{x}}$ emissions due to the low temperature and prevalence of oxidizing agent $(\mathrm{O} 2)$. But the lean-burn itself lowered the cylinder combustion temperature and helps to reduce the $\mathrm{NO}_{\mathrm{x}}$ formation.

\section{Carbon Monoxide (CO)}

$\mathrm{CO}$ is a pollutant in its own right because of its direct health effects. In rich mixture why carbon monoxide appears in the exhaust should be clear: There is insufficient oxygen to combust all the carbon contained in the fuel to carbon dioxide. In lean burn engines, there appears to be an additional source of $\mathrm{CO}$ caused by the flame-fuel interaction with the walls, the oil films, and the deposits. The most important engine parameter influencing carbon monoxide emissions is the fuel-air equivalence ratio. All other variables cause second-order effects. Thus the key to minimizing $\mathrm{CO}$ emissions is to minimize the times the engine must run rich (such as during start up) and to develop an induction system that minimize variance fuel-air ratio from cylinder to cylinder or cycle to cycle.

\section{Hydrocarbon (HC)}

Hydrocarbon emission generally means unburned fuel and is the result of lack of proper mixing and incomplete combustion. Most of these species made up of the fuel can be found in exhaust. The major part of hydrocarbon emissions 
from natural gas engines is unburned methane, which result from improper fuel/air ratio and incomplete mixing. Since methane emissions are much less reactive than the heavier hydrocarbon emissions from diesel fueled vehicles, they do not contribute significantly to smog problem. ${ }^{[5]}$ WVU transportable laboratory is able to distinguish unburned methane from total hydrocarbons, the result showed that the heavier hydrocarbons from natural gas engines are about the same order as that of diesel engines. ${ }^{[14]}$

\section{Particulate Matter (PM)}

Basically, particulate matters are any substances other than water that can be collected by filtering the exhaust. Not only are they physically dirty, but they are suspected as being carcinogenic. Particulate emissions from diesel engines are much greater than that from gasoline engines due to the properties of diesel fuel and combustion. The material collected on filter is usually divided into two parts: a solid carbon material or soot and organic fraction that is hydrocarbons and their partial oxidation products condensed into filter or adsorbed to the soot. The organic fraction is influenced by the process that dilutes the exhaust with air upon expulsion from the engine. One of the most benefits provided by natural gas engine it the significant particulate reduction. Actually, if natural gas engine is well-tuned and operated normally, the particulate emissions can be considered as negligible. This is because the hydrocarbons in natural gas are non-condensable under atmospheric conditions. The small amount of particulate matter measured 
from natural gas vehicles is probably generated from the burning of lubrication oil or dirt accumulated on the cylinder wall ${ }^{[12]}$. Since more stringent standards for particulate matter emissions from heavy-duty diesel vehicles have been adopted, CNG is promising as an alternative fuel in terms of particulate emissions. 


\section{CHAPTER 4}

\section{DETERMINATION OF INSTANTANEOUS DILUTION}

\section{FACTOR IN NATURAL GAS VEHICLE TESTING}

\subsection{Current Dilution Factor Calculation}

As discussed in Chapter 2, the emission measurement system in WVU Transportable Heavy-duty Vehicle Emission Testing Laboratories is CFV-CVS (Critical Flow Venturi - Constant Volume Sampler) system. Vehicle tailpipe exhaust emitted from engine exhaust valves was diluted by background air to form a constant mixture volume flow rate, which is maintained by the critical flow venturi. Dilution factor is the parameter describing the dilution process and current dilution factor used in WVU laboratory is based on CFR Title 40 Part 144. EPA specifies a formula to calculate dilution factor for CVS emissions measurement system and use it to correct the mass emission calculations for the pollutant concentration in the dilution air. The formula specified in CFR 40 is:

$$
D F=\frac{S P C O 2}{C O 2+C O+H C}
$$

Where:

$\mathrm{SPCO} 2=13.4$

for petroleum-fueled vehicles 


$$
S P C O 2=\frac{100 x}{x+y / 2+3.76(x+y / 4-z / 2)}
$$

for vehicles where fuel composition is $\mathrm{C}_{\mathrm{x}} \mathrm{H}_{\mathrm{y}} \mathrm{O}_{\mathrm{z}}$

$\mathrm{CO}_{2}, \mathrm{CO}$ and $\mathrm{HC}$ are the concentrations measured in the diluted sample expressed as percent volume.

Although the derivation of the equation is not documented in CFR, we can make the calculations based on the assumptions made by EPA. First, the fuel is considered under chemically correct (stoichiometric) combustion. Second, background pollutant effect is negligible.

The equation for the combustion of a stoichiometric mixture of fuel $\mathrm{C}_{\mathrm{x}} \mathrm{H}_{\mathrm{y}} \mathrm{O}_{\mathrm{z}}$ is then as follows:

$$
\mathrm{C}_{\mathrm{x}} \mathrm{H}_{\mathrm{y}} \mathrm{O}_{\mathrm{z}}+a(\mathrm{O} 2+3.76 \mathrm{~N} 2) \rightarrow b \mathrm{CO}_{2}+d \mathrm{H}_{2} \mathrm{O}+e \mathrm{~N}_{2}
$$

Considering the atomic chemical balance:

$$
\mathrm{C}: \mathrm{b}=\mathrm{x}
$$

$\mathrm{H}: \mathrm{d}=\mathrm{y} / 2$

$O: 2 b+d=2 a+z$

$\mathrm{N}: \mathrm{e}=3.76 \mathrm{a}$

We get: $e=3.76 a=3.76 *(2 b+d-z) / 2=3.76(x+y / 4-z / 2)$

The stoichiometric percent of $\mathrm{CO}_{2}$ in the exhaust mixture is then:

$$
S P C O 2=\frac{100 b}{b+d+e}=\frac{100 x}{x+y / 2+3.76(x+y / 4-z / 2)}
$$


For petro-fuel as gasoline and diesel fuel, the assumed carbon-hydrogen ratio is 1:1.85 according to CFR 40 and SPCO2 is considered as constant 13.4, which is used in WVU laboratory. For natural gas whose composition is $\mathrm{CH}_{4}$, the value is 9.5. For methanol is 11.57 and for ethanol is 15.97 . If the carbon-containing compounds, including $\mathrm{CO}_{2}, \mathrm{CO}$, and $\mathrm{HC}$ concentrations in the diluted mixture is determined, dilution factor can be calculated using the EPA formula.

This formula is used directly for emission testing where a slipstream of the mixture is pumped into sample bags and pollutant concentrations were measured only to determine the average pollutant concentrations during the whole test phase. In WVU transportable emission testing, however, the emission measurement technique is different. Rather than just measuring the pollutant concentrations in the sample bags, the gas analyzers measure pollutant concentrations in diluted mixture continuously with the frequency of $10 \mathrm{~Hz}$. Mass emissions were calculated by integrating the measured diluted mixture and corrected for background pollutant using dilution factor. The modified EPA formula used in WVU laboratory is then expressed as:

$$
D F=\frac{N \times S P C O 2}{\sum_{i=1}^{N}\left(\mathrm{CO}_{i}+\mathrm{CO}_{i}+H C_{i}\right)}
$$

Where $i$ is the emission concentration measured at every time interval and $N$ is the total time intervals of the test phase. For example, $N$ is 5740 for CBD test cycle as 
CBD cycle lasts 574 seconds and emission concentrations in the diluted mixture were measured every 0.1 second. Obviously, the dilution factor is calculated as an average value over the whole test cycle.

Review of this formula indicates that it is not suitable for application in WVU heavy-duty vehicle emission testing, as described below.

1. As vehicle emissions levels are developing towards near zero emissions standards, the effects of background pollutant on mass emission calculations are more distinct than ever. In fact, recent WVU heavy-duty vehicle tests have encountered cases that pollutant concentration in the vehicle tailpipe are approaching that in the background, as $\mathrm{CO}$ emissions from some natural gas vehicles and $\mathrm{HC}$ emissions from some diesel vehicles. The CFR dilution factor equation did not consider the background and thus will cause errors.

2. The CFR formula assumes engine exhaust to be stoichiometric mixture of the combusted fuel at all engine operation modes. It is a good approximation for spark-ignition gasoline engines, whose combustion is closely around stoichiometric under modern engine control technology. However, this is not the case for the heavy-duty vehicles tested by WVU transportable laboratory. Most test vehicles were powered by either compression-ignition diesel engines or lean-burn natural gas engines. Combustion in neither type of engines can be considered as near stoichiometric combustion and the $\mathrm{CO}_{2}$ concentration in the vehicle tailpipe exhaust is deviated from stoichiometric percentage greatly. 
3. The CFR formula is designed for emission testing that pollutant concentrations in the diluted sample bags is measured only to determine the average pollutant concentration over the whole test phase. The calculated average dilution factor can then be used to determine the undiluted exhaust pollutant concentration with "reverse dilution" technique. However, emission concentrations in dilution tunnel are varying with time because of varying emission concentrations in the engine exhaust as well as varying dilution factor. To determine the undiluted tailpipe concentration in any point of time need to determine the instantaneous dilution factor. Otherwise, the concentration in tailpipe would be masked by dilution tunnel measurements if dilution factor were computed only as average value during the test phase.

As stated above, an approach to determine the instantaneous dilution factor needs to be developed to shed light on continuos undiluted vehicle tailpipe concentration and to improve mass emission calculation accuracy. 


\subsection{Improved Dilution Factor Calculations}

As the concern over vehicle tailpipe emissions increases, concern over emission measurement technique also rises. Recently, some agencies have questioned the validity and accuracy of EPA formula and some have developed new equations.

The New York Department of Environmental Conservation has developed a modified form of equation that accounts for contamination in the background air. A two-step approach is required to obtain to a more accurate dilution factor value. First, the dilution factor is calculated using the standard EPA formula that neglects the background pollutant, then the calculated dilution factor is used in combination with the measured carbonaceous species concentration of the background air to obtain a more accurate dilution factor. The equation is:

$$
D F_{N Y}=\frac{13.4}{\left[C O_{2-d i}+C O_{d i}+H C_{d i l}\right]-\left[C O_{2-b a c k}+C O_{b a c k}+H C_{b a c k}\right]\left[1-\frac{1}{D F_{E P A}}\right]}
$$

Where 13.4 is the stoichiometric volume percentage of $\mathrm{CO}_{2}$ in the total exhaust flow for petroleum fuel. The subscript dil denotes the concentration in the diluted mixture and back denotes those in the ambient background, EPA denotes the value obtained using EPA formula and $N Y$ denotes the value obtained using the NYDOEC formula. This modified formula can accurately correct the background pollutant effects on dilution factor. However, this is only when the engine is operating stoichiometrically. For diesel engines or lean-burn gas 
engines, the combustion is far from stoichiometric and $\mathrm{CO}_{2}$ percentage in the engine exhaust will not be 13.4.

Most recently, Austin and Caretto at Sierra Research ${ }^{[9]}$ proposed a new dilution factor equation that accounts for both the effects of background pollutants and nonstoichiometric combustion. The equation goes:

$$
D F=\frac{K_{1} \mathrm{CO}_{2-\text { back }}+K_{2} \mathrm{CO}_{\text {back }}+H C_{\text {back }}}{\left[100-K_{1}\left(C O_{2-\text { dil }}-C O_{2-b a c k}\right)-K_{2}\left(C O_{\text {dil }}-C O_{\text {back }}\right)-\left(H C_{\text {dil }}-H C_{b a c k}\right)-\left(1+r_{N}\right) O_{2-\text { dil }}\right.}
$$

Where $K_{1}$ and $K_{2}$ are fuel-related properties, $\mathrm{r}_{\mathrm{N}}$ is the moles of nitrogen to the moles of oxygen in the air, which is usually treated as 3.76 in EPA calculations. The equation is based on the fuel of $\mathrm{CH}_{\mathrm{y}} \mathrm{O}_{\mathrm{z}}$ composition with the following balanced chemical equation:

$$
\begin{aligned}
& \mathrm{CH}_{\mathrm{y}} \mathrm{O}_{\mathrm{z}}+[\mathrm{a}+\mathrm{b} / 2+(\mathrm{y} / 4-\mathrm{z} / 2)(\mathrm{a}+\mathrm{b})+\mathrm{f}]\left[\mathrm{O}_{2}+\mathrm{r}_{\mathrm{N}} \mathrm{N}_{2}\right] \rightarrow \\
& \mathrm{aCO}_{2}+\mathrm{bCO}+\mathrm{cCH}_{\mathrm{y}} \mathrm{O}_{\mathrm{z}}+[\mathrm{y}(\mathrm{a}+\mathrm{b}) / 2] \mathrm{H}_{2} \mathrm{O}+\mathrm{fO}_{2}+\mathrm{r}_{\mathrm{N}}[\mathrm{a}+\mathrm{b} / 2+(\mathrm{y} / 4-\mathrm{z} / 2)(\mathrm{a}+\mathrm{b})+\mathrm{f}] \mathrm{N}_{2}
\end{aligned}
$$

The formula proposed is very accurate, which eliminates all factors that will cause deviation in the dilution factor calculation. However, use of this equation requires the measurement of oxygen concentration in the diluted mixture, which is not available in WVU emission testing facility and most other facilities. For spark-ignition gasoline engines that normally operate with complete stoichiometric combustion or slightly rich combustion, the oxygen in the exhaust is negligible and its concentration can be assumed to be zero. But this is not the case for diesel engines or lean-burn natural gas engines, where the oxygen concentration in the exhaust is relatively high and can not be neglected. More 
importantly, the formula is designed for sample bag emissions measurement instead of continuous emissions measurement and thus, dilution factor is still calculated as an average static value instead of dynamically.

In WVU and most other chassis dynamometer emission testing equipment, engine exhaust, passing through the vehicle tailpipe, was diluted by background air in the dilution tunnel. This is to mimic the situation that engine exhaust being emitted into the atmosphere. Pollutant concentrations were measured in dilution tunnel instantaneously and mass emissions were calculated based on the dilute measurements. Dilution factor is needed in mass emission calculations to account for background pollutant effects. Usually the dilution factor (DF), which is defined as dilution tunnel flow rate over tailpipe exhaust flow rate, is simply calculated as an average value over the whole test cycle. The error caused by this simplification needs to be investigated, especially in low emission vehicle testing. Moreover, there is interest in study of engine exhaust emission concentration from dilution tunnel measurement. In this case, considering dilution factor as constant at different engine load will lead wrong and misleading answer. To achieve this goal, we need to calculate dilution factor dynamically. Unfortunately, the CVS dilution tunnel testing facility was set up to measure only the instantaneous total dilution tunnel flow rate, not the instantaneous engine exhaust flow or instantaneous dilution ratio. The discussion of next section describes how we arrived at an estimate of instantaneous dilution factor for natural gas vehicles. We 
noticed that in natural gas vehicles tested in WVU testing laboratory, we have the continuously measured lambda value that is unique in natural gas vehicles. Lambda value reflects the oxygen level in the engine exhaust at the time it is measured. Using this clue, an approach can be developed to calculate the instantaneous dilution factor accounting for nonstoichiometric combustion and background pollutant, as discussed next. 


\subsection{An Approach to Calculate Instantaneous Dilution Factor}

Natural gas, whose principal component is methane, can be written as $\mathrm{CH}_{4}$ to represent its chemical composition. A stoichiometric reaction is defined such that the only products are carbon dioxide and water vapor. We can readily obtain the chemical balance equation assuming the stoichiometric combustion of $\mathrm{CH}_{4}$ as:

$$
\mathrm{CH}_{4}+2\left(\mathrm{O}_{2}+3.76 \mathrm{~N}_{2}\right) \rightarrow \mathrm{CO}_{2}+2 \mathrm{H}_{2} \mathrm{O}+7.52 \mathrm{~N}_{2}
$$

The stoichiometric air-fuel ratio by mass is:

$$
A F R_{s}=\frac{2 \times(32+3.76 \times 28)}{12+4}=17.16
$$

The equivalent air/fuel ratio $\lambda$ is defined as the actual air/fuel ratio $\mathrm{AFR}_{\mathrm{a}}$ divided by the stoichiometric air/fuel ratio $\mathrm{AFR}_{\mathrm{s}}$.

$$
\lambda=\mathrm{AFR}_{\mathrm{a}} / \mathrm{AFR}_{\mathrm{s}}
$$

If $\lambda>1$ the mixture is called lean since there exists surplus air needed to combust the fuel. If $\lambda<1$ the mixture is called rich since there is no enough air to combust the fuel. If $\lambda=1$ the mixture is said to be stoichiometric.

A general combustion reaction of $\mathrm{CH}_{4}$ with equivalent air/fuel ratio of $\lambda$ can be written:

$$
\mathrm{CH}_{4}+2 \lambda\left(\mathrm{O}_{2}+3.76 \mathrm{~N}_{2}\right) \rightarrow a \mathrm{CO}_{2}+b \mathrm{H}_{2} \mathrm{O}+c \mathrm{~N}_{2}+d \mathrm{O} 2+e \mathrm{CO}+f \mathrm{CH} 4
$$

The reasonable assumptions made in the general chemical equation are: 
1. Trace species, as oxides of nitrogen and hydrogen etc., are negligible and do not have a significant effect on the amounts of other major combustion products.

2. The exhaust hydrocarbon is mainly made of unburned fuel and can be represented as same composition as methane $\mathrm{CH}_{4}$.

The general equation can accommodate both lean and rich combustion. Most natural gas engines employ lean-burn technology and the air-fuel mixture in a properly tuned natural gas engine can be considered as lean at all operation modes. A convenient approximation for lean combustion is to set $e=0$, assume complete combustion and $\mathrm{CO}$ concentration in the exhaust to be very small. We apply atom-balance to the chemical equation to determine the combustion product composition:

C balance: $\mathrm{a}+\mathrm{f}=1$

H balance: $2 b+4 f=4$

O balance: $2 a+b+2 d=4 \lambda$

$\mathrm{N}$ balance: $\mathrm{c}=7.52 \lambda$

As there are five unknowns and four equations, we get:

$$
\begin{aligned}
& a=1-f \\
& b=2-2 f \\
& c=7.52 \lambda \\
& d=2 \lambda-2+2 f
\end{aligned}
$$


We can't determine f, but this is not our focus. What we need to determine is the carbon-containing components $\left(\mathrm{CO}_{2}\right.$ and $\mathrm{CH}_{4}$ in our case) percentage in the exhaust stream. We use $C C$ to stand for the carbonaceous components.

$$
C C_{e x} \%=\frac{100 \times(a+f)}{a+b+c+d+f}=\frac{100}{1+9.52 \lambda}
$$

Thus, the carbonaceous component percentage in the total exhaust volume with the equivalent air/fuel ratio of $\lambda$ is determined. We have continuously measured $\lambda$ value, the $\mathrm{CC}_{\mathrm{ex}} \%$ can then be determined continuously.

Fig 4.1 shows the measured lambda value versus the instantaneous vehicle power while Fig 4.2 shows the calculated carbon-containing compounds volume percentage in the total exhaust during the whole test cycle. The tested natural gas vehicle is a 1997 model year transit bus powered with Cummins GL-10-300E+ lean-burn natural gas engine running on CBD cycle. The transmission type is 5speed automatic transmission as we can see that the vehicle horsepower curve is very smooth without the fluctuations caused by manual transmission gear shifting. We can see that $\lambda$ value is between 1.2 to 1.4 during whole testing phase, denoting that the engine combustion is under lean condition at all times. In Fig 4.2, we can see that the $C_{e x}$ (mainly $\mathrm{CO}_{2}$ ) percentage changes with lambda value, in the range from $7 \%$ to $9 \%$. It is not a strong function of vehicle traction power profile, as comparing with the measured $\mathrm{CO}_{2} \mathrm{ppm}$ in the diluted mixture positively correlating with the vehicle horsepower. 


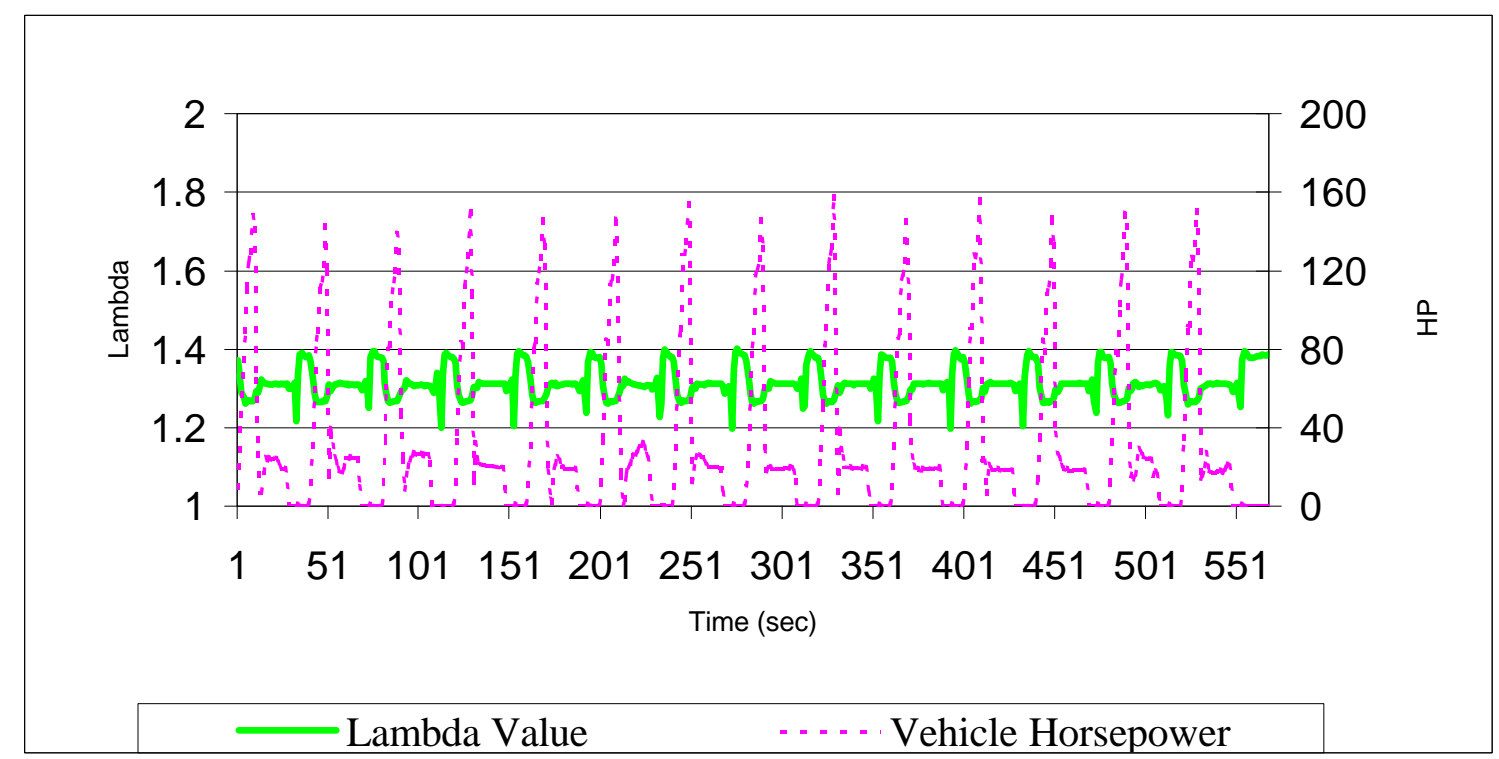

Figure 4.1 Measured Lambda Value from a Natural Gas Vehicle along with Vehicle Horsepower

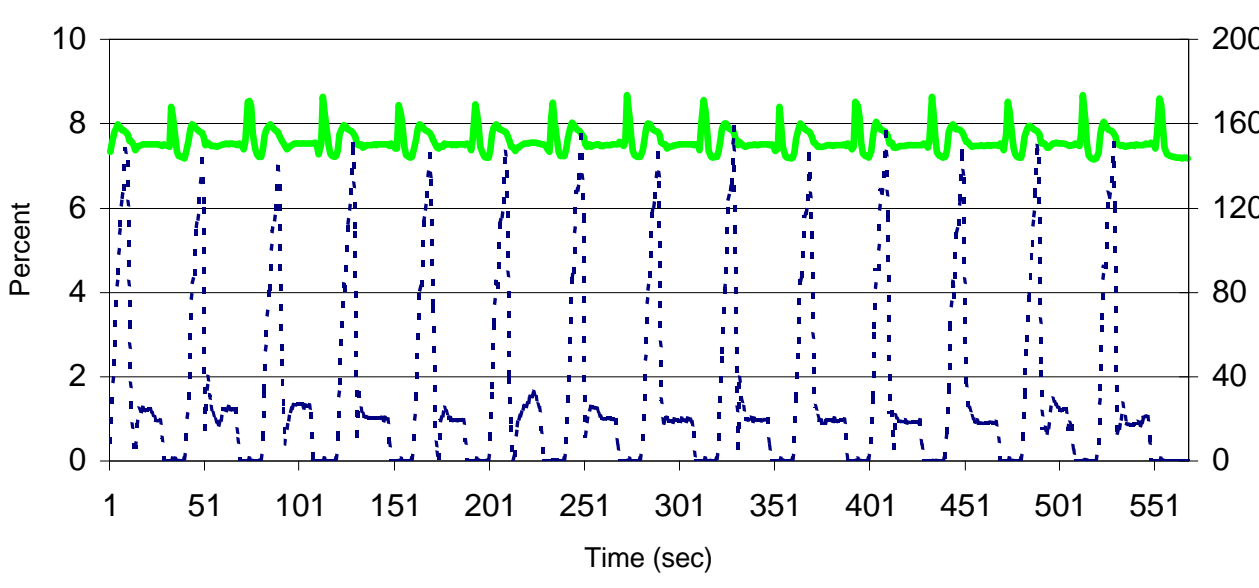

오

\section{Compound Percentage $\quad$..... Vehicle Horsepower}

Figure 4.2 Carbon-containing Compound Volume Percentage in the Natural Gas Vehicle Tailpipe 
At any point of time in the test, we know the $C C_{e x}$, which is the carboncontaining compound percentage in the engine exhaust. We also have the measured carbon-containing compounds $\left(\mathrm{CO}_{2}, \mathrm{CO}, \mathrm{HC}\right)$ percentage in the diluted mixture $C C_{d i}$, where each species concentration data is aligned with vehicle power data individually to adjust for the measurement delay as discussed in chapter 2 . This assures that all emission data were aligned together to reflects the emission concentrations at the same point of time. We can use these two percentages to calculate the dilution factor at any specific point of time, which is the instantaneous dilution factor. First, we can ignore background pollutant and get:

$$
D F^{\prime}=\frac{C C_{e x}}{C C_{d i}}
$$

We have also measured background pollutant concentrations in the dilution air sample bag, which could be treated as constant during the test. $C C_{\text {back }}$ is the sum of $\mathrm{CO}_{2}, \mathrm{CO}$, and $\mathrm{HC}$ percentage in the ambient background. We employ NYDOEC formula discussed in the previous section to account for the effect of background pollutant. The final instantaneous dilution factor considering the background pollutant is:

$$
D F=\frac{C C_{e x}}{C C_{d i}-C C_{b a c k}\left[1-\frac{1}{D F^{\prime}}\right]}=\frac{C C_{e x}}{C C_{d i}-C C_{b a c k} *\left[C C_{e x}-C C_{d i}\right] / C C_{e x}}
$$


Using this formula, Fig. 4.3 shows the continuous dilution factor with vehicle horsepower of the natural gas transit bus test shown in Fig 4.1. That shows a reasonable instantaneous dilution factor curve which is correlated with vehicle horsepower curve inversely. When vehicle is in full power, more fuel is needed to provide the traction power and the exhaust flow rate is high. As the volume flow in the CVS system is constant, the dilution factor would be low. While vehicle is in idle or deceleration, the amount of fuel/air mixture entering the engine is very small and the engine exhaust flow rate is low, thus the corresponding dilution factor would be very high. For this specific vehicle testing, we can see that dilution factor is varying with vehicle horsepower in the range of 6 when vehicle is at full power to 40 when vehicle is at idle. The CFR calculated average dilution factor is 11.6.

Using this instantaneous dilution factor, we can calculate the undiluted engine exhaust pollutant concentration using "reverse dilution" technique, which restores the engine exhaust pollutant concentration curve at different operation mode. Using the instantaneous dilution factor instead of the average value could also improve the accuracy of mass emission calculation. As can be seen from the next chapters. 


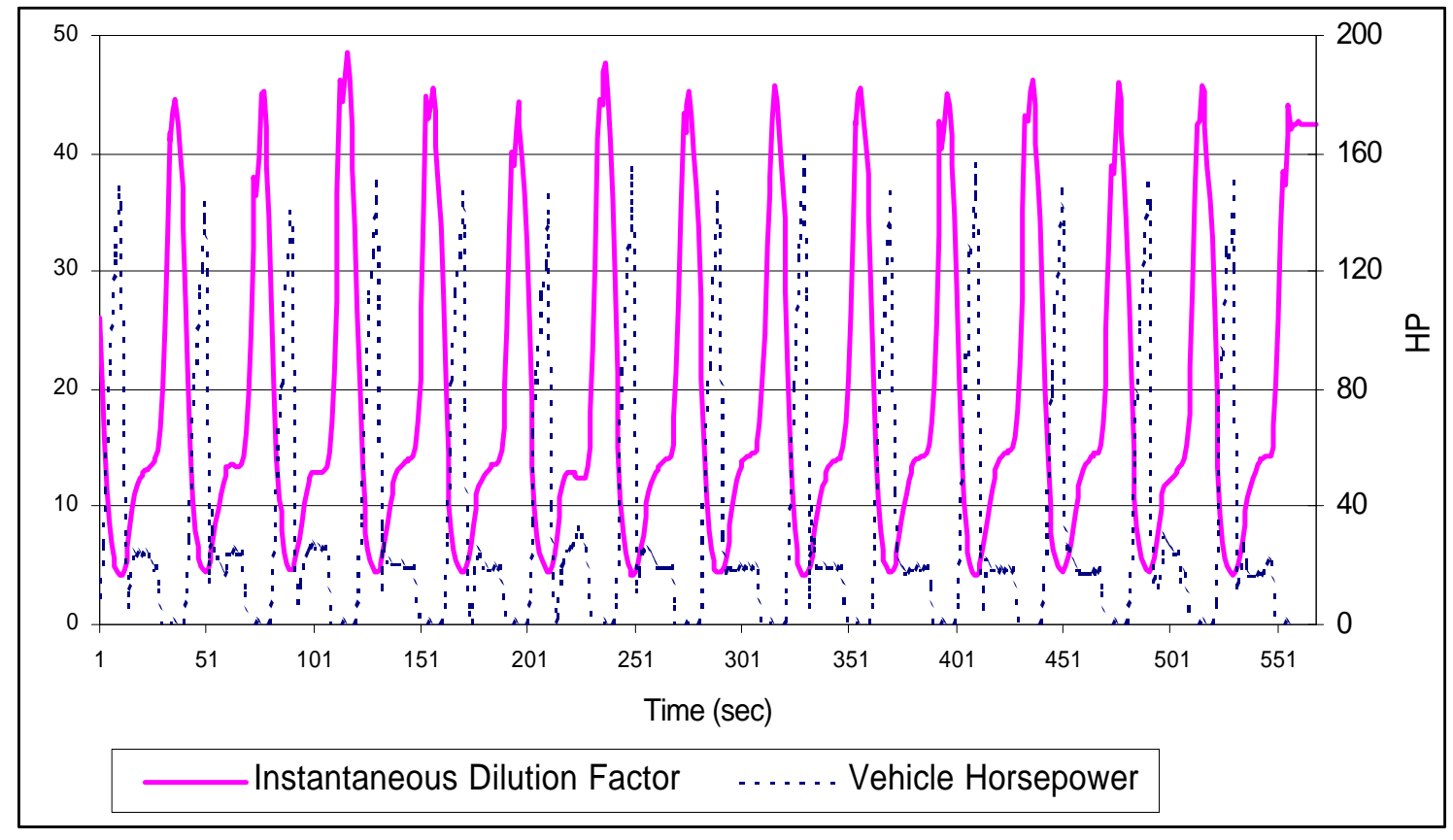

Figure 4.3 Instantaneous Dilution Factor of the Natural Gas Vehicle Testing along with Vehicle Horsepower 


\section{CHAPTER 5}

\section{MASS EMISSION CALCULATIONS USING INSTANTANEOUS DILUTION FACTOR}

\subsection{Current Mass Emission Calculations}

In WVU emission testing laboratories, the algorithm for the calculation is complicated. This section will briefly describe the formula for the calculation of emissions for diesel and alternative fuel vehicles.

Regular gas emissions, such as carbon monoxide (CO), oxides of nitrogen $\left(\mathrm{NO}_{\mathrm{x}}\right)$, particular matter $(\mathrm{PM})$, and carbon dioxide $\left(\mathrm{CO}_{2}\right)$, are measured and reduced for all tests. All the emissions and fuel economy calculation formula and methods given here are based on the CFR- $40^{[1]}$, EPA report, and SAE Recommended Practice. These methods are also used in the data management system program to get the final report to Alternative Fuel Data Center (AFDC) of NREL database and to the fleet owners.

Non-methane hydrocarbon emissions (NMHC) for CNG fueled vehicle emissions tests are also measured and reduced using Gas Chromatograph since September 1995. This consideration is based on the fact that most of the FID hydrocarbon emissions from CNG vehicles is unburned methane. Only NMHC is compatible to the $\mathrm{HC}$ emissions of conventionally fueled emissions tests. 
1. Calculation of the dilute exhaust sample volume $V_{m i x}$ :

$V_{\text {mix }}$ is the total dilute exhaust sample volume in $\mathrm{ft}^{3}$ per test phase corrected to standard conditions of $528^{\circ} \mathrm{F}\left(20^{\circ} \mathrm{C}\right.$, or $\left.293^{\circ} \mathrm{K}\right)$ and $760 \mathrm{mmHg}(101.3 \mathrm{kPa})$. For Critical Flow Venturi-Constant Volume System (CFV-CVS), which is used in WVU laboratory, $V_{m i x}=\Sigma V_{m i x_{i}}$ with $V_{m i x_{i}}=K_{v} \Delta T \frac{P_{v}}{\sqrt{T_{v}}}$, where

$K_{v}$ : CFV calibration constant in $\mathrm{ft}^{3} / \mathrm{min}$

$\Delta T$ : time interval in minute

$P_{v}: \mathrm{CFV}$ inlet depression in $\mathrm{lb} / \mathrm{ft}^{2}$

$T_{v}$ : CFV inlet temperature in ${ }^{\circ} \mathrm{R}$

All the calculation of the emission gas volume is based on the summation of the instantaneous dilute exhaust sample volume multiple by the corrected gas concentration.

2. Calculation of the dilution factor $D F$ :

$D F$ : Dilution Factor is $D F=\frac{S P C O 2}{C O_{2 c}+\left(\Sigma O M_{c}+C O_{c}\right) \times 10^{-4}}$ 
where:

- $\mathrm{SPCO}_{2}$ : Stoichiometric percent of $\mathrm{CO}_{2}$ in undiluted exhaust.

- $\mathrm{CO}_{2 c}$ : concentration of $\mathrm{CO}_{2}$ in dilute exhaust sample in percent

- $\mathrm{CO}_{c}$ : concentration of $\mathrm{CO}$ in dilute exhaust sample in ppm

- $O M_{c}$ : summation of the concentration of individual components of organic matter in ppm. If $\frac{F I D_{p p m}}{C O_{2 c}+C O_{c}}<0.02$, use $F I D_{p p m}$ only.

$F I D_{p p m}$ : concentration of $O M$ measured by FID in ppm

3. $C O$ mass emissions calculation:

$C O_{\text {mass }}=\rho_{C O} \times \sum_{i}\left\{V_{\text {mixi }} \times \frac{C O_{c}-C O_{d} \times\left(1-\frac{1}{D F}\right)}{10^{6}}\right\}$

$V_{\text {mixi }}$ and $D F$ are as the described as above. $\rho_{C O}$ is the density of carbon monoxide in gram $/ \mathrm{ft}^{3}$ at normal condition of $20^{\circ} \mathrm{C}$ and 760 mmHg. $\rho_{C O}=32.97 \mathrm{gram} / \mathrm{ft}^{3}$ is used.

$\mathrm{CO}_{c}$ : carbon monoxide concentration of the dilute exhaust sample volume corrected for water vapor and carbon dioxide extraction, in ppm, $\quad C O_{c}=\left(1-(0.01+0.005 \times H C R) \times C O 2_{c}-0.000323 \times R\right) \times C O_{c m}$ where 
$H C R$ : hydrogen-to-carbon ratio of the fuel

$$
H C R=\frac{E F H / 1.008}{E F C / 12.011}
$$

$\mathrm{CO}_{c}$ : carbon dioxide concentration of the dilute exhaust sample, in percent

$\mathrm{R}$ : relative humidity of the dilution air, in percent

$C O_{c m}$ : carbon monoxide concentration of the dilute exhaust sample as measured, in ppm

$\mathrm{CO}_{d}$ : carbon monoxide concentration of the dilution air corrected for water vapor extraction, in ppm, $C O_{d}=(1-0.000323 \times R) \times C O_{d m}$ where

$\mathrm{CO}_{d m}$ : carbon monoxide concentration of the dilution air sample as measured, in ppm

4. $\mathrm{CO}_{2}$ mass emissions calculation:

$$
C O 2_{\text {mass }}=\rho_{C O 2} \times \sum_{i}\left\{V_{\text {mixi }} \times \frac{C O 2_{c}-C O 2_{d} \times\left(1-\frac{1}{D F}\right)}{10^{6}}\right\}
$$


$V_{\text {mixi }}$ and $D F$ are as the described as above. $\rho_{C O 2}$ is the density of carbon dioxide in gram $/ \mathrm{ft}^{3}$ at normal condition of $20^{\circ} \mathrm{C}$ and 760 $\mathrm{mmHg} . \rho_{\mathrm{CO} 2}=51.81 \mathrm{gram} / \mathrm{ft}^{3}$ is used.

$\mathrm{CO}_{c}$ : carbon dioxide concentration of the dilute exhaust sample as measured, in ppm

$\mathrm{CO}_{d}$ : carbon dioxide concentration of the dilution air as measured, in $\mathrm{ppm}$

5. $N O_{x}$ mass emission calculations:

$N O x_{\text {mass }}=K_{H} \times \rho_{N O x} \times \sum_{i}\left\{V_{\text {mixi }} \times \frac{N O x_{c}-N O x_{d} \times\left(1-\frac{1}{D F}\right)}{10^{6}}\right\}$

$V_{\text {mixi }}$ and $D F$ are as the describe as above. $\rho_{N O x}$ is the density of oxides of nitrogen in gram $/ \mathrm{ft}^{3}$ at normal condition of $20^{\circ} \mathrm{C}$ and 760 mmHg. $\rho_{N O x}=54.16$ gram $/ \mathrm{ft}^{3}$ is used.

$N O x_{c}$ : oxides of nitrogen concentration of the dilute exhaust sample as measured, in ppm

$N O x_{d}$ : oxides of nitrogen concentration of the dilution air as measured, in ppm 
$K_{H}$ : humidity correction factor for the calculation of $N O_{x}$ emissions.

$$
K_{H}=\frac{1}{1-0.0047 \times(H-10.71)}
$$

where $H$ is the absolute humidity in grains of water per pound of dry air.

6. FIDHC mass emissions calculation:

$$
F I D H C_{\text {mass }}=\rho_{H C} \times \sum_{i}\left\{V_{\text {mixi }} \times \frac{H C_{c}-H C_{d} \times\left(1-\frac{1}{D F}\right)}{10^{6}}\right\}
$$

FID measured Hydrocarbon (FIDHC) emissions are the $\mathrm{HC}$ emissions measured by FID directly without any correction. $V_{\text {mixi }}$ and $D F$ are as the described as above. $\rho_{N O x}$ is the density of hydrocarbon in gram $/ \mathrm{ft}^{3}$ at normal condition of $20^{\circ} \mathrm{C}$ and $760 \mathrm{mmHg}$. It's different for different fuel because the exhaust hydrocarbon component varies from each other. $\rho_{H C}=\frac{14.135}{E F C}$ is used to calculate the $\mathrm{HC}$ density for different fuel. The following is a list of the HC density. 
Table 5.1 HC density for different fuels

\begin{tabular}{|l|l|l|}
\hline Fuel & HC density $(\mathrm{g} / \mathrm{ft} 3)$ & $\mathrm{EFC}$ \\
\hline gasoline & 16.32 & 0.866 \\
\hline \#1 Diesel, JA & 16.42 & 0.861 \\
\hline \#2 Diesel & 16.27 & 0.869 \\
\hline CNG & 18.85 & 0.75 \\
\hline Methanol & 37.69 & 0.375 \\
\hline Ethanol & 27.18 & 0.52 \\
\hline
\end{tabular}

$H C_{c}$ : hydrocarbon concentration of the dilute exhaust sample measured by FID directly, in ppm 


\subsection{Mass Emission Calculations Using Instantaneous Dilution Factor}

As we can see from the previous section, although mass emission calculations for different emission species are different, the common is the integration of engine exhaust emission rate over the test cycle. That is:

$$
\text { MassEmissions }=\sum E R_{e x}=\sum\left(E R_{d i}-E R_{\text {back }}\right)
$$

$E R$ means the emission rate of the pollutants in the various flow streams. Since the WVU laboratories continuously measure the diluted stream concentrations instead of engine exhaust concentrations, dilution factor is needed to account for background pollutant effects. Based on CFR-40, the dilution factor is calculated as an average value and thus, the pollutant emission rates in the background air are considered constant during the test phase. As the vehicle emission levels are approaching that of background air, the accuracy of this simplification needs to be investigated.

When instantaneous dilution factor is determined in the previous chapter, the emission concentrations in the undiluted mixture and the engine exhaust flow rate in the CVS system can both be determined. The two parameters can be used to develop a more accurate equation to calculate mass emissions.

The instantaneous mixture flow rate $V_{\text {mixi }}$ in the dilution tunnel is calculated in equation 5.1. The flow rate depends on the calibration constant of critical-flow veturi, venturi inlet pressure and temperature. The calibration constant $K_{v}$ is used to adjust dilution tunnel flow rate and it is constant for one test. The venturi inlet 
pressure is also constant in the same test site. The changing temperature of the engine exhaust causes the changing temperature of the venturi inlet temperature, which varies from $200 \mathrm{~F}$ to $300 \mathrm{~F}$. This causes minor variations in the otherwise steady dilution tunnel flow rate. However, the dilution tunnel volume flow rate is still generally considered as constant in the whole test cycle, which is the basis of Constant Volume Sampler. The relationship between the engine exhaust flow rate $\mathrm{FR}_{\mathrm{ex}}$ and diluted mixture flow rate $\mathrm{FR}_{\mathrm{di}}$ is simply as:

$$
\mathrm{FR}_{\mathrm{ex}}=\mathrm{FR}_{\mathrm{di}} / \mathrm{DF}_{\mathrm{i}}=\mathrm{V}_{\text {mixi }} / \mathrm{DF}_{\mathrm{i}}
$$

Fig 5.1 shows the engine exhaust flow rate and the diluted mixture flow rate with the vehicle horsepower. The flow rate of the diluted mixture in the dilution tunnel is generally a constant, which is maintained by the critical-flow venturi. But it is obvious that when the vehicle is at full load or the horsepower is high, the engine exhaust flow rate is also high. That is because much more fuel and air is needed to provide the traction power for the vehicle. When engine is in idle or deceleration, the engine exhaust flow rate is low. At this time, no traction power is needed and the engine acts as an air pump, only a small amount of air/fuel is breathed to maintain the engine operation. If the dilution factor were treated as constant over the test cycle, the engine exhaust flow rate curve would scale with the dilution tunnel flow rate, which is generally a steady flow. This obviously contradicts the real situation. 


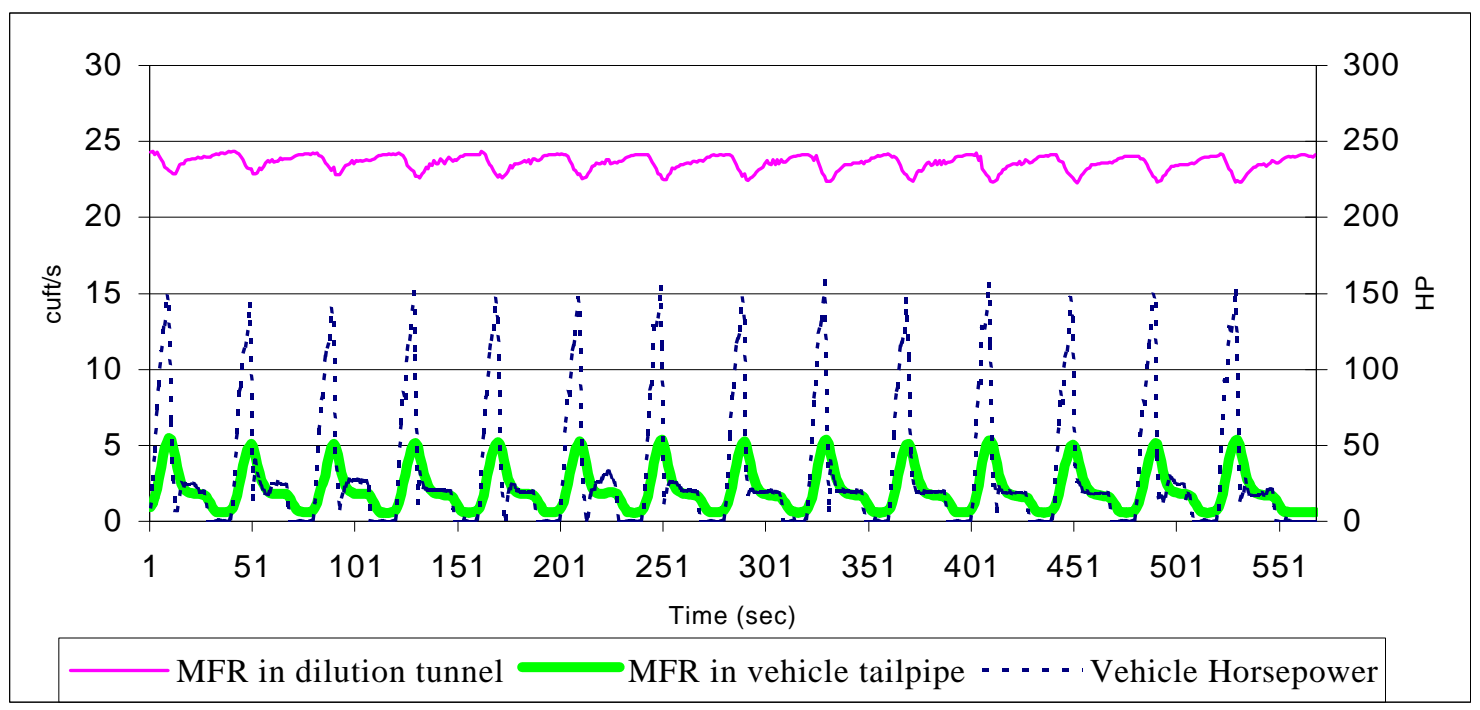

Figure 5.1 Mass Flow Rate in Dilution Tunnel and Vehicle Tailpipe

Knowing the engine exhaust flow rate and emission concentration in the flow stream, the emission rate in raw engine exhaust $\mathrm{ER}_{\mathrm{ex}}$ can be determined.

$$
E R_{e x}=\rho \times C_{e x} \times F R_{e x}=\rho \times C_{e x} \times V_{\text {mixi }} / D F
$$

For natural gas vehicles, the pollutant concentration $C_{e x}$ is determined in chapter 4, which is:

$$
C_{e x}=\left[C_{d i} C_{b a c k}(1-1 / D F)\right] \times D F
$$

Then:

$$
E R_{e x}=\rho \times V_{\text {mixi }} \times\left[C_{d i} C_{b a c k}(1-1 / D F)\right]
$$

Where: $C_{d i}$ is measured continuously in the dilution tunnel and $D F$ is calculated continuously. $C_{b a c k}$ is the constant measured during the test in the sample bag and $\rho$ is constant for the specific species.

This equation applies to all gaseous emission species. Some species need to apply water vapor and carbon dioxide extraction factor or humidity factor as 
described in section 5.1. Integration of the emission rate of engine exhaust over the whole test cycle obtains the net total mass emissions emitted from engine during the whole cycle.

$$
E_{\text {mass }}=\sum_{i=1}^{N} E R_{e x}
$$

$N$ is the total test point.

Table 5.1 lists the calculation results of the two methods. The test number is 1008-01 and the tested vehicle is the transit bus powered by DDC Series 50G natural gas engine. The first one uses the CFR procedure that considers the dilution factor as a constant over the test cycle. The latter one uses the instantaneous dilution factor. This method is different from the CFR method in that it considers the varying accurate dilution factor during a test cycle instead of using a roughly estimated average one for the whole test cycle. This results the varying background pollutant emission rates.

The average emission concentrations measured in the dilution tunnel and in the background air bag are given for comparison. In this specific test, the $\mathrm{CO}$ concentration measured in background air is $3.65 \mathrm{ppm}$, while the sample bag CO concentration is $5.38 \mathrm{ppm}$. This shows that $\mathrm{CO}$ emissions from this natural gas engine are approaching the background level and the background effect on the mass emission calculation is significant. For other species as $\mathrm{CO}_{2}, \mathrm{HC}$, and $\mathrm{NO}_{\mathrm{x}}$, the concentrations in the average dilute bag are much higher than the background level. A comparison is given in table 5.1 using two methods. 
Table 5.1 Mass Emission Calculation with Two Methods

\begin{tabular}{|l|l|l|l|l|l|l|}
\hline $\begin{array}{l}\text { Emission } \\
\text { Species }\end{array}$ & $\begin{array}{c}C_{d i} \\
(\mathrm{ppm})\end{array}$ & $\begin{array}{c}C_{\text {back }} \\
(\mathrm{ppm})\end{array}$ & $\begin{array}{l}C_{\text {back }} \\
C_{d i}(\%)\end{array}$ & $\begin{array}{l}\text { Method I } \\
(\mathrm{g} / \mathrm{mile})\end{array}$ & $\begin{array}{l}\text { Method II } \\
(\mathrm{g} / \mathrm{mile})\end{array}$ & $\begin{array}{l}\text { Difference } \\
(\%)\end{array}$ \\
\hline $\mathrm{CO}_{2}$ & 7049.25 & 639.88 & 9.1 & 4558.79 & 4566.34 & 0.17 \\
\hline $\mathrm{NO}_{x}$ & 87.18 & 8.34 & 9.6 & 63.49 & 63.56 & 0.11 \\
\hline $\mathrm{CO}$ & 5.38 & 3.65 & 67.8 & 1.78 & 1.83 & 2.73 \\
\hline $\mathrm{HC}$ & 132.85 & 2.53 & 1.9 & 32.93 & 32.94 & 0.03 \\
\hline
\end{tabular}

Where: $C_{d i}$ : pollutant concentration measured in dilute bag as the average diluted mixture concentration

$C_{\text {back: }}$ : pollutant concentration measured in the background dilution air

Method I: current calculation using roughly estimated constant dilution factor of 13.1

Method II: new calculation using accurate instantaneous dilution factor which is dynamically varying during the test

From the results, we can see that when emission concentrations in the dilute bag are much higher than those in the background air, the variance between the two methods is every small. When the ratio of background emission species concentration to that of average value in dilution tunnel is small (less than 10\%), the variance between the two methods is also very small (within 0.2\%). Since background emissions are only a small fraction in the total emissions, roughly 
estimating dilution factor as an constant in the test cycle is a good and convenient approximation.

While the emission concentration in the engine exhaust is very close to the level in the background air, the variance becomes obvious. For $\mathrm{CO}$ emission in this case, the average dilution tunnel measurement is 5.38ppm and the background level is $3.65 \mathrm{ppm}$, which are at the same magnitude. If using constant dilution factor of 13.1 that is computed in this test using CFR procedure, the calculated $C O$ emission is $1.78 \mathrm{~g}$ over the whole test cycle. If using the calculated instantaneous dilution factor in the previous chapter, the result is $1.83 \mathrm{~g}$. The error, $0.05 \mathrm{~g}$, is not negligible comparing to the engine exhaust emission level. If considering the extreme case that the background $\mathrm{CO}$ concentration is the same as that in the sample bag, which is $5.38 \mathrm{ppm}$. The error is then as high as $6.95 \%$. When current vehicle emission standards are approaching zero-emission levels, variances between vehicle emissions are getting very small. These small variances must be measured to make it possible to arrive at engineering decisions. In this circumstance, using accurate instantaneous dilution factor should greatly improve the accuracy of mass emission calculations. 


\subsection{Modal Mass Emission Analysis}

After determining the accurate pollutants in the vehicle tailpipe, integration of the pollutant emission rates in the raw exhaust over the driving cycle results in one mass number for each constituent for the complete test. However, for vehicle emission researchers to understand emission formation and evaluate engine design improvement and engine control optimization, they must know what each type of vehicle operation contributes to the total mass of pollutants from the vehicle. Modal mass emission analysis helps to determine the contribution of each mode of operation to the total mass emissions of the vehicle.

The CBD cycle is comprised of 14 repetitive sub-cycles, which then can be divided into 4 operation modes: idle, acceleration, deceleration, and cruise. Idle period is the mode when both vehicle traction power and vehicle speed are approaching zero. Acceleration period is when vehicle is accelerating from idle to the constant speed (20mph). Cruise period is when the vehicle running at the constant speed and the deceleration period is when the vehicle is applying brakes to slow speed to idle. Thus, the CBD cycle is composed of 14 idle, acceleration, cruise, and deceleration modes.

In the previous section, all pollutant emission rates in the vehicle tailpipe is adjusted for time delay and is reflecting the emissions of the corresponding operation mode. Integrating of the emission rates over one mode duration gives the mass emissions emitted in the specific mode. Summation of the modal mass 
over the test cycle then points out the contribution of individual modes to the total mass emission results. Table 5.2 gives the modal mass analysis for a transit bus powered by DDC S50G engine.

Table 5.2 Modal Mass Emission Analysis for a DDC S50 G Engine

\begin{tabular}{|c|c|c|c|c|c|c|}
\hline & Modes & Idle & Acce. & Cruise & Dece. & Cycle \\
\hline & Duration (s) & 101 & 149 & 261 & 63 & 574 \\
\hline & Work (hp-hr) & 0 & 3.735 & 1.371 & 0 & 5.112 \\
\hline & el Consumed $(\mathrm{g})$ & 98.84 & 804.45 & 650.54 & 68.30 & 1622.14 \\
\hline & Mass Emissions $(\mathrm{kg})$ & 0.258 & 2.166 & 1.749 & 0.183 & 4.359 \\
\hline $\mathrm{CO}_{2}$ & $\begin{array}{l}\text { Emission Power } \\
\text { Ratio (kg/hp-hr) }\end{array}$ & N/A & 0.58 & 1.275 & N/A & \\
\hline & $\begin{array}{l}\text { Emissions Mass } \\
\text { Fuel Ratio (g/g) }\end{array}$ & 2.61 & 2.69 & 2.69 & 2.69 & \\
\hline & Mass Emissions(g) & 1.507 & 47.484 & 34.738 & 3.063 & 86.791 \\
\hline $\mathrm{NO}_{\mathrm{x}}$ & $\begin{array}{l}\text { Emission Power } \\
\text { Ratio (g/hp-hr) }\end{array}$ & N/A & 12.713 & 25.338 & N/A & \\
\hline & $\begin{array}{l}\text { Emissions Mass } \\
\text { Fuel Ratio }(\mathrm{g} / \mathrm{kg})\end{array}$ & 15.25 & 59.03 & 53.40 & 44.85 & \\
\hline & Mass Emissions(g) & 1.790 & 5.284 & 7.272 & 0.787 & 15.133 \\
\hline $\mathrm{CO}$ & $\begin{array}{l}\text { Emission Power } \\
\text { Ratio (g/hp-hr) }\end{array}$ & N/A & 1.41 & 5.30 & N/A & \\
\hline & $\begin{array}{l}\text { Emissions Mass } \\
\text { Fuel Ratio }(\mathrm{g} / \mathrm{kg})\end{array}$ & 18.11 & 6.57 & 11.18 & 11.53 & \\
\hline & Mass Emissions(g) & 3.984 & 12.944 & 9.914 & 1.093 & 27.935 \\
\hline $\mathrm{HC}$ & $\begin{array}{l}\text { Emission Power } \\
\text { Ratio (g/hp-hr) }\end{array}$ & N/A & 3.47 & 7.23 & N/A & \\
\hline & $\begin{array}{l}\text { Emissions Mass } \\
\text { Fuel Ratio }(\mathrm{g} / \mathrm{kg})\end{array}$ & 40.31 & 16.09 & 15.24 & 16.01 & \\
\hline
\end{tabular}

Where in the table:

Duration: the summation of mode time 
Work: the summation of vehicle traction power during the mode.

$W=\sum_{1}^{14} \int h p(t) d t$

Fuel Consumed: Vehicle fuel consumption during the operation mode.

$$
M=\frac{\frac{12}{44} m_{c o 2}+\frac{12}{28} m_{c o}+\frac{12}{16} m_{h c}}{\frac{12}{16}}
$$

Mass Emissions: Pollutant mass emitted during an operation mode.

$m_{i}=\sum_{1}^{14} \int E R_{i}(t) d t$

Emission Power Ratio: Mass emissions divided by mode work

Emission Mass Fuel Ratio: Mass emissions divided by mode fuel consumed

From the table, we can see that for $\mathrm{NO}_{\mathrm{x}}$ emissions, emission mass fuel ratio is quite low at idle period comparing with other modes, which proves that $\mathrm{NO}_{\mathrm{x}}$ emissions were mainly formed at high vehicle horsepower mode. For the same amount of fuel injected into the engine, very high $\mathrm{NO}_{\mathrm{x}}$ emissions were measured at high load, as the cylinder temperature and pressure is high at load, favoring the formation of $\mathrm{NO}_{\mathrm{x}}$. But for $\mathrm{CO}$ and $\mathrm{HC}$ emissions, the emission mass fuel ratios are high at idle mode, indicating that a large amount of $\mathrm{CO}$ and $\mathrm{HC}$ were formed at low vehicle horsepower mode due to incomplete combustion at low engine load. 


\section{CHAPTER 6}

\section{DETERMINATION OF VEHICLE TAILPIPE POLLUTANT CONCENTRATIONS}

\subsection{Emission Concentration in Vehicle Tailpipe and in Dilution Tunnel}

Currently in WVU emissions testing, results are reported as the mass of emissions produced per unit distance driven, thus neglecting the transient characteristics of the emission profile. Recently, there is interest in identifying emissions produced at a specific point of time of during a specific operation mode, or the so-called modal analysis. To perform the analysis, the simultaneous measurement of exhaust pollutant concentration and exhaust flow rate is needed. Unfortunately, the CVS system is set up only to continuously measure the pollutant concentration in the diluted stream and the total volume flow rate in the dilution tunnel. Since currently, dilution factor during the whole test cycle is considered as constant, it's impossible to distinguish emission concentrations in vehicle tailpipe from those measured in dilution tunnel. The emission concentration curve in the undiluted mixture is thought as the same shape as those measured in the dilution tunnel, only magnified by the dilution factor. It is also impossible to determine a change in diluted concentration is caused by a change in exhaust concentration or in exhaust flow rate. Fig 6.1 shows the $\mathrm{CO}_{2}$ concentration measured in the dilution tunnel as the test shown in Fig 4.1. The 
calculated dilution factor using CFR method is 11.6. Using this dilution factor, if the background $\mathrm{CO}_{2}$ can be negligible, the $\mathrm{CO}_{2}$ concentration in the undiluted engine exhaust would be the concentration in dilution tunnel times the dilution factor, as also shown in Fig 6.1 with heavy-line. From the figure, the $\mathrm{CO}_{2}$ concentration in the undiluted mixture seems to be positively correlated vehicle horsepower. But actually, we know that $\mathrm{CO}_{2}$ concentration in the vehicle tailpipe is determined only by the engine equivalent air/fuel ratio, not by the vehicle horsepower, although the engine equivalent air/fuel ratio may vary with vehicle horsepower. The same applies to other emission species of $\mathrm{CO}, \mathrm{HC}$, and $\mathrm{NO}_{\mathrm{x}}$. The concentrations measured in the diluted mixture can't reflect the concentrations in the undiluted engine exhaust, because the dilution factor is dynamically varying during the test cycle. Using the instantaneous dilution factor we calculated before for the natural gas vehicles, we can determine the real emission concentrations in the undiluted engine exhaust using "reverse dilution" technique, this will reveal that pollutant concentration curve in the engine exhaust is different from that measured in the dilution tunnel. 


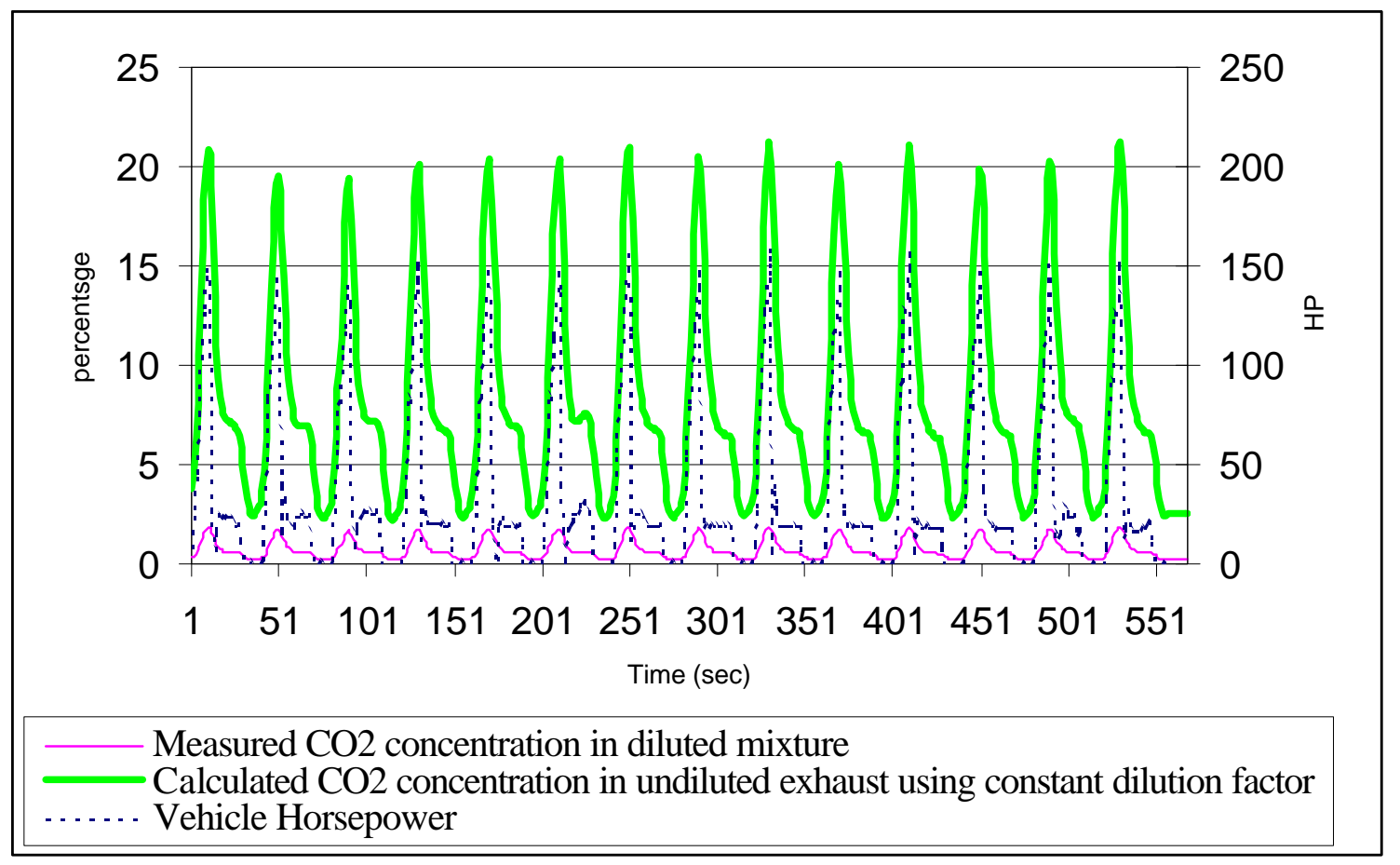

Figure 6.1 $\mathrm{CO}_{2}$ Concentrations from the Natural Gas Vehicle 


\subsection{Determine Vehicle Tailpipe Emission with Instantaneous Dilution Factor}

As we have determined the instantaneous dilution factor in natural gas vehicles, we can use it to determine natural gas vehicle tailpipe emission concentration using "reverse dilution" technique.

Recalling the CFV-CVS system used in WVU transportable laboratory, we can see the mechanism of dilution: one part (by volume or by mole) of engine exhaust through vehicle tailpipe is diluted by (DF-1) part of ambient air to form DF part of constant volume flow rate. The relationship among emission concentrations in the engine exhaust, $C_{e x}$, the diluted mixture, $C_{d i}$, the ambient background, $C_{\text {back }}$, is governed by the equation of mass-balance:

$$
C_{e x}=\frac{C_{d i}+C_{b a c k}(D F-1)}{D F}
$$

The equation can then be written to determine the engine exhaust concentration from the measured background and diluted mixture concentrations.

$$
\mathrm{C}_{\mathrm{ex}}=(\mathrm{DF}) \mathrm{C}_{\mathrm{di}}-(\mathrm{DF}-1) \mathrm{C}_{\mathrm{back}}
$$

Or as:

$$
\mathrm{C}_{\mathrm{ex}}=\left[\mathrm{C}_{\mathrm{di}} \mathrm{C}_{\text {back }}(1-1 / \mathrm{DF})\right] \mathrm{DF}
$$

These equations can be applied to all gaseous exhaust emission species, including $\mathrm{CO}_{2}, \mathrm{CO}, \mathrm{HC}$, and $\mathrm{NO}_{\mathrm{x}}$. The measured background emission concentration $C_{\text {back }}$ is considered as constant during the whole test cycle, which is the value measured in the background sample bag. We have the continuously measured diluted 
mixture concentration and also the corresponding instantaneous dilution factor, the emission concentrations in the engine exhaust can be determined using the equations.

Fig 6.2 shows the $\mathrm{CO}$ emission concentration measured in the diluted mixture and the calculated $\mathrm{CO}$ emission concentration in the undiluted engine exhaust. The tested vehicle is a natural gas transit bus powered by DDC Series 50G lean-burn natural gas engine. It proves that pollutant concentrations in dilution tunnel and in vehicle tailpipe are of different shape and thus have different characteristics at different engine operation modes. Emissions modal analysis should be based on emissions concentrations in the vehicle tailpipe instead of those measured in the dilution tunnel. The next section discusses the characteristics of pollutant concentrations in the engine exhaust at different engine operation modes for different natural gas engines. 


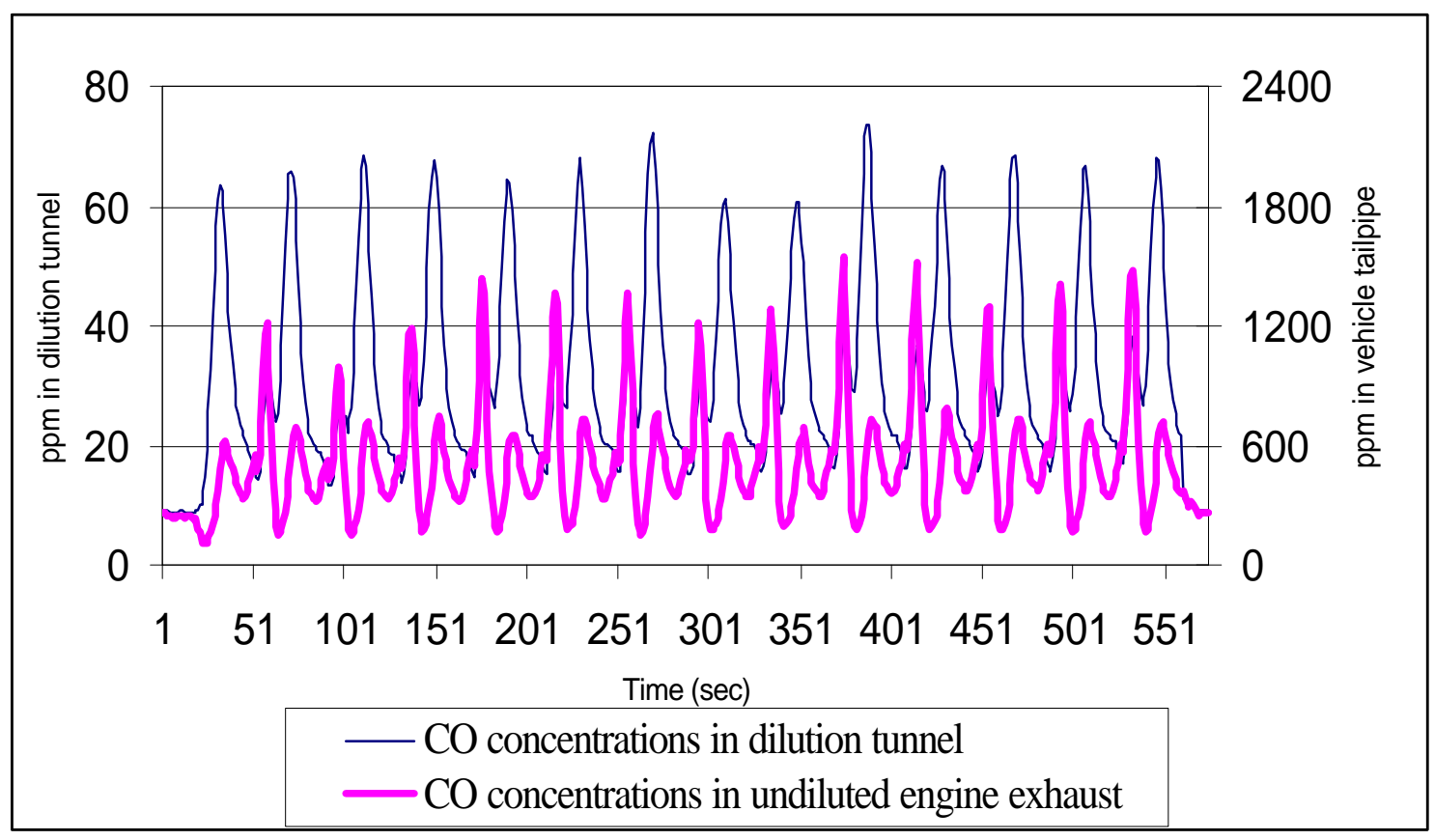

Figure 6.2 CO Emissions Concentrations in Dilution Tunnel and Vehicle Tailpipe 


\subsection{Modal Emission Analysis Based on Tailpipe Emission Concentrations}

There has been increasingly interest in correlating emissions concentrations with vehicle horsepower recently. However, due to CVS system, pervious study is limited on dilution tunnel concentrations, which have been proved to be quite different from that in the engine exhaust or vehicle tailpipe. Since we have determined pollutant concentrations in the vehicle tailpipe using instantaneous dilution factor, we can study the emissions characteristics based on tailpipe pollutant concentrations. As engine emissions are closely related with engine specifications, emissions analysis is categorized to different engine types. Three vehicle test runs were chosen to study emissions from different natural gas engines. The vehicle information of the three engines is given in Table 6.1.

Table 6. 1 Selected Test Vehicles Specifications

\begin{tabular}{c|c|c|c}
\multirow{2}{*}{$\begin{array}{c}\text { Vehicle } \\
\text { Information }\end{array}$} & DDC S 50G & Cummins L-10 240 G & Caterpillar 3306 \\
\cline { 2 - 4 } Fleet Owner & $\begin{array}{c}\text { New York City } \\
\text { Transit Authority }\end{array}$ & $\begin{array}{c}\text { Tribo Coach } \\
\text { Company }\end{array}$ & $\begin{array}{c}\text { New York City } \\
\text { Department of } \\
\text { Sanitation }\end{array}$ \\
\hline Vehicle Type & Transit Bus & Transit Bus & Refuse Truck \\
\hline $\begin{array}{c}\text { Vehicle Model } \\
\text { Year }\end{array}$ & 1991 & 1994 & 1994 \\
\hline $\begin{array}{c}\text { Gross Vehicle } \\
\text { Weight (lb) }\end{array}$ & 36900 & 39500 & 69897 \\
\hline $\begin{array}{c}\text { Transmission Type } \\
\text { Transmission } \\
\text { Configuration }\end{array}$ & Automatic & Automatic & Automatic \\
\hline $\begin{array}{c}\text { Engine } \\
\text { Displacement (L) }\end{array}$ & 8.5 & $5-$ Speed & $4-$ Speed \\
\hline
\end{tabular}




\begin{tabular}{c|c|c|c}
\hline $\begin{array}{c}\text { Number of } \\
\text { Cylinders }\end{array}$ & 4 & 6 & 6 \\
\hline $\begin{array}{c}\text { Engine Rated } \\
\text { Power }\end{array}$ & 275 & 240 & 250 \\
\hline Test Cycle & CBD & CBD & CBD \\
\hline Test Date & $12 / 29 / 96$ & $12 / 18 / 96$ & $10 / 14 / 96$ \\
\hline $\begin{array}{c}\text { Selected Test Run } \\
\text { Sequence Number }\end{array}$ & $823-01$ & $821-01$ & $772-01$ \\
\hline
\end{tabular}

\section{DDC Series 50G Natural Gas Engine}

The DDC Series $50 \mathrm{G}$ natural gas engine is an 8.5L 4-stroke cycle overhead cam engine utilizing a lean burn combustion process. This natural gas engine is derived from DDC Series 60 diesel engine. Figure 6.3 is the measured Lambda value along with vehicle horsepower over the CBD cycle from a transit bus powered by DDC Series $50 \mathrm{G}$ natural gas engine. We can see that the air/fuel ratio setting is positively related with vehicle horsepower. When vehicle is at high load, the Lambda value is set as high as 1.4. While the load is low, the Lambda value decreases to 1.2. The engine is operating in lean-burn condition at all engine loads as with the engine design. Figure 6.4 shows the calculated instantaneous dilution factor over the test cycle to be varying from 6 (when engine load is high) to 30 (when engine load is low). The average dilution factor calculated by CFR method is 15.2. Figure 6.4 also shows the volume flow rate both in dilution tunnel and in the vehicle tailpipe or engine raw exhaust. While the flow rate in dilution tunnel is generally constant, the flow rate from vehicle tailpipe is alternating with 
vehicle horsepower, the flow rate increases and decreases with horsepower closely, which is very reasonable. $\mathrm{CO}_{2}$ emissions

Figure 6.5 shows the $\mathrm{CO}_{2}$ emissions concentrations and flow rate in the dilution tunnel and vehicle tailpipe. The $\mathrm{CO}_{2}$ percentage in the diluted mixture is measured by the gas analyzer. The percentage in the vehicle tailpipe is determined by measured air/fuel ratio and engine combustion equation. We can see that the variation of $\mathrm{CO}_{2}$ concentration in the engine exhaust is small. It is only the function of vehicle instantaneous air/fuel ratio instead of vehicle horsepower. The big variation of the $\mathrm{CO}_{2}$ concentration measured in the dilution tunnel is caused by varying engine exhaust flow rate being diluted to a generally constant flow rate. The $\mathrm{CO}_{2}$ emission flow rate in the vehicle tailpipe is again the function of vehicle horsepower. That is because when vehicle horsepower is high, the engine exhausts flow rate is high, which causes the emission flow rate to be high. $N O_{x}$ emissions

Figure 6.6 shows the $\mathrm{NO}_{\mathrm{x}}$ emissions from the engine. The $\mathrm{NO}_{\mathrm{x}}$ emissions concentrations in the dilution tunnel are a strong function of vehicle horsepower, while the concentration in the raw exhaust or vehicle tailpipe has the same trend, only shows some more fluctuations. $\mathrm{NO}_{\mathrm{x}}$ formation is determined largely by cylinder temperature and pressure. When engine load is high, the in-cylinder temperature and pressure also rises, causing $\mathrm{NO}_{\mathrm{x}}$ concentration to be high. 
However, since the air/fuel ratio at high engine load for the DDC S50 G engine is high, which means there's more surplus air to decrease the cylinder temperature, the $\mathrm{NO}_{\mathrm{x}}$ formation in high engine load is somewhat controlled, only about four time of that during idle period. As to the $\mathrm{NO}_{\mathrm{x}}$ flow rate from the vehicle tailpipe, it's again a strong function of vehicle horsepower.

CO emissions

As with the $\mathrm{CO}_{2}$ concentration in the dilution tunnel, the $\mathrm{CO}$ concentration in the dilution tunnel also positively related with vehicle horsepower. It seems that when vehicle horsepower is high, the $\mathrm{CO}$ concentration in the engine exhaust is also high. But the restored $\mathrm{CO}$ concentration in the vehicle tailpipe shows another picture. The $\mathrm{CO}$ concentration from raw engine exhaust is inversely related with engine power. When engine load is at its peak, the $\mathrm{CO}$ concentration is at its lowest point. While during vehicle idle period, the $\mathrm{CO}$ concentrations are at vertex. This indicates that in terms of $\mathrm{CO}$ emissions, the combustion at high engine load is very complete and the $\mathrm{CO}$ concentration is very low, about 100ppm. While during low engine load or idle period, the CO concentration rises to as high as $1000 \mathrm{ppm}$, indicate the incomplete combustion during idle period or the insufficient lean combustion as the air/fuel ratio was set low.

HC emissions 
The HC emissions in the dilution tunnel shows that when vehicle horsepower is high, the $\mathrm{HC}$ concentration is high, when vehicle is in idle, there exists a peak, but much lower than that at horsepower peak. It seems that $\mathrm{HC}$ emissions are high both at high engine load and idle period. The concentration in the raw exhaust shows that $\mathrm{HC}$ concentration in the vehicle tailpipe is extremely high during idle period, while at acceleration or cruise period, the concentration is about equally low comparing to idle period. This proves further that during low engine load, the combustion in the engine cylinder is incomplete and emitted a large amount of unburned fuel. The $\mathrm{HC}$ flow rate in the vehicle tailpipe is high at high load, as the exhaust flow rate is high. The flow rate in idle period is higher than in cruise period because although the total engine exhaust flow rate during idle is lower than that in cruise period, the $\mathrm{HC}$ concentration at idle is relatively high. An important measure to control $\mathrm{HC}$ emissions is to control the complete combustion during engine idle and low horsepower period. Increasing air/fuel ratio during idle period may decrease the $\mathrm{HC}$ emissions.

\section{Cummins L10G Natural Gas Engine}

The Cummins L10G natural gas engine is lean-burn, spark ignited, with closed-loop air/fuel ratio management system for improved overall engine performance. Figure 6.3 shows the Lambda value along with vehicle horsepower for a vehicle powered by this engine over the CBD cycle. We can see that the Lambda setting is opposite with DDCS50 natural gas engine, when in high engine 
load, the Lambda value is as low as 1.1. When vehicle is in low load or idle period, the Lambda value increase to about 1.5. This setting will effect the emissions formation. Figures 6.9 to 6.12 show the emissions from the Cummins L10 natural gas engine

$\mathrm{CO}_{2}$ emissions

The measured $\mathrm{CO}_{2}$ concentration in the dilution tunnel is positively related with vehicle horsepower. The calculated $\mathrm{CO}_{2}$ concentration in the raw engine exhaust is only the function of instantaneous air/fuel ratio. Since the air/fuel ratio variation is large, the $\mathrm{CO}_{2}$ percentage in the engine exhaust is also large, comparing to the DDC Series $50 \mathrm{G}$ natural gas engine. The $\mathrm{CO}_{2}$ flow rate in the vehicle tailpipe is also positively related with vehicle horsepower.

$N O_{x}$ emissions

The $\mathrm{NO}_{\mathrm{x}}$ emissions concentration in the dilution tunnel and in the vehicle tailpipe shows the same trend. The concentration during high engine load is significantly higher than in the cruise and idle period. Part of the reason is the low air/fuel ratio at high engine load, causing the cylinder temperature to increase sharply, and high $\mathrm{NO}_{\mathrm{x}}$ formation. While in low load and idle period, the air/fuel ratio is high, there exists surplus air to decrease the already lower combustion temperature, and thus the $\mathrm{NO}_{\mathrm{x}}$ concentration is very low. 
CO emissions

While the $\mathrm{CO}$ emission concentration measured in dilution tunnel seems to be irregular for the Cummins L10 natural gas engine, the restored CO concentration in the vehicle tailpipe indicates that $\mathrm{CO}$ concentration is high during idle period and low at acceleration and cruise period. This is the same as DDC S50G engine. This shows that in idle period, the combustion is rather incomplete comparing to other periods. To reduce $\mathrm{CO}$ emissions, the attention should be put on idle period. However, it is noticed that the overall $\mathrm{CO}$ emission is low for this type lean-burn natural gas engine.

HC emissions

The HC emissions measured in the dilution tunnel is positively related with vehicle horsepower and the concentration in the vehicle tailpipe shows the same trend. The HC concentration in the tailpipe is high in idle period indicates that a large portion of $\mathrm{HC}$ emissions is unburned fuel due to incomplete combustion at low engine load.

\section{Caterpillar 3306 Natural Gas Engine}

Although most natural gas engines employing lean-burn technology, Caterpillar 3306 natural gas engine is considered as stoichiometric natural gas engine. Figure 6.3 shows the measured Lambda value along with the vehicle horsepower for this engine. It's quite different from those of DDC S50G and Cummins L10 lean-burn natural gas engine, whose air/fuel ratios are cyclical 
during the test cycle. The Lambda value of Caterpillar 3306 engine is irregular, shows a great fluctuation. However, the engine is generally operates on lean side, with only a very little time running on rich side over the whole test cycle. It seems that air/fuel ratio value is not maintained by close-loop control. Figures 6.13 to 6.16 show the emissions profiles from this engine.

$\mathrm{CO}_{2}$ emissions

The $\mathrm{CO}_{2}$ concentration in dilution tunnel is positively related with vehicle horsepower as with other engines. While the $\mathrm{CO}_{2}$ percentage in the vehicle tailpipe is shows irregular variations due to the irregular air/fuel ratio of the engine. When engine is operating near rich side, the $\mathrm{CO}_{2}$ percentage is near 10 percent. When in lean side, the $\mathrm{CO}_{2}$ percentage is near 6 percent. This variance is large comparing to other two engines.

$N O_{x}$ emissions

The $\mathrm{NO}_{\mathrm{x}}$ emissions measured in dilution tunnel are also related with vehicle horsepower, but shows more fluctuations. The concentration in the vehicle tailpipe is somewhat different. The $\mathrm{NO}_{\mathrm{x}}$ concentration peak in the raw exhaust seems to appear in the next to power peak. There is also $\mathrm{NO}_{\mathrm{x}}$ peak at idle period. The concentration curve is more complex than those from DDC and Cummins engines. It is mainly due to the erratic air/fuel ratio. 
CO emissions

The $\mathrm{CO}$ emissions measured in the dilution tunnel is roughly related with vehicle horsepower. The restored $\mathrm{CO}$ concentration in the vehicle tailpipe indicates that concentration peaks occur at idle periods and also cruise periods. The concentration is low at high vehicle horsepower. This shows the CO emissions are also mainly formed during low engine load due to incomplete combustion.

HC emissions

The HC emissions measured in dilution tunnel shows peaks both in high horsepower and idle periods. The restored concentration in the vehicle tailpipe shows that $\mathrm{HC}$ level is extremely low at high engine load, while is significantly higher when in idle periods. The concentration is also high when vehicle changing from acceleration to cruise periods. To reduce $\mathrm{HC}$ emissions, the emphasis is to decrease $\mathrm{HC}$ emission level at idle periods. 

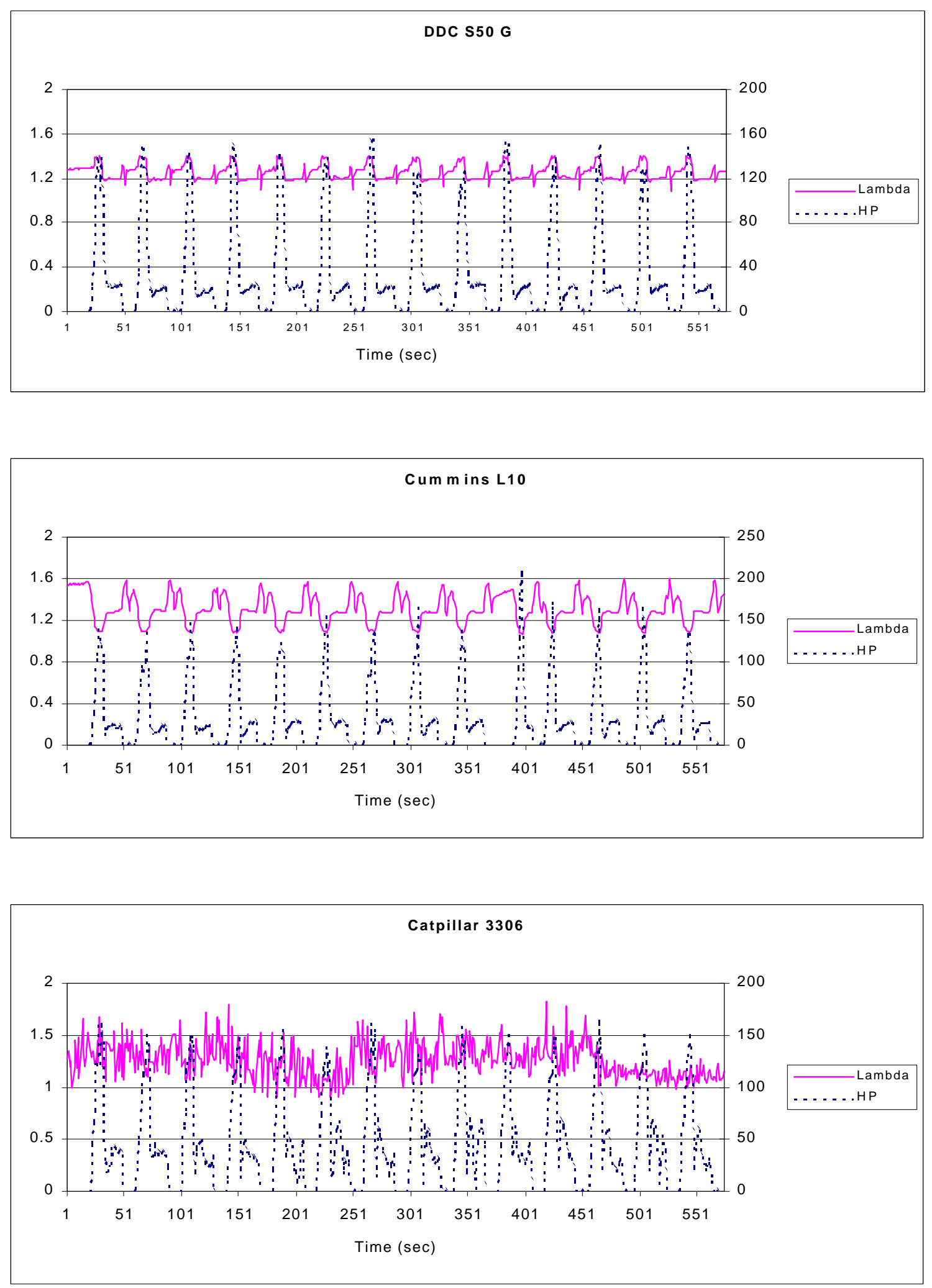

Figure 6.3 Measured Lambda Value along with Vehicle Horsepower over the CBD Cycle for Different Natural Gas Engines 

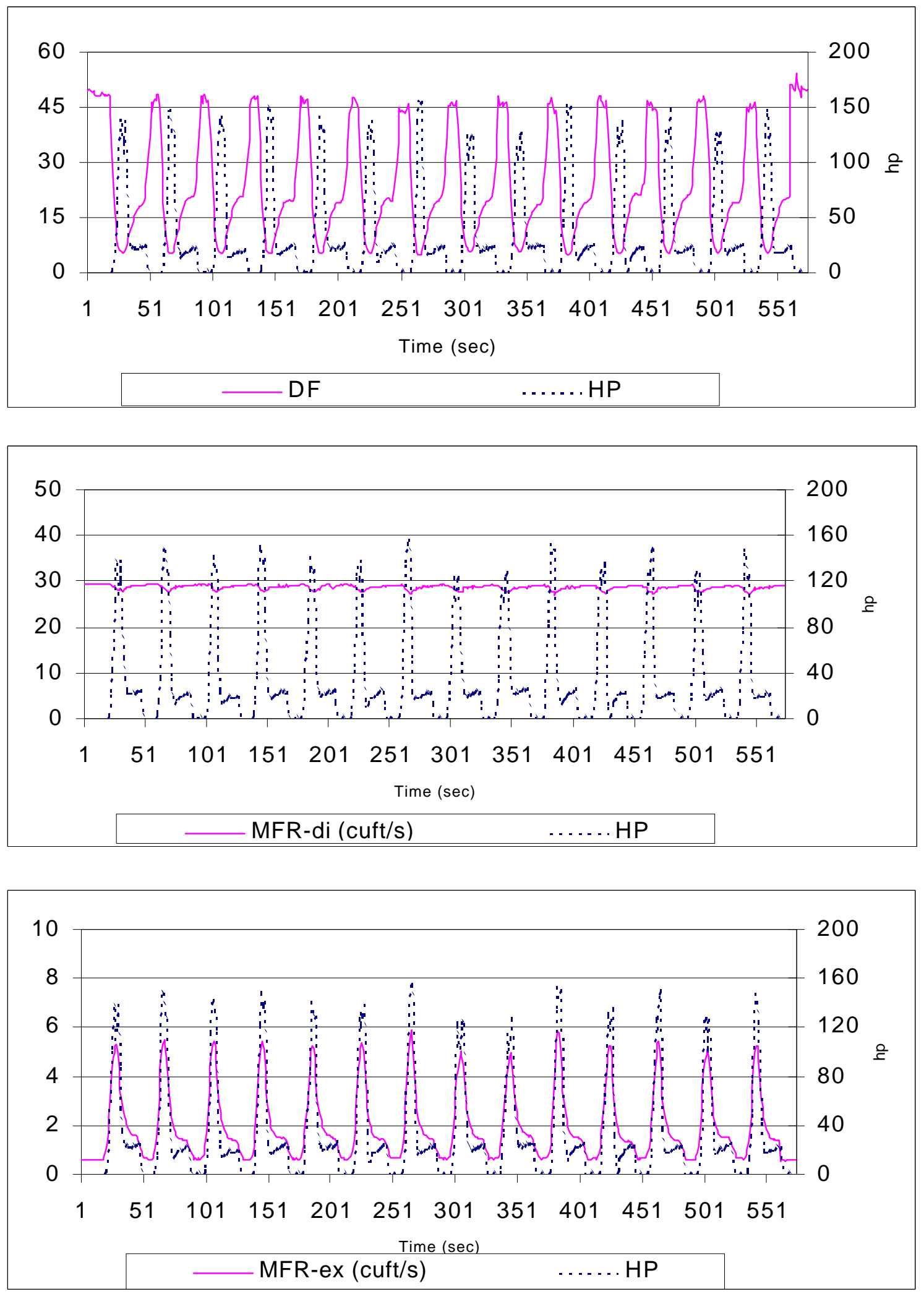

Figure 6.4 Dilution Factor and Flow Rates in the Dilution Tunnel and Vehicle Tailpipe from a Natural Gas Vehicle Powered by DDC S50G Engine 

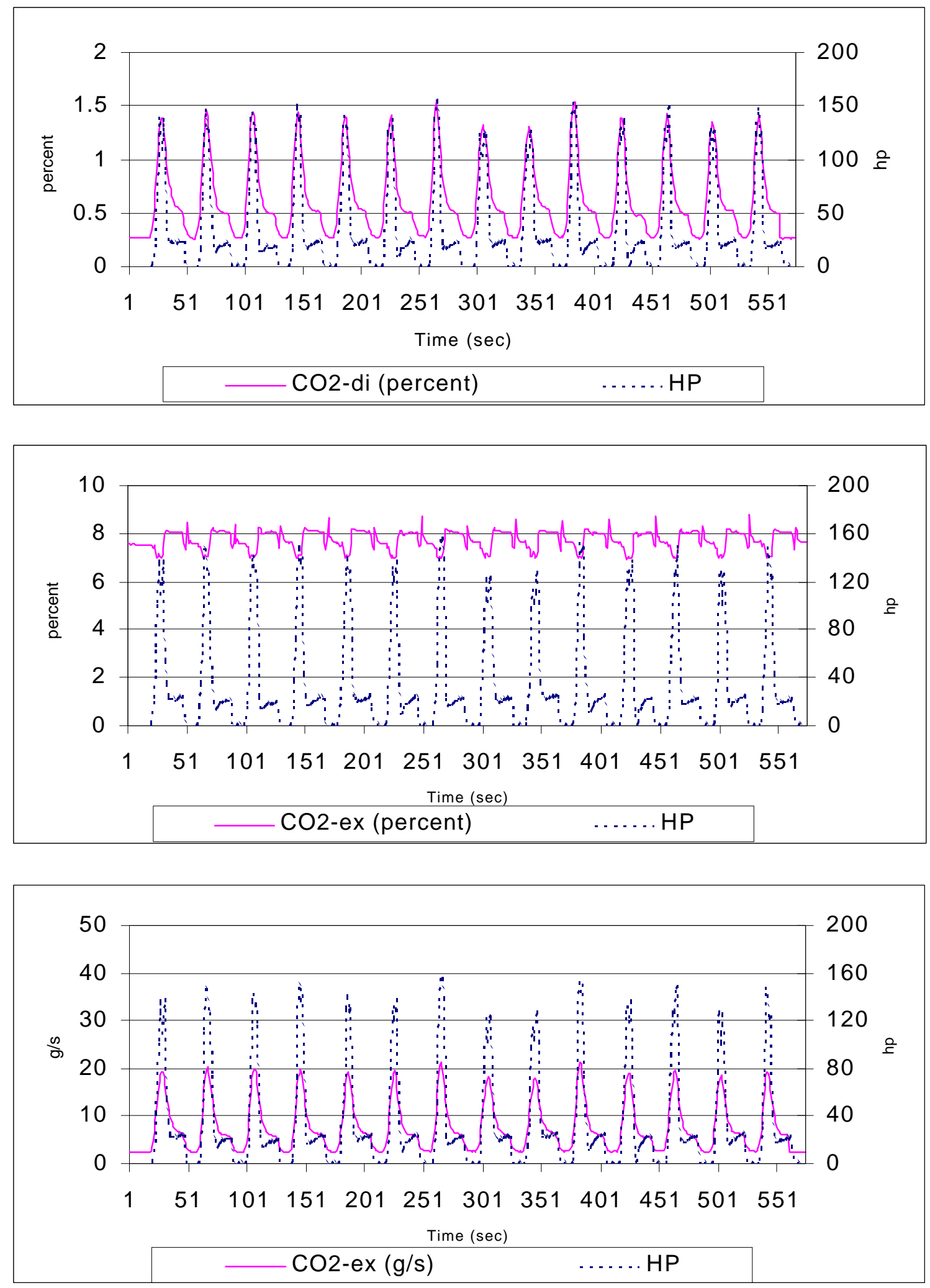

Figure 6.5 CO2 Emissions from DDC S50 G Engine 

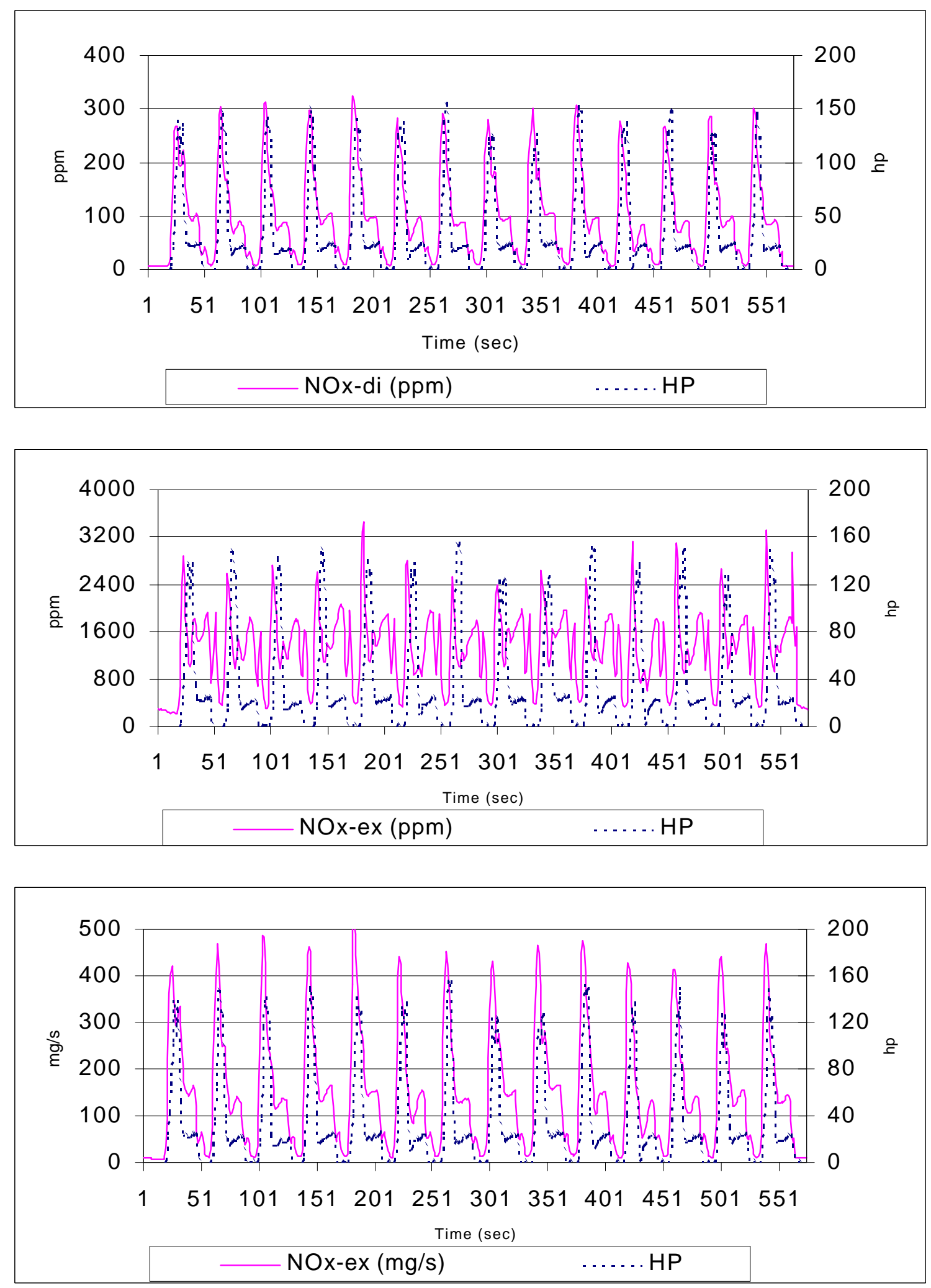

Figure 6.6 $\mathrm{NO}_{\mathrm{x}}$ Emissions from DDC S50 G Engine 

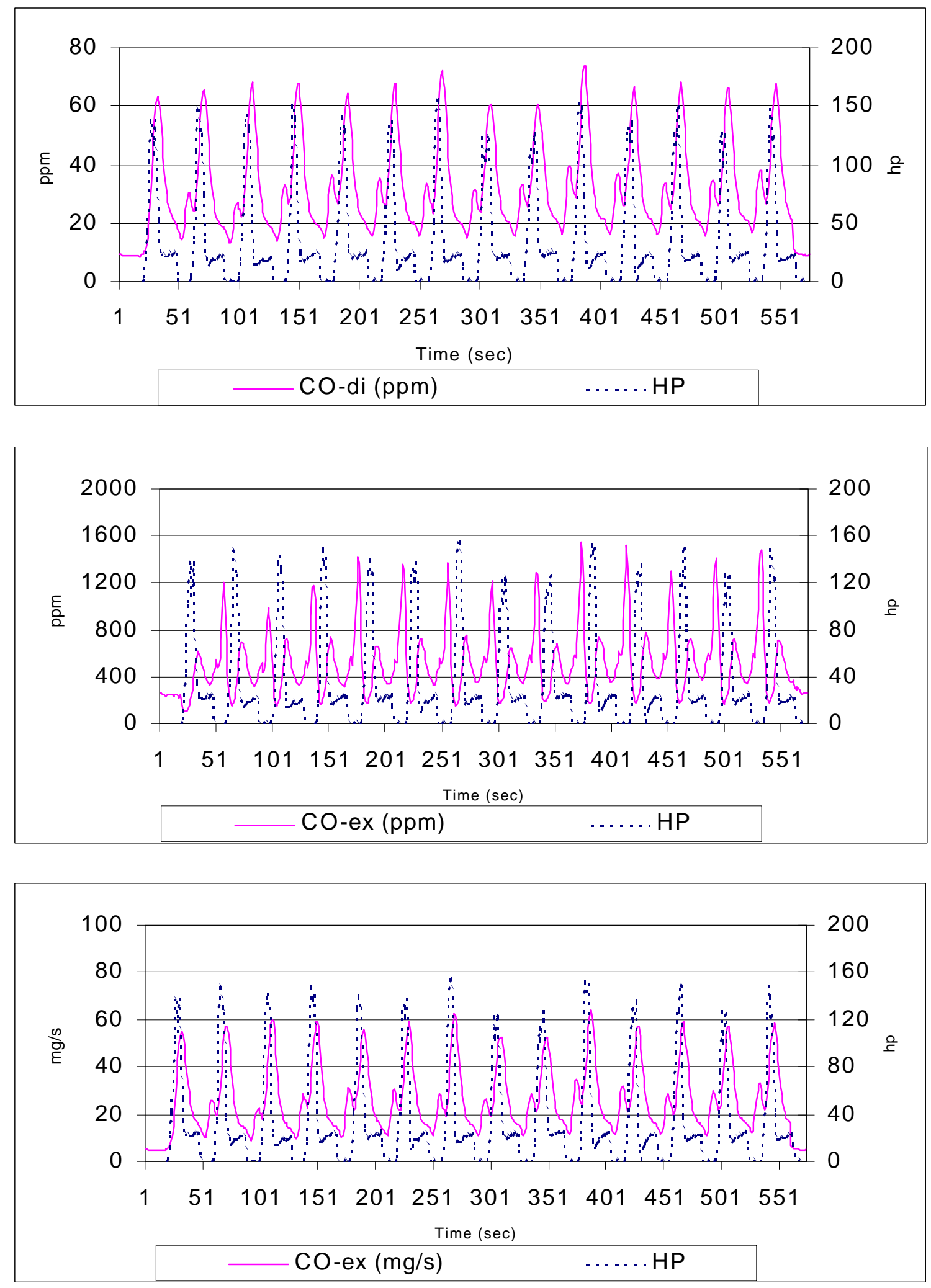

Figure 6.7 CO Emissions from DDC S50 G Engine 

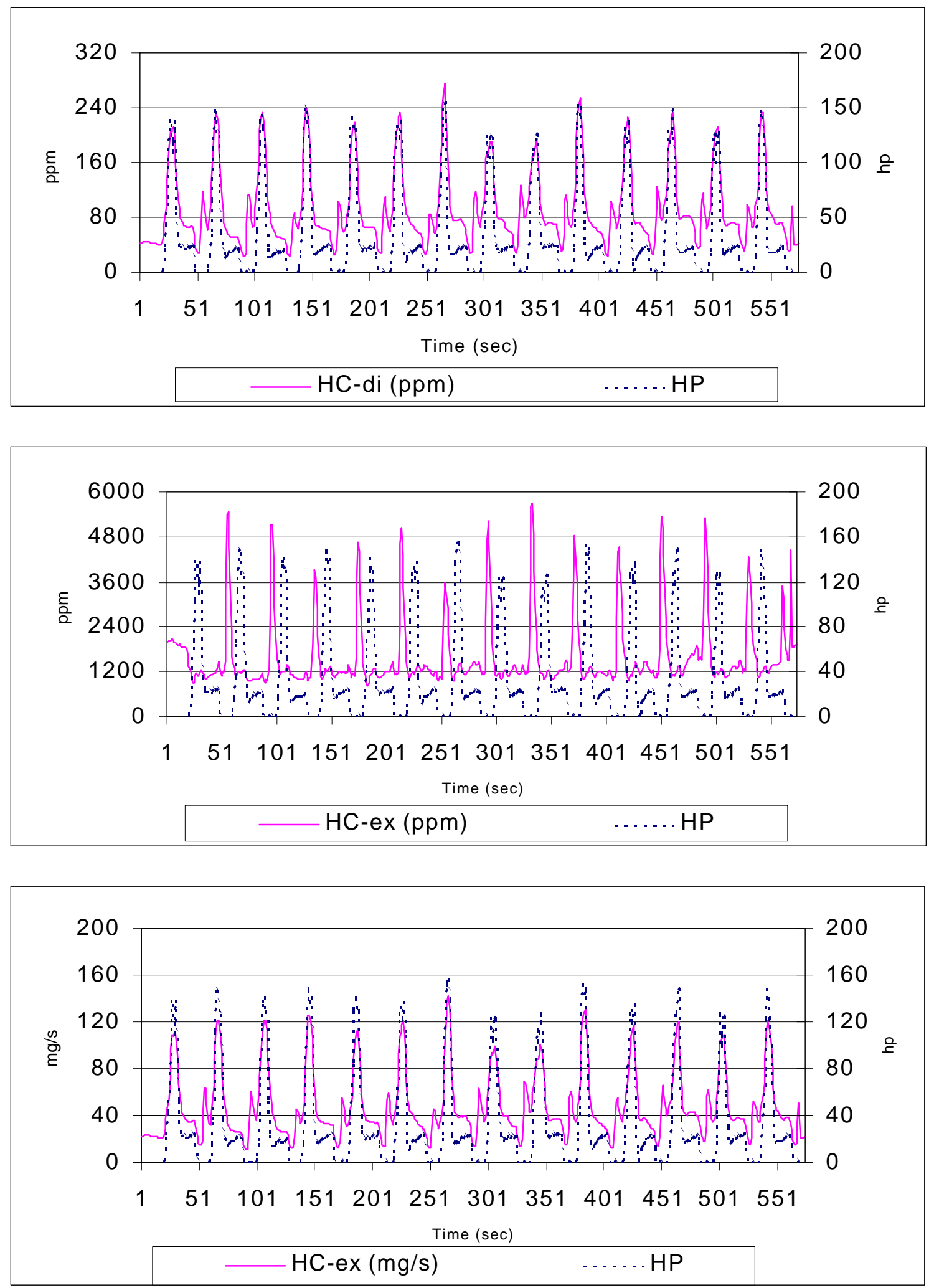

Figure 6.8 HC Emissions from DDC S50 G Engine 

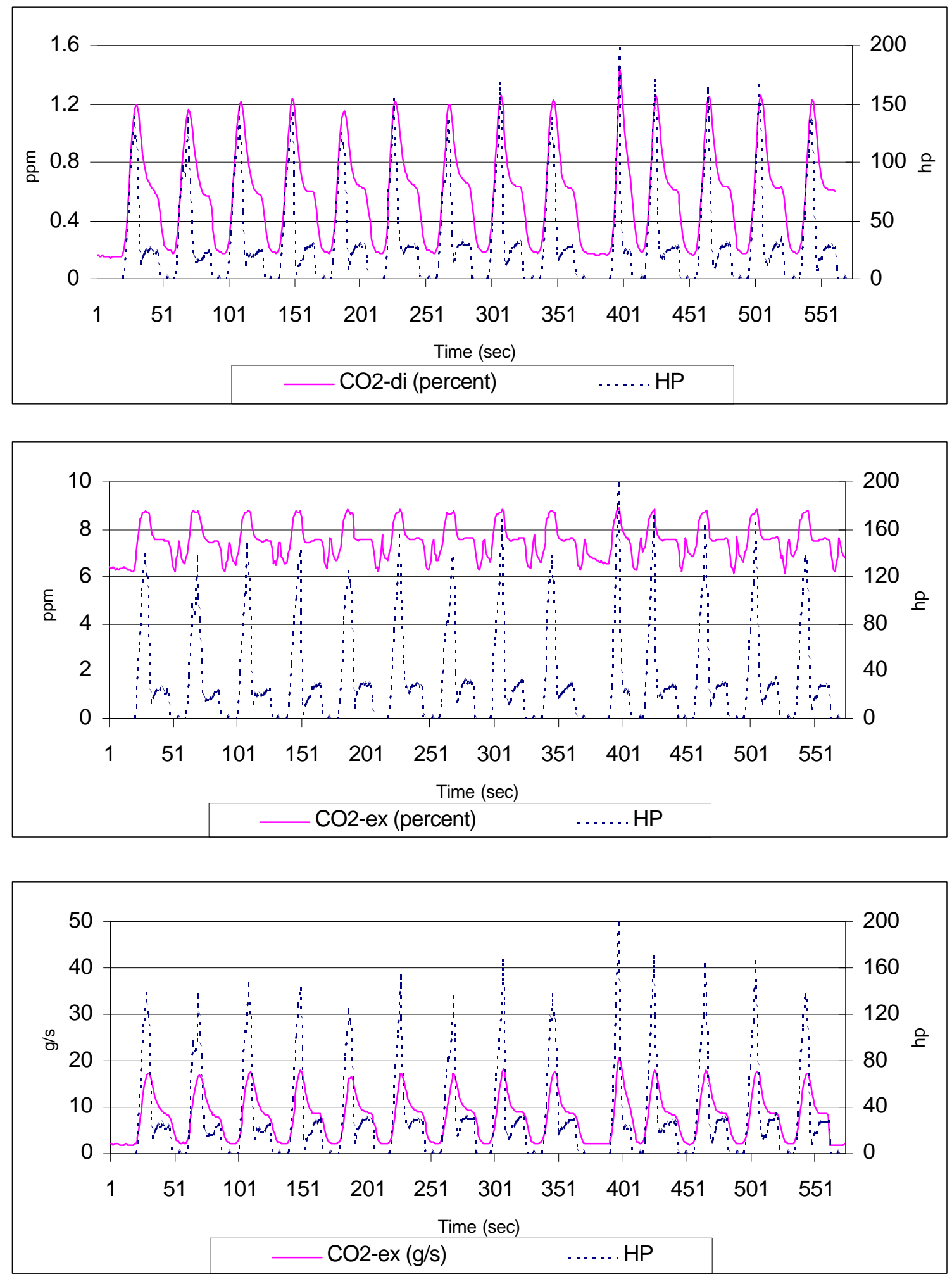

Figure $6.9 \mathrm{CO}_{2}$ Emissions from Cummins L-10 Engine 

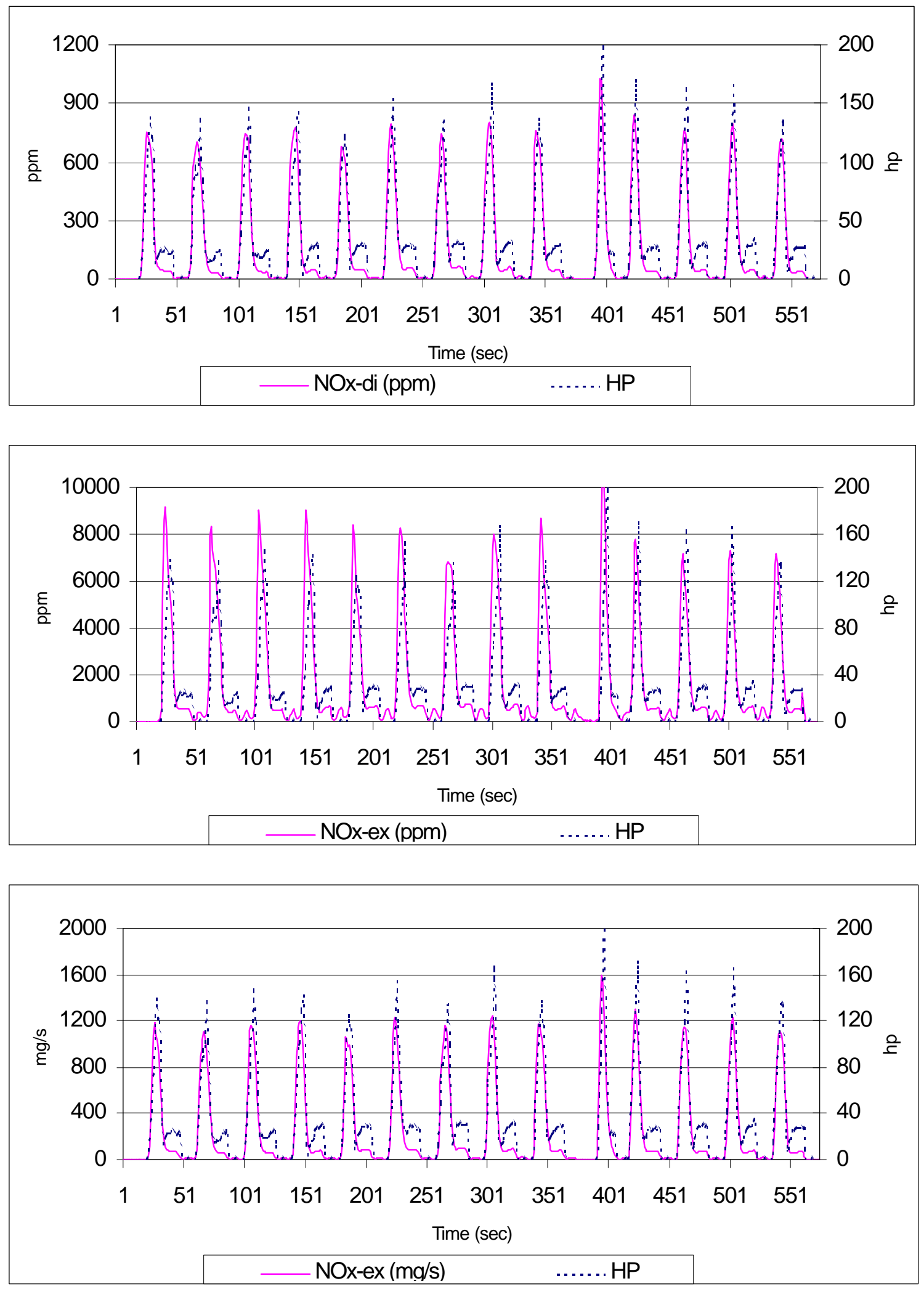

Figure 6.10 $\mathrm{NO}_{\mathrm{x}}$ Emissions from Cummins L-10 Engine 

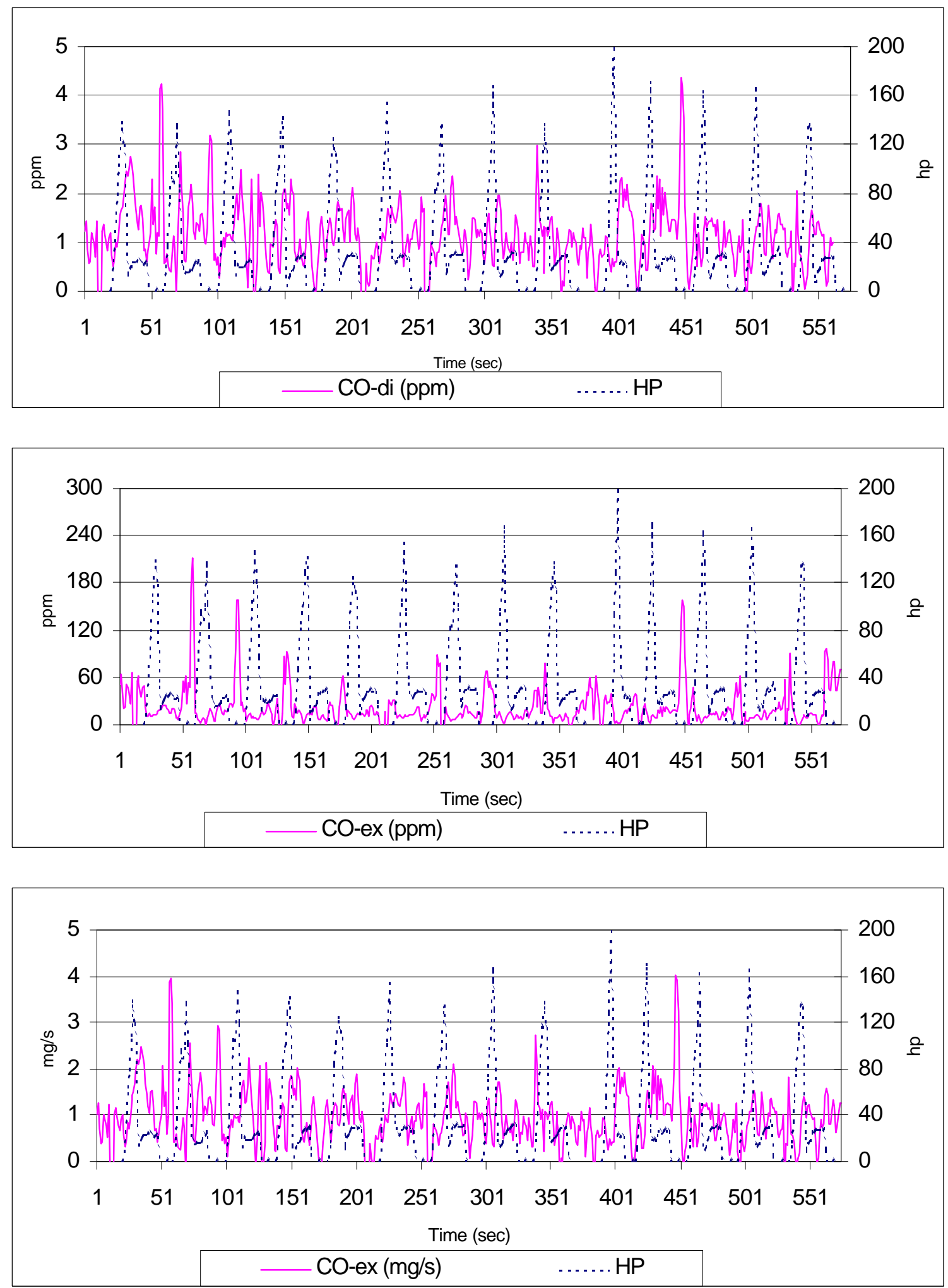

Figure 6.11 CO Emissions from Cummins L-10 Engine 

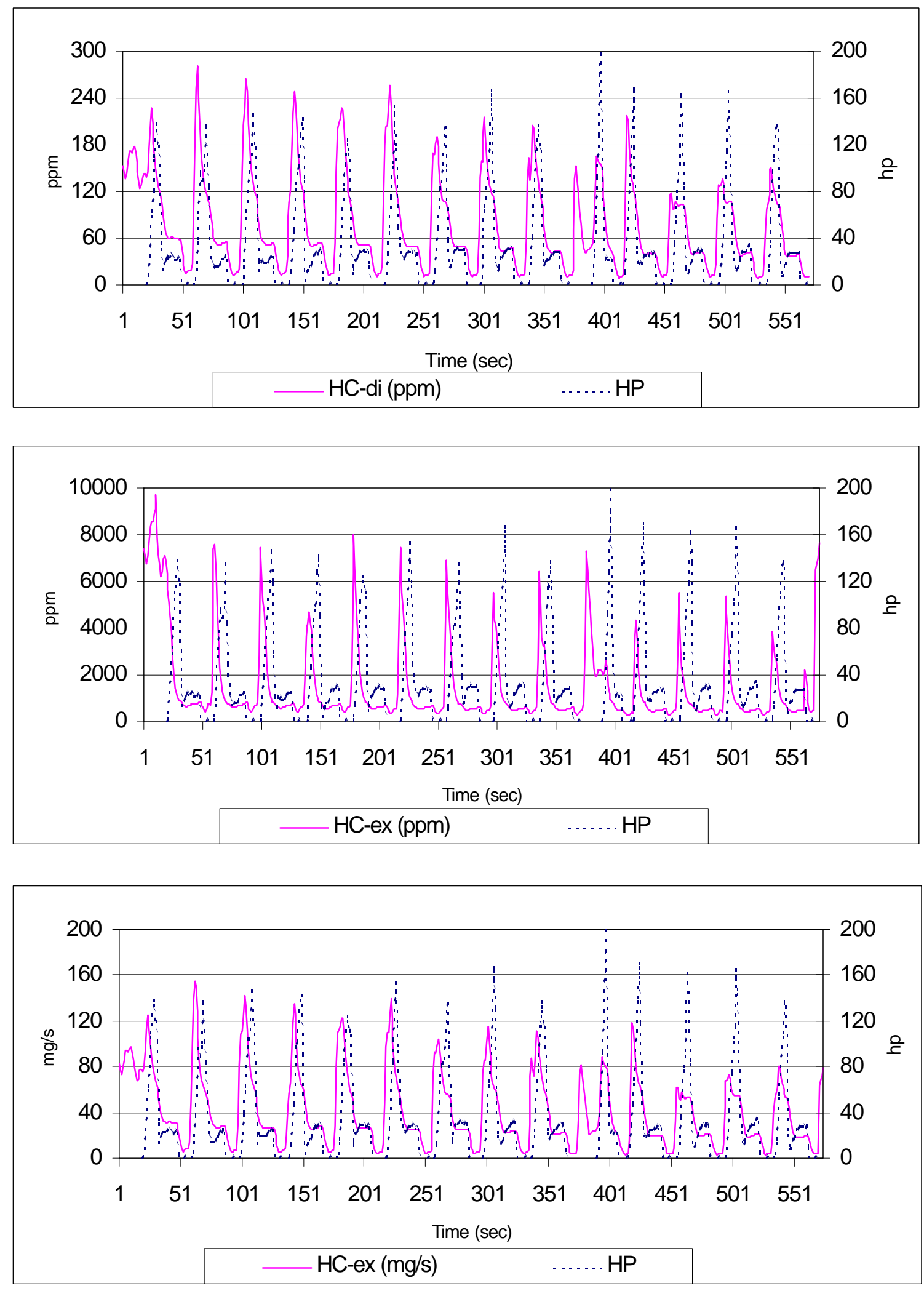

Figure 6.12 HC Emissions from Cummins L-10 Engine 

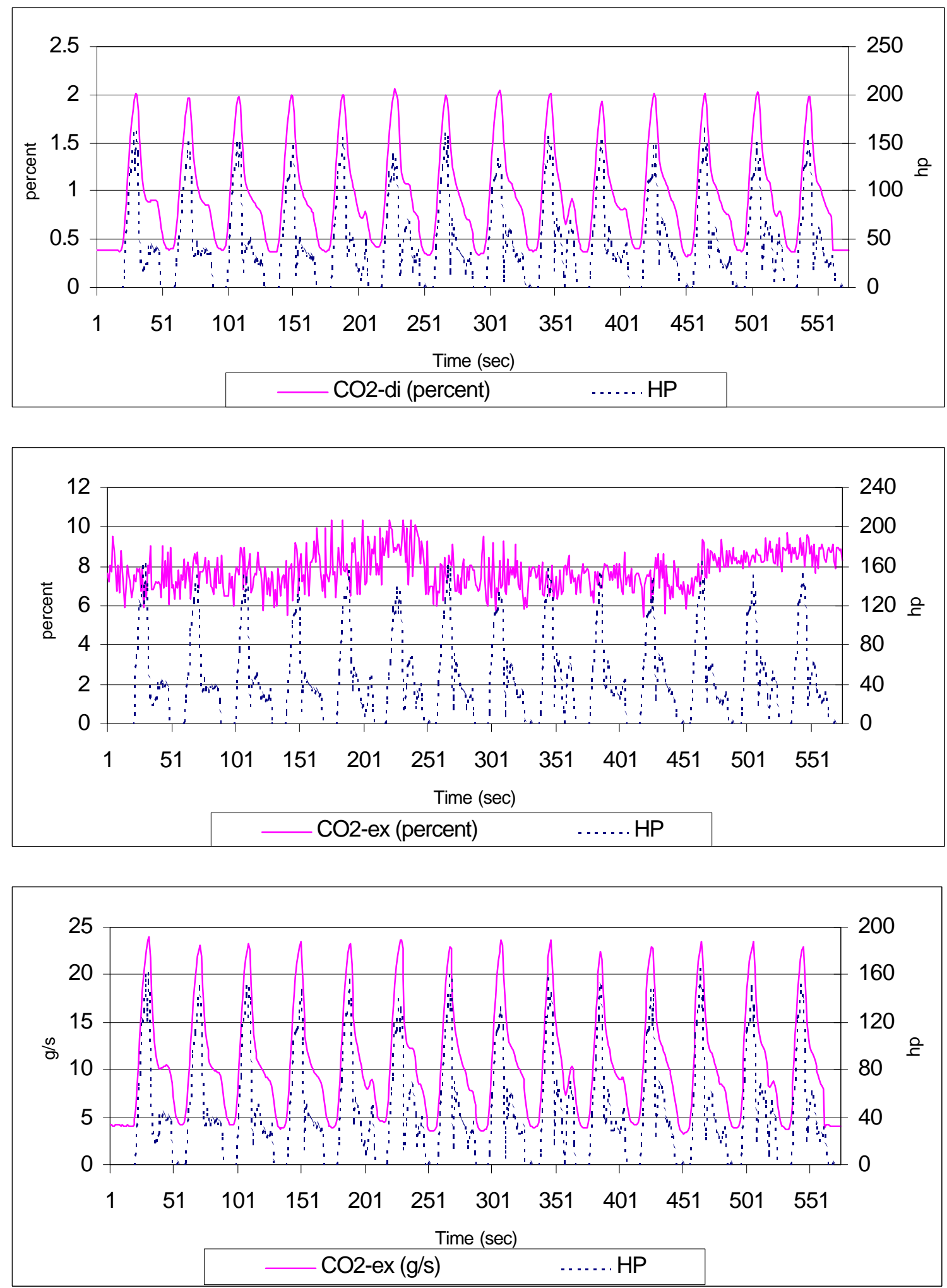

Figure $6.13 \mathrm{CO}_{2}$ Emissions from Caterpillar 3306 Engine 

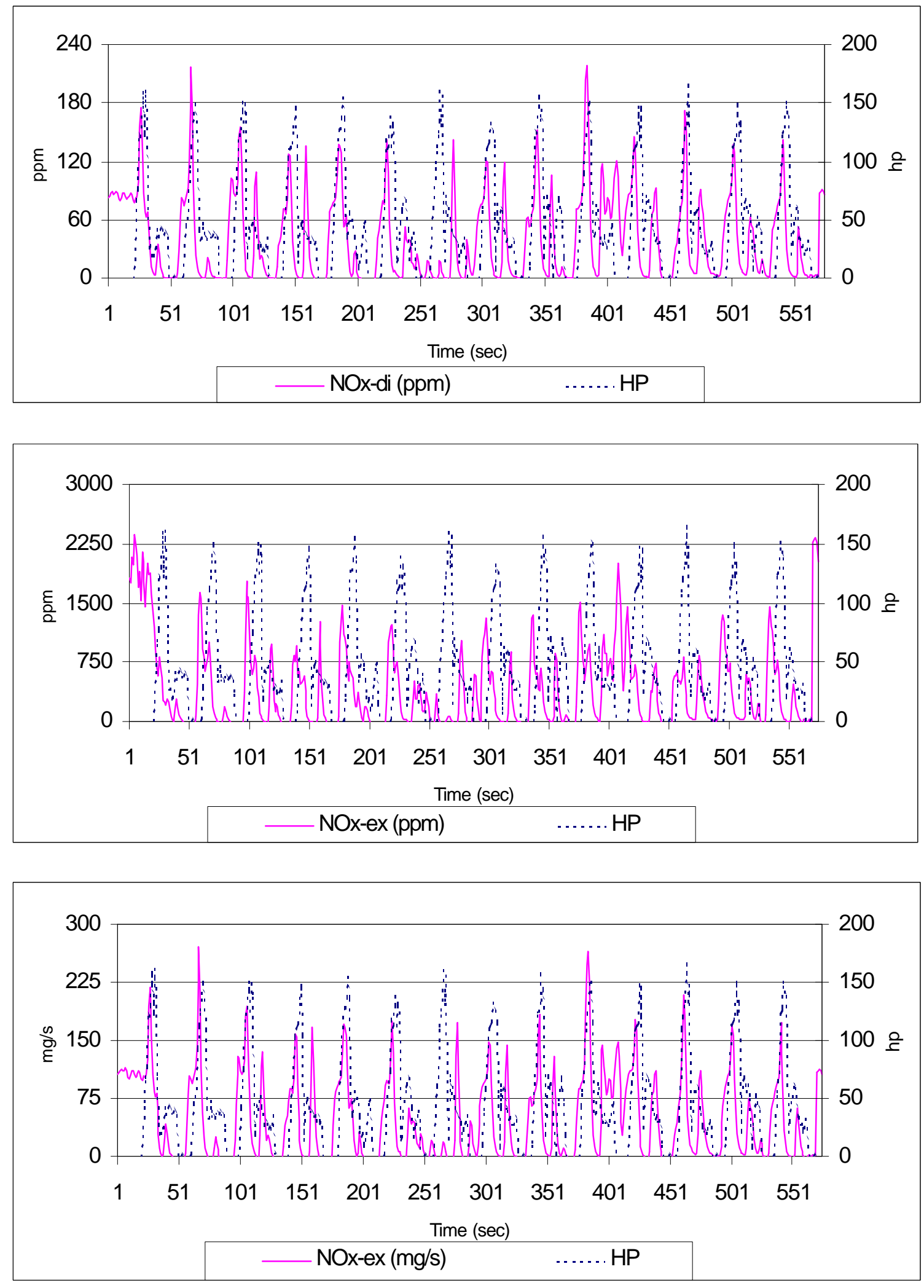

Figure 6.14 $\mathrm{NO}_{\mathrm{x}}$ Emissions from Caterpillar 3306 Engine 

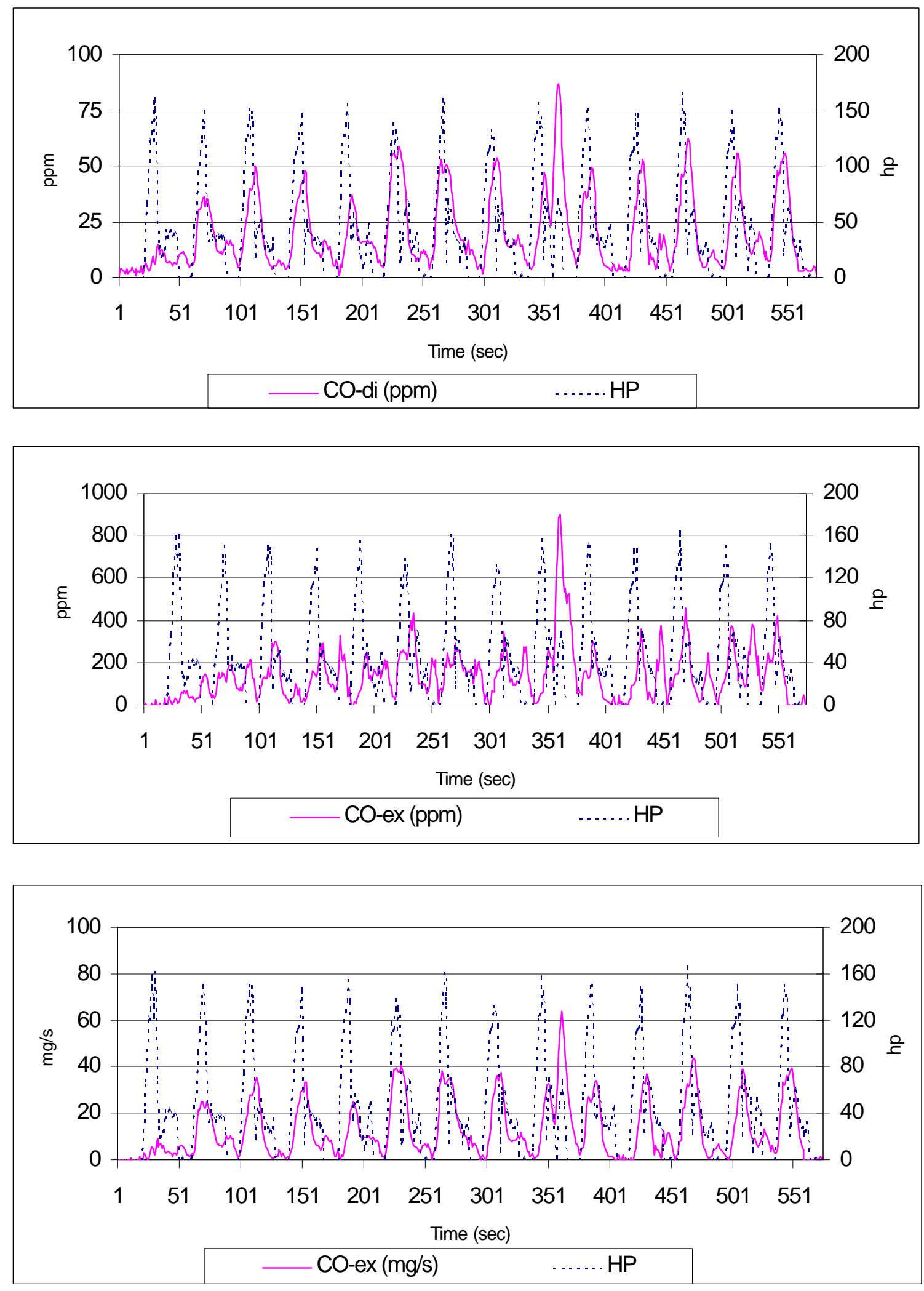

Figure 6.15 CO Emissions from Caterpillar 3306 Engine 

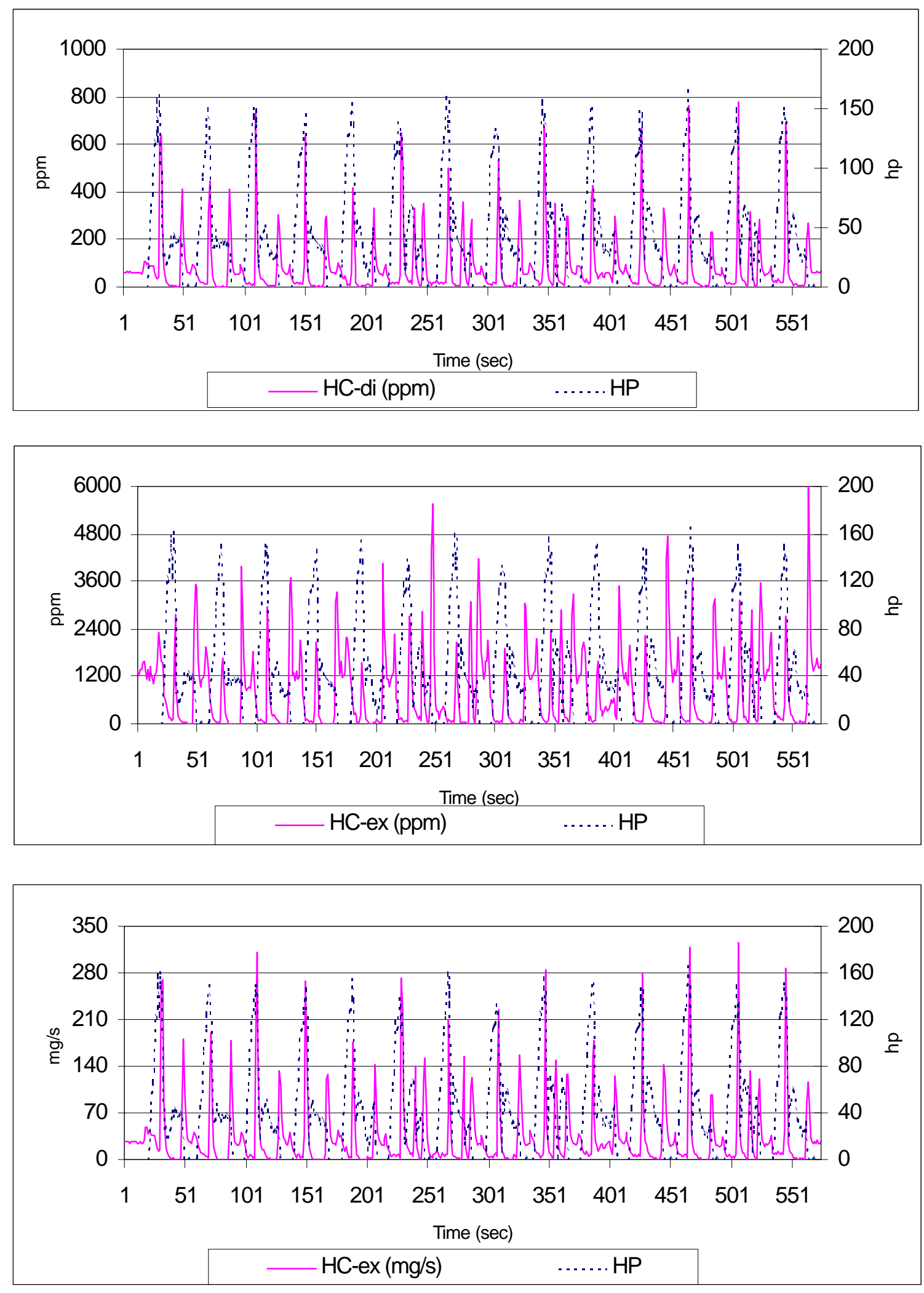

Figure 6.16 HC Emissions from Caterpillar 3306 Engine 


\section{CHAPTER 7}

\section{SUMMARY AND CONCLUSIONS}

\subsection{Summary}

- The current mass emissions calculations used in WVU heavy-duty vehicle emission testing needs improvement for accuracy, and engine exhaust emission concentrations should be distinguished from dilution tunnel measurement for further emission analysis.

- Instantaneous dilution factor can be determined for natural gas vehicles equipped with Lambda sensors. Using instantaneous dilution factor to calculate mass emissions can improve the calculation accuracy, especially when engine emissions are approaching ambient background levels.

- Emissions concentrations in the engine exhaust or vehicle tailpipe can be restored with "reverse dilution" technique using instantaneous dilution factors.

- Emissions modal analysis based on engine exhaust emission rates and emission concentrations were made for different type of natural gas engines. The analysis shed light on emission formations during different engine operation modes. Measures to reduce emissions were also discussed based on the analyses. 


\subsection{Conclusions and Future Work}

- Instantaneous dilution factor should be employed instead of average dilution factor in WVU transportable heavy-duty vehicle emission testing laboratories to improve mass emission calculation accuracy.

- Engine exhaust emission concentrations can be distinguished from dilution tunnel measurement in CVS system using instantaneous dilution factor. Emission analysis can be made based on the un-diluted engine exhaust emission characters.

- Instantaneous dilution factor can now only be calculated in natural gas vehicles with Lambda sensors. Diesel and most other alternative fuel engines were in the category of compression ignition engine, which has different air/fuel ratio characteristic with that of natural gas spark-ignition engine. An empirical compression ignition engine model should be established to obtain the diesel engine air/fuel ratio data over the test cycle. The instantaneous dilution factor and emissions concentrations in the vehicle tailpipe of diesel and other alternative fuel vehicles can then be determined.

- An easy experimental method to obtain vehicle tailpipe emissions is to measure $\mathrm{CO} 2$ concentrations in the vehicle tailpipe continuously. $\mathrm{CO} 2$ can then be used as tracer gas to determine other pollutant concentrations in the tailpipe based on dilution tunnel measurement. 
- Variable Volume Sampler (VCS) system can keep the optimized dilution factor as constant instead of keep flow volume constant over the test cycle. The benefits include direct procurement of engine exhaust emission concentrations from dilution tunnel measurement without the calculation of instantaneous dilution factor, decreasing the possibilities of water condensation in dilution tunnel and narrowing the gas analyzer detection range. This system should be considered for replacing Constant Volume Sampling (CVS) system in WVU heavy-duty vehicle emission testing facilities.

- Recently, real-time measurement of particulate emission from heavy-duty vehicles is being developed. This more advanced method enables researchers to characterize transient particulate emissions from different engine operations. The continuos PM measurement capability is now desirable in WVU laboratory. 


\section{REFERENCES}

1. Code of Federal Regulations, Title 40, Part 86, Protection of Environment, 1994.

2. Ferguson, C., "Internal Combustion Engines", John Wiley \& Sons, Inc., New York, NY, 1986.

3. Taylor, C., "The Internal Combustion Engine in Theory and Practice", The MIT Press, Cambridge, MA, 1985.

4. Owen, K., Coley, T., "Automotive Fuels Reference Book", $2^{\text {nd }}$ Edition, SAE R-151, 1990.

5. Maxwell, T., Jones, J., "Alternative Fuels: Emissions, Economics, and Performance”, SAE R-143, 1994.

6. "Engine Emissions and Emissions Measurement", SAE SP-1161, 1996.

7. Messer, J., Clark, N., and Lyons, D., "Measurement Delay and Modal Analysis for a Heavy Duty Transportable Emissions Testing Laboratory", SAE Paper 950218, 1995.

8. Beaumont, A., "Signal Reconstruction Techniques for Improved Measurement of Transient Emissions", SAE Paper 900233, 1990.

9. Austin, T., Caretto, L., "Improving the Calculation of Exhaust Gas Dilution During Constant Volume Sampling”, SAE Paper 980678, 1998.

10. Wolfgang, T., "Progress in CVS Technique- A Variable Flow CVS", SAE Paper 940966, 1994.

11. Murphy, M., "Properties of Alternative Fuel”, FTA-OH-06-0060-94-1, Federal Transit Administration, 1994.

12. Poulton, M., "Alternative Fuels for Road Vehicles", Computational Mechanics Publications, 1994.

13. Ferguson, D., Gautam, M., Palmer, G., Loth, J., Nussear, D., Lyons, D., Clark, N., Wang, W., Bata, R., Naplitano, M., Smith, R., "Emissions Measurement System for a Transportable Heavy Duty Vehicle Transit Chassis Test Facility", ISATA Paper 920456, 1992. 
14. Wang, W., Sun, X., Bata, R., Gautam, M., Clark, N., Palmer, G., Lyons, D., "A Study of Emissions From CNG and Diesel Fueled Heavy-duty Vehicles", SAE Paper 932826, 1993.

15. Wang, W., Gautam, M., Sun, x., Bata, R., Clark, N., Palmer, G., Lyons, D., "Emissions Comparisons of Twenty-six Heavy-duty Vehicles Operated on Conventional and Alternative Fuels", SAE Paper 932952, 1993.

16. Clark, N., Wang, W., Lyons, D., Gautam, M., Bata, R., "Troubleshooting High Emissions from In-Service Alternative Fueled Buses", Proceedings of the Windsor Workshop on Alternative Fuels, 1996.

17. Wiers, Ward W., Scheffler, C.E., "Carbon Dioxide Tracer Technique for Modal Mass Exhaust Emission Measurements”, SAE Paper 720162,1972.

18. De Petris, C., Diana, S., Giglio U., Police, G., "Some Problems in the Improvement of Measurement of Transient Emissions", SAE Paper 941949, 1994.

19. Stone, R., "Introduction to Internal Combustion Engines", Second Edition, SAE R$129,1993$. 


\section{APPROVAL OF EXAMINATION COMMITTEE}

Nigel N. Clark, Ph.D.

Mridul Gautam, Ph.D.

Date

Wen G. Wang, Ph.D., Chairman 